\author{
UNIVERSIDADE DE SÃO PAULO \\ FACULDADE DE MEDICINA DE RIBEIRÃO PRETO
}

AMANDA RAFAELA SILVEIRA GOSHIMA KRONKA

Atenção domiciliar e perfil dos pacientes assistidos em Núcleos de Saúde da Família

ligados à Faculdade de Medicina de Ribeirão Preto da Universidade de São Paulo 
AMANDA RAFAELA SILVEIRA GOSHIMA KRONKA

\section{Atenção domiciliar e perfil dos pacientes assistidos em Núcleos de Saúde da Família ligados à Faculdade de Medicina de Ribeirão Preto da Universidade de São Paulo}

Dissertação apresentada ao Programa de Pós-Graduação em Saúde na Comunidade da Faculdade de Medicina de Ribeirão Preto da Universidade de São Paulo como parte dos requisitos obrigatórios para obtenção do título de Mestre em Saúde na Comunidade

Versão corrigida contendo as alterações solicitadas pela comissão julgadora em 17 de abril de 2017. A versão original encontra-se disponível tanto na Biblioteca da Unidade que aloja o Programa, quanto na Biblioteca Digital de Teses e Dissertações da USP (BDTD).

Área de Concentração: Saúde na Comunidade

Orientadora: Prof. ${ }^{\text {a }}$ Dra. Luane Marques de Mello 
Autorizo a reprodução e divulgação total ou parcial deste trabalho, por qualquer meio convencional ou eletrônico, para fins de estudo e pesquisa, desde que citada a fonte.

Catalogação da Publicação

Preparada pela Biblioteca do Serviço e Documentação

Faculdade de Medicina de Ribeirão Preto da Universidade de São Paulo

Amanda Rafaela Silveira Goshima Kronka

Atenção domiciliar e perfil dos pacientes assistidos em Núcleos de Saúde da Família ligados à Faculdade de Medicina de Ribeirão Preto da Universidade de São Paulo

Faculdade de Medicina de Ribeirão Preto da Universidade de São Paulo. Ribeirão Preto, São Paulo, 2017.

76 f.: il.

Dissertação apresentada à Faculdade de Medicina de Ribeirão Preto da Universidade de São Paulo. Departamento de Medicina Social. Programa de Pósgraduação em Saúde na Comunidade.

Orientadora Prof. a Dra. Luane Marques de Mello. - Ribeirão Preto, 2017.

1. Atenção domiciliar. 2. Visita domiciliar. 3. Assistência domiciliar. 


\section{FOLHA DE APROVAÇÃO}

Goshima-Kronka, Amanda Rafaela Silveira. Atenção domiciliar e perfil dos pacientes assistidos em Núcleos de Saúde da Família ligados à Faculdade de Medicina de Ribeirão Preto da Universidade de São Paulo

Dissertação apresentada à Faculdade de Medicina de Ribeirão Preto da Universidade de São Paulo como parte dos requisitos obrigatórios para obtenção do título de Mestre em Saúde na Comunidade.

Orientadora: Profa. Dra. Luane Marques de Mello

Aprovado em:

\section{BANCA EXAMINADORA}

Prof.(a) Dr.(a) Luane Marques de Mello

Instituição: Faculdade de Medicina de Ribeirão Preto da Universidade de São Paulo (FMRPUSP)

Assinatura:

Prof.(a) Dr.(a) Aldaísa Cassanho Forster

Instituição: Faculdade de Medicina de Ribeirão Preto da Universidade de São Paulo (FMRPUSP)

Assinatura:

Prof.(a) Dr.(a) Guilherme Arantes de Mello

Instituição: Faculdade de Medicina da Universidade Federal de São Paulo (UNIFESP)

Assinatura: 
A Deus, à minha família e orientadora, com todo meu amor e gratidão, pelo apoio, força, compreensão e companheirismo. Sem eles nada disso seria possível. 


\section{AGRADECIMENTOS}

A Deus por estar comigo e me amparar em todos os momentos e suprir todas as minhas necessidades.

À minha orientadora Luane M. de Mello pela atenção e apoio durante o processo de orientação e por contribuir para meu crescimento científico e intelectual.

Ao meu esposo Danilo Kronka e minha família pelo apoio, incentivo e cooperação.

Ao Departamento de Medicina Social pela oportunidade de realização do curso de mestrado.

Aos Núcleos de Saúde da Família e suas equipes pela disposição e colaboração.

A todos os colegas e professores da pós-graduação em Saúde na Comunidade pelo convívio e aprendizado. 
"A menos que modifiquemos a nossa maneira de pensar, não seremos capazes de resolver os problemas causados pela forma como nos acostumamos a ver o mundo". Albert Einstein 


\section{RESUMO}

GOSHIMA-KRONKA, A. R. S. Atenção domiciliar e perfil dos pacientes assistidos em Núcleos de Saúde da Família ligados à Faculdade de Medicina de Ribeirão Preto da Universidade de São Paulo. 2017. 78 f. Dissertação (Mestrado) - Faculdade de Medicina de Ribeirão Preto, Universidade de São Paulo, Ribeirão Preto, 2017.

O Ministério da Saúde define Saúde da Família como estratégia de reorientação do modelo assistencial, operacionalizada mediante a implantação de equipes multiprofissionais em unidades básicas de saúde. Esta equipe oferece Assistência Integral, levando em consideração o meio ambiente e os comportamentos interpessoais. Segundo a Organização Mundial da Saúde (OMS), Assistência Domiciliar é entendida como oferta de serviços de saúde por prestadores formais e informais para promover, restaurar e manter o conforto e saúde das pessoas em nível máximo, incluindo cuidados para uma morte digna. Neste contexto, a Atenção Domiciliar (AD) é valioso instrumento de monitorização da situação de saúde das famílias pelas equipes de saúde, favorecendo o acompanhamento clínico e melhores prognósticos, evitando a hospitalização e suas consequências, sendo considerada importante recurso de humanização do atendimento. Assim, o objetivo deste estudo foi avaliar o perfil clínico-epidemiológico dos indivíduos atendidos em $\mathrm{AD}$ pelas equipes dos Núcleos de Saúde da Família ligados à Faculdade de Medicina de Ribeirão Preto da Universidade de São Paulo, localizados no Distrito de Saúde Oeste do Município de Ribeirão Preto/SP. O estudo se deu entre janeiro de 2015 e dezembro de 2016 com vistas a nortear estratégias de aprimoramento do atendimento através do planejamento e organização do trabalho do profissional executor da visita domiciliar (VD), favorecendo maior resolubilidade da(s) demanda(s) e maior satisfação do usuário. Realizou-se um estudo de corte transversal coletando informações sobre os usuários assistidos por esta modalidade de cuidado e sobre o processo de $\mathrm{AD}$, através de questionários elaborados com base na literatura sobre o assunto. Entre os 150 pacientes visitados, 106 (70,7\%) eram mulheres, 66 (44\%) eram casados, $84(56 \%)$ eram aposentados, 101 (67,3\%) pertenciam a famílias anciãs, $84(56 \%)$ possuíam ensino fundamental e $102(68 \%)$ tinham cuidadores. Com relação à média de idade, o NSF 2 apresentou a maior média de idade $(72,5)$ e o NSF 5 a menor média $(59,9)$. Os diagnósticos mais encontrados foram Acidentes Vasculares Cerebrais [21(14\%)] e Demência [16(10,7\%)] e as classes de medicamentos mais utilizadas foram anti-hipertensivos [93(62\%)]. Com relação às modalidades de $\mathrm{AD}, 128$ (85,3\%) visitas foram classificadas como AD1, $13(8,7 \%)$ como AD2 e somente $9(6 \%)$ como AD3. Também foram avaliadas outras características da AD e observou-se que 137 (91,3\%) das VD's realizadas foram agendadas, 65 $(43,33 \%)$ estavam em acompanhamento domiciliar e somente $30(20 \%)$ foram busca ativa. Após as VD's, $83(55,3 \%)$ pacientes mantiveram-se em acompanhamento domiciliar e 65 $(43,3 \%)$ pacientes retornaram para seguimento na Unidade. Por fim, os resultados permitem delinear o perfil de vida e saúde dos pacientes, sendo a maioria idosos, mulheres, aposentados, pertencentes à famílias anciãs, possuindo cuidadores e os diagnósticos prevalentes foram doenças crônicas degenerativas. Ademais, identificou-se a necessidade de fortalecimento de ações de prevenção e promoção de saúde, reduzindo-se complicações e internações desnecessárias. Assim, políticas públicas específicas voltadas principalmente para a população mais idosa devem ser consideradas prioridades. Além disto, as AD se realizavam de forma quase intuitiva, provavelmente em decorrência da alta demanda que as unidades precisam atender, evidenciando a necessidade de sistematização da atividade.

Palavras-Chave: Atenção domiciliar; Visita Domiciliar; Assistência Domiciliar. 


\begin{abstract}
GOSHIMA-KRONKA, A.R.S. Home care and profile of assisted patients in Health Centers of Family linked to the Faculty of Medicine of Ribeirão Preto, University of São Paulo. 2017. Master's degree Dissertation. Ribeirão Preto Medical School, University of São Paulo, Ribeirão Preto, 2017.
\end{abstract}

The MS defines Family's Health as a strategy for reorganize the care model, operationalized through the implantation of multiprofessional teams in basic health units. This team offers Integral Assistance, taking into consideration the environment and interpersonal behavior. According to the World Health Organization (WHO), home care is understood as providing health services by formal and informal providers to promote, restore and maintain the comfort and health of people at the highest level, including care for a dignified death. In this context, Home Care (HC) is a valuable tool for monitoring the health situation of families by health teams, favoring clinical follow-up and better prognoses, avoiding hospitalization and its consequences, being considered an important humanization resource. Thus, the objective of this study was to evaluate the clinical and epidemiological profile of individuals assisted in HC by the teams of the Family Health Centers connected to the Medical School of Ribeirão Preto of University of São Paulo, located in the Western District of the Municipality of Ribeirão Preto/SP. The study was conducted between January 2015 and December 2016 with a view to guiding strategies for improving care through the planning and organization of the work performed by the home visiting professional, favoring greater resolubility of the demands and greater user satisfaction. A cross-sectional study was carried out, collecting information about the users assisted by this modality of care and about the HC process, through questionnaires elaborated based on the literature on the subject. Among the 150 patients visited, $106(70.7 \%)$ were women, $66(44 \%)$ were married, $84(56 \%)$ were retired, $101(67.3 \%)$ belonged to elderly families, $84(56 \%)$ had elementary school and $102(68 \%)$ had caregivers. Regarding the mean age, NSF 2 had the highest mean age (72.5) and NSF 5 had the lowest mean (59.9). The most frequent diagnoses were Cerebral Vascular Accidents [21 (14\%)] and Dementia [16 (10.7\%)] and the most used classes of drugs were antihypertensive [93 (62\%)]. Regarding HC modalities, $128(85.3 \%)$ visits were classified as $\mathrm{HC} 1,13(8.7 \%)$ as $\mathrm{HC} 2$ and only $9(6 \%)$ as HC3. Other characteristics of the $\mathrm{HC}$ were also evaluated, and 137 (91.3\%) of the HVs performed were scheduled, $65(43.33 \%)$ were under housekeeping and only $30(20 \%)$ were active. After the HVs, $83(55.3 \%)$ patients were followed up at home and $65(43.3 \%)$ returned for follow-up at the Unit. Finally, the results allow to delineate the life and health profile of the patients, being the majority elderly, women, retired, belonging to the elderly families, having caregivers and the prevalent diagnoses were chronic degenerative diseases. In addition, it was identified the need to strengthen health prevention and promotion actions, reducing unnecessary complications and hospitalizations. Thus, specific public policies aimed primarily at the older population should be considered priorities. In addition, the HCs were performed in an almost intuitive way, probably due to the high demand that the units need to attend, evidencing the need to systematize the activity.

Keywords: Home Care; Home Visit; Home Assistance. 


\section{LISTA DE TABELAS}

Tabela 1 - Distribuição dos pacientes por NSF segundo gênero

Tabela 2 - Idade média, mediana, idade mínima e máxima dos pacientes que receberam

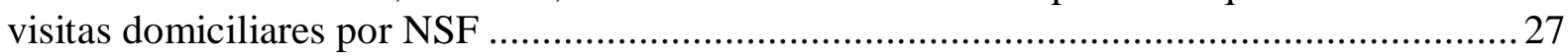

Tabela 3 - Distribuição dos pacientes por NSF segundo as variáveis sociodemográficas......... 31

Tabela 4 - Distribuição dos pacientes por NSF segundo a higiene ..................................... 32

Tabela 5 - Distribuição dos pacientes por NSF segundo a mobilização e presença de sondas, estomias e úlceras

Tabela 6 - Distribuição dos pacientes por NSF segundo a alimentação, ingesta hídrica, e

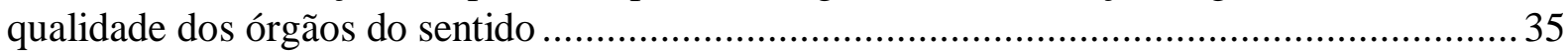

Tabela 7 - Distribuição dos pacientes por NSF segundo a relação familiar, atividade de lazer e

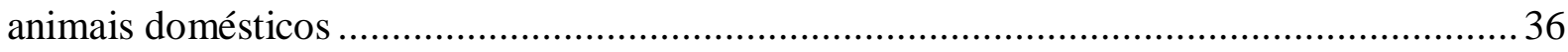

Tabela 8 - Distribuição dos exames checados durante as VDs por NSF ............................. 38

Tabela 9 - Distribuição dos seguimentos dos pacientes por NSF segundo a especialidade .... 39

Tabela 10 - Distribuição por NSF segundo diagnósticos principais (CID 10) ...................... 41

Tabela 11 - Distribuição das classes de medicamentos utilizados pelos pacientes por NSF .. 42

Tabela 12 - Distribuição das características da Atenção Domiciliar por NSF ....................... 43

Tabela 13 - Perfil demográfico, epidemiológico e clínico dos pacientes visitados segundo as modalidades de Atenção Domiciliar:

Tabela 14 - Perfil demográfico, epidemiológico e clínico dos pacientes visitados segundo os tipos de solicitação.....

Tabela 15 - Perfil demográfico, epidemiológico e clínico dos pacientes visitados segundo as condutas.

Tabela 16 - Perfil demográfico, epidemiológico e clínico dos pacientes visitados segundo os tipos de atenção domiciliar.....

Tabela 17 - Perfil demográfico, epidemiológico e clínico dos pacientes visitados segundo a 


\section{LISTA DE GRÁFICOS}

Gráfico 1 - Distribuição dos pacientes por NSF segundo gênero .....................................27

Gráfico 2 - Distribuição dos pacientes por NSF segundo o estado civil ..............................28

Gráfico 3 - Distribuição dos pacientes por NSF segundo a profissão ................................ 28

Gráfico 5- Distribuição dos pacientes por NSF segundo o ciclo de vida..............................29

Gráfico 4 - Distribuição dos pacientes por NSF segundo a escolaridade ..............................29

Gráfico 6 - Distribuição dos pacientes por NSF segundo a presença de cuidador ................... 30

Gráfico 7 - Distribuição dos seguimentos dos pacientes nas especialidades........................ 40

Gráfico 8 - Distribuição dos diagnósticos por CID 10 …................................................. 40

Gráfico 9 - Distribuição das classes de medicamentos ................................................. 43

Gráfico 10 - Distribuição dos pacientes por NSF segundo a microárea ...............................44

Gráfico 11 - Distribuição dos pacientes por NSF segundo a modalidade de Atenção

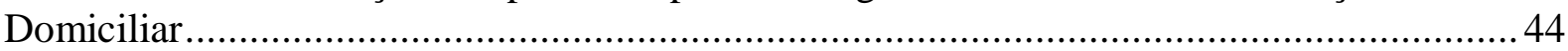

Gráfico 12 - Distribuição dos pacientes por NSF segundo o tipo de solicitação .................... 45

Gráfico 13 - Distribuição dos pacientes por NSF segundo a conduta tomada frente a solicitação de visita domiciliar

Gráfico 14 - Distribuição dos pacientes por NSF segundo o tipo de atendimento realizado... 46

Gráfico 15 - Distribuição dos pacientes por NSF segundo a conclusão ou desfecho da Atenção

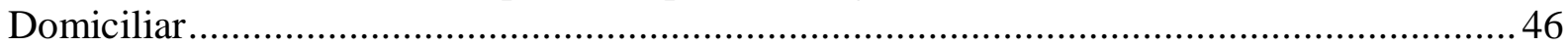




\section{LISTA DE ABREVIATURAS E SIGLAS}

ABNT: Associação Brasileira de Normas Técnicas

AD: Atenção Domiciliar

APS: Atenção Primária à Saúde

AVC: Acidente Vascular Cerebral

CIB: Comissão Intergestores Bipartite

CID 10: Classificação Estatística Internacional de Doenças e Problemas relacionados com a Saúde

CIR: Comissão Intergestores Reginal

CKMB: Isoenzima da CK

CONASS: Conselho Nacional de Secretários de Saúde

DCNT: Doença Crônica Não Transmissível

EMAD: Equipe Multiprofissional de Atenção Domiciliar

EMAP: Equipe Multiprofissional de Apoio

ESF: Estratégia de Saúde da Família

eSF: equipe de Saúde da Família

FAEPA: Fundação de Apoio ao Ensino, Pesquisa e Assistência

FMRP: Faculdade de Medicina de Ribeirão Preto

FSH: Hormônio Folículo estimulante

HC: Hospital das Clínicas

HSPE: Hospital dos Servidores Púbicos do Estado de São Paulo

IBGE: Instituto Brasileiro de Geografia e Estatística

INCA: Instituto Nacional do Câncer

NASF: Núcleo de Apoio à Saúde da Família

NSF: Núcleo de Saúde da Família

OMS: Organização Mundial de Saúde

PAD: Plano de Atenção Domiciliar

SAD: Serviço de Atenção Domiciliar

SAMDU: Serviço de Assistência Médica Domiciliar e de Urgência

SAMU: Serviço de Atendimento Móvel de Urgência

SUS: Sistema Único de Saúde

UBS: Unidade Básica de Saúde

USP: Universidade de São Paulo

VD: Visita Domiciliar 


\section{SUMÁRIO}

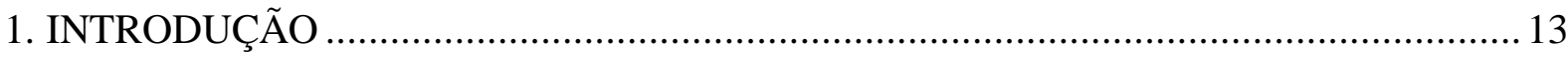

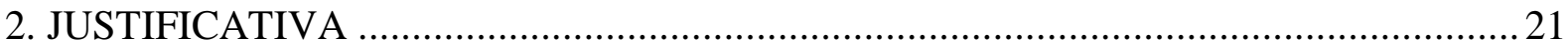

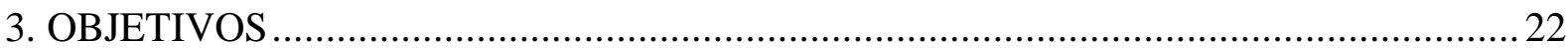

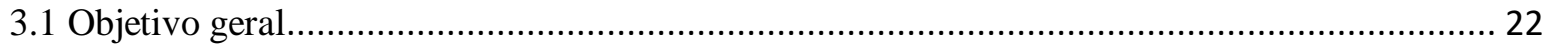

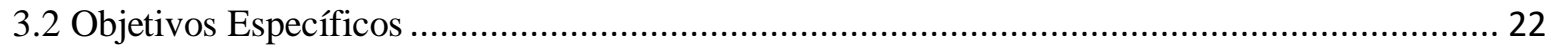

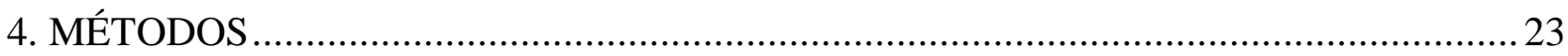

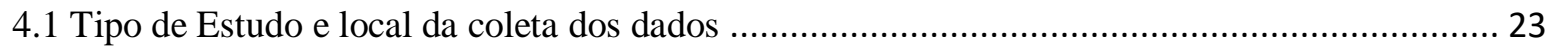

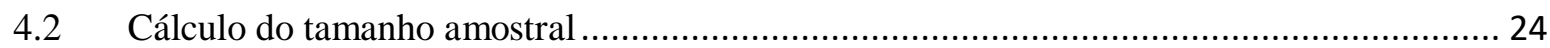

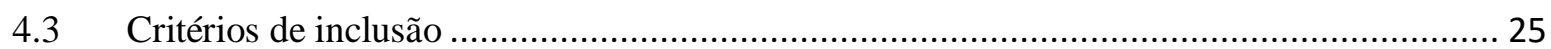

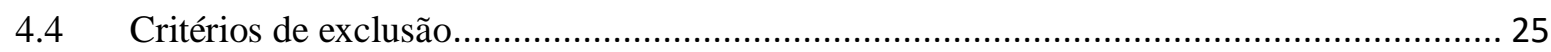

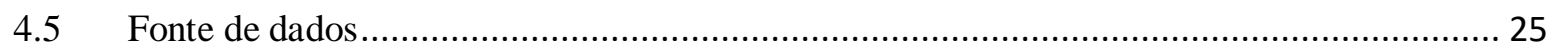

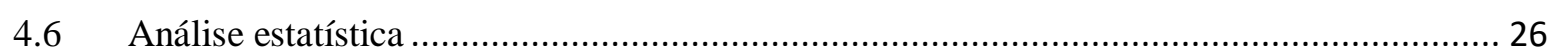

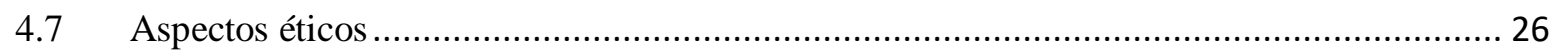

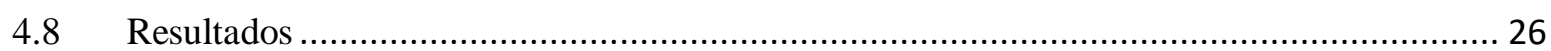

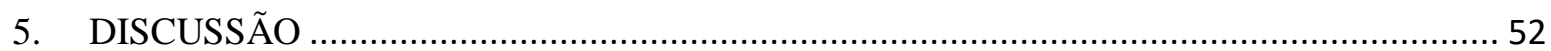

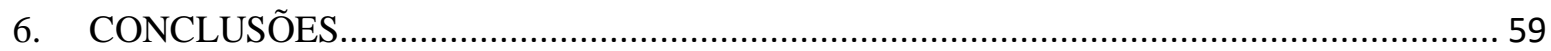

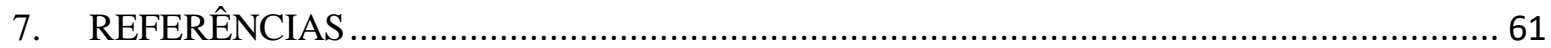

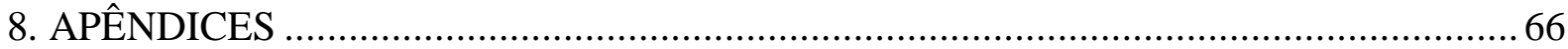

APÊNDICE A - Termo de Consentimento Livre e Esclarecido …................................................... 66

APÊNDICE B - Ficha 1: Solicitação de VD - Acolhimento.......................................................... 68

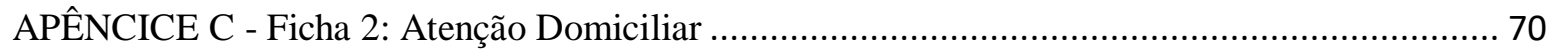

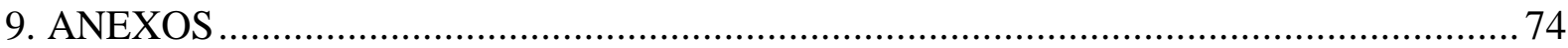

ANEXO A - Parecer Consubstanciado do Comitê de Ética em Pesquisa (CEP).............................. 74 


\section{INTRODUÇÃO}

O Ministério de Saúde define Saúde da Família como uma estratégia de reorientação do modelo assistencial, operacionalizada mediante a implantação de equipes multiprofissionais em unidades básicas de saúde. É considerado um projeto dinamizador do Sistema Único de Saúde (SUS) que tem como base a assistência universal (independentemente da situação socioeconômica), integral (oferece cuidados para todas as necessidades e em todos os níveis de atenção), equânime (oferece mais cuidados a quem mais necessita), contínua e resolutiva para a população, objetivando um atendimento adequado às reais condições de risco às quais as famílias estão expostas $(1,2)$.

Desta forma, em consonância com os fundamentos do SUS, a Estratégia de Saúde da Família (ESF) assume o compromisso de prestar assistência integral à população da sua área de abrangência, tanto nas dependências da própria Unidade de Saúde quanto no domicílio do paciente, de acordo com as necessidades apresentadas (3). Também é considerada um espaço de construção de cidadania e de integração com outras instituições sociais, configurando a intersetorialidade $(4,5)$.

A ESF conta com a atuação de uma equipe multiprofissional (eSF) que possui algumas competências, entre elas a atuação na assistência integral à saúde - tendo como centro das suas ações a pessoa e o meio ambiente - e na assistência domiciliar, cuja principal finalidade é a monitorização da situação de saúde das famílias, contribuindo para o fortalecimento das relações familiares, respeitando vínculos afetivos $(6,7,8)$. Assim, segundo a Organização Mundial da Saúde (OMS), a Assistência Domiciliar pode ser definida como "(...) a provisão de serviços de saúde por prestadores formais e informais com o objetivo de promover, restaurar e manter o conforto, função e saúde das pessoas num nível máximo, incluindo cuidados para uma morte digna" $(1,9,10,11)$. É uma atividade que se constrói fora do espaço hospitalar e dos ambulatórios de especialidades, oferecendo assistência personalizada e humanizada, considerando o aspecto social e familiar do paciente (12). É considerada um importante instrumento da ESF para a ampliação da qualidade de vida dos usuários (4). Resulta, ainda, em um atendimento humanizado, com o qual se observa maior rapidez na recuperação dos pacientes e que tem contribuído para a otimização dos leitos hospitalares e diminuição dos custos.

Esta prática de saúde no domicílio é tão antiga quanto a própria vida em sociedade. Na Grécia Antiga, médicos percorriam vilarejos prestando assistência às famílias de casa em casa 
$(13,4,14)$. Porém, a primeira referência de um cuidado domiciliar ofertado de modo organizado data de 1796 e encontra-se registrado no Dispensário de Boston, hoje The New England Medical Center (14).

Porém, a partir do século XIX, com o surgimento dos hospitais como um espaço de consolidação da identidade de doente, de assistência, segregação e exclusão, a residência deixa de ser o lugar onde o sofrimento se manifestava em sua forma possível (4).

Com a crise desse modelo e de novas necessidades decorrentes do envelhecimento populacional e da transição epidemiológica, há uma maior demanda por cuidados integrais e contínuos, fazendo da atenção domiciliar uma alternativa de qualidade ao cuidado hospitalar.

A primeira unidade de Atenção Domiciliar surgiu nos EUA no pós-guerra, em 1947, como prática institucionalizada, quando várias enfermeiras se reuniram e passaram a atender os pacientes em casa com objetivo de descongestionar os hospitais. Em 1960 esse movimento cresce e surgem as Nursing Home com atendimento direcionado para idosos portadores de doenças crônicas terminais (15).

Na Europa, a primeira experiência formal de assistência em domicílio data de 1957 e aconteceu em Paris (França), culminando com a criação do Santé Service que até hoje presta assistência sociosanitária a pacientes crônicos. Na Espanha, a demanda pela atenção domiciliar surge em 1981 a partir da necessidade dos usuários de uma atenção mais humanizada e dos gestores pelos excessivos custos hospitalares (15). No Brasil isso acontece em 1949 com o Serviço de Assistência Médica Domiciliar e de Urgência (SAMDU) vinculado ao Ministério do Trabalho para os assegurados e beneficiários dos Institutos e Caixas de Aposentadorias e Pensões que recebiam visitas de urgência ou regulares para aqueles que apresentavam doenças crônicas. Em 1963, implantou-se o Serviço de Assistência Domiciliar do Hospital dos Servidores Públicos do Estado de São Paulo (HSPE) que oferecia serviço domiciliar para atendimento a pacientes com doenças crônicas que não necessitassem de cuidados diários de médicos e enfermeiros (15).

Com a Constituição de 1988 e a implementação do SUS, o Brasil modificou e estabeleceu novos conceitos, redimensionando as ações de saúde no Brasil (15). Assim, seguindo uma tendência mundial, os brasileiros iniciam a expansão na forma do cuidado domiciliar em que serviços como a ESF, a Atenção Domiciliar e suas modalidades, os cuidados paliativos, as residências terapêuticas, as Unidades de Cuidados Continuados, o tele monitoramento de pacientes, entre outros, começam a tomar força $(13,15)$. 
Em 1998, motivada pela diminuição dos custos com internação hospitalar e humanização do atendimento, surge a Portaria $\mathrm{n}^{\mathrm{o}} 2.416$ que definiu requisitos para credenciamento de hospitais e critérios para a modalidade de Internação Domiciliar no SUS, retomando o cuidado no domicílio como forma de organização da assistência (16).

Em 2002, o governo aprova a Lei no 10.424 que dispõe sobre a Assistência Domiciliar no SUS (17) e em janeiro de 2006 aprova a Resolução da Diretoria Colegiada da Agência Nacional de Vigilância Sanitária - RDC/ANVISA nº 11 que regulamenta, do ponto de vista técnico, os Serviços que prestam Atenção Domiciliar no âmbito do Sistema Único de Saúde. Esta resolução define os requisitos mínimos de segurança e os critérios normativos e adota as seguintes definições, a saber:

- Admissão em Atenção Domiciliar: processo de indicação, elaboração do Plano de Atenção Domiciliar e início da prestação da assistência ou internação domiciliar;

- Alta da Atenção Domiciliar: encerramento da prestação de serviços de atenção domiciliar em função de internação hospitalar, alcance da estabilidade clínica, cura, a pedido do paciente e/ou responsável ou óbito;

- Atenção Domiciliar (AD): termo genérico que envolve ações de promoção à saúde, prevenção, tratamento de doenças e reabilitação desenvolvidas em domicílio;

- Assistência Domiciliar: conjunto de atividades de caráter ambulatorial, programadas e continuadas desenvolvidas em domicílio;

- Internação Domiciliar: conjunto de atividades prestadas em domicílio, caracterizadas pela atenção em tempo integral ao paciente com quadro clínico mais complexo e com necessidade de tecnologia especializada;

- Vigilância Domiciliar: envolve ações de promoção, prevenção, educação e busca ativa da população da área de abrangência, geralmente vinculados à vigilância da saúde que a Unidade desenvolve, dentre elas, visitas a puérperas, busca de recém-nascidos, busca ativa dos Programas de Prioridades e abordagem familiar para diagnóstico e tratamento (18).

- Visita Domiciliar (VD): Instrumento de realização da atenção domiciliar, sendo constituído de ações sistematizadas para viabilizar o cuidado a pessoas com algum nível de alteração no estado de saúde ou para realizar atividades vinculadas aos programas de saúde (18). 
Esta resolução ainda define outros termos ligados à atenção domiciliar:

- Cuidador: pessoa(s), com ou sem vínculo familiar com o usuário, apta(s) para auxiliá-lo em suas necessidades e atividades da vida cotidiana e que, dependendo da condição funcional e clínica do usuário, deverá(ão) estar presente(s) no atendimento domiciliar (19);

- Equipe Multiprofisssional de Atenção Domiciliar (EMAD): profissionais que compõem a equipe técnica da atenção domiciliar com a função de prestar assistência clínico-terapêutica e psicossocial ao paciente em seu domicílio;

- Plano de Atenção Domiciliar (PAD): documento que contempla um conjunto de medidas que orienta a atuação de todos os profissionais envolvidos de maneira direta e/ou indireta na assistência a cada paciente em seu domicílio desde sua admissão até a alta. Deve conter a prescrição da assistência clínico-terapêutica e psicossocial para o paciente e a periodicidade dos relatórios de evolução e acompanhamento;

- Serviço de Atenção Domiciliar (SAD): serviço substitutivo ou complementar à internação hospitalar ou ao atendimento ambulatorial, responsável pelo gerenciamento e operacionalização das Equipes Multiprofissionais de Atenção Domiciliar (EMAD) e Equipes Multiprofissionais de Apoio (EMAP). Para que os municípios tenham SAD é necessário apresentar isoladamente ou por meio de agrupamento de Municípios - conforme pactuação prévia na Comissão Intergestores Bipartite (CIB) e, se houver, na Comissão Intergestores Regional (CIR) - população igual ou superior a 20.000 (vinte mil) habitantes, com base na população estimada pelo Instituto Brasileiro de Geografia e Estatística (IBGE); estar coberto por Serviço de Atendimento Móvel de Urgência (SAMU - 192) e possuir hospital de referência no Município ou região a qual integra (20).

Também em 2006, o Conselho Nacional de Secretários de Saúde (CONASS) publicou uma nota técnica propondo a implantação da Política Nacional de Internação Domiciliar. A discussão contempla formas de funcionamento e controle para Internação Domiciliar (21). Em 2011 surgiu a Portaria n 2.029 que institui a Política Nacional de AD e a participação do gestor federal no funcionamento dos serviços (22). 
Mais recentemente, em outubro de 2011, surgiu a Portaria $\mathrm{n}^{\circ} 2.527$ que define três modalidades de AD:

- AD1: Usuários que possuam problemas de saúde controlados/compensados e com dificuldade ou impossibilidade física de locomoção até uma Unidade de Saúde que necessitem de cuidados de menor complexidade, de menor frequência, com menor necessidade de recursos de saúde e dentro da capacidade de atendimento das UBS's - e que não se enquadrem nos critérios previstos para as modalidades $\mathrm{AD} 2$ e AD3. A prestação da assistência nesta modalidade é de responsabilidade das equipes de atenção básica por meio de visitas regulares em domicílio, no mínimo, uma vez por mês;

- AD2: Usuários que possuam problemas de saúde e dificuldade ou impossibilidade física de locomoção até uma Unidade de Saúde e que necessitem de maior frequência de cuidado, recursos de saúde e acompanhamento contínuo, podendo ser oriundos de diferentes serviços da rede de atenção. São levadas em consideração a demanda por procedimentos de maior complexidade que podem ser realizados em domicílio, a dependência de monitoramento frequente de sinais vitais, a necessidade frequente de exames de laboratório de menor complexidade, a adaptação do usuário e/ou cuidador ao uso do dispositivo de traqueostomia, de órteses/próteses, sondas e ostomias, o acompanhamento domiciliar no pós-operatório, a reabilitação de pessoas com deficiência permanente ou transitória que necessitem de atendimento contínuo até apresentarem condições de frequentarem serviços de reabilitação, o uso de aspirador de vias aéreas para higiene brônquica, o acompanhamento de ganho ponderal de recém-nascidos de baixo peso, a necessidade de atenção nutricional permanente ou transitória, a necessidade de cuidados paliativos, a necessidade de medicação endovenosa ou subcutânea e ainda a necessidade de fisioterapia semanal $(13,23)$;

- $\mathrm{AD} 3$ : Semelhante à $\mathrm{AD} 2$, mas preconiza que o usuário faça uso de equipamentos/procedimentos especiais. É necessário que exista pelo menos uma das situações admitidas como critério de inclusão para cuidados na modalidade AD2 e a necessidade do uso de, no mínimo, um dos seguintes equipamentos/procedimentos: Suporte Ventilatório não invasivo - Pressão 
Positiva Contínua nas Vias Aéreas (CPAP) e Pressão Aérea Positiva por dois Níveis (BIPAP), diálise peritoneal ou paracentese $(13,23)$.

Na América Latina e América Central existem programas de AD com diferentes inserções e vinculações ao Sistema de Saúde, porém, com pouca influência do governo federal. Por outro lado, na Espanha tem-se buscado articular os programas e serviços sociais e de saúde neste contexto. Desta forma, as equipes de Atenção Primária têm se responsabilizado pela identificação de pessoas em risco e uma enfermeira de referência é designada para cada caso criando uma vinculação entre os serviços e os usuários (15).

O Canadá também vem buscando a articulação entre os serviços e a base comunitária, embora ainda não exista uma clara distinção entre as atribuições dos serviços de $\mathrm{AD}$ e Assistência Social. Um exemplo é o Programa-Dia destinado aos portadores da Doença de Alzheimer (15).

No Brasil, as políticas públicas em saúde voltadas para esse tipo de atenção vêm se fortalecendo, principalmente no sentido organizacional e estrutural. Porém, ainda é um grande desafio, pois, ao mesmo tempo em que ocorre a "desospitalização" e o envelhecimento da população, cria-se uma nova demanda para suprir as necessidades de cuidados como suporte social, econômico e afetivo, agora realizadas no domicílio (12). Por outro lado, temos a organização do processo de trabalho da equipe e a articulação com os diferentes níveis de atenção, o que contribui sobremaneira para o sucesso deste modo de assistência.

Mas não é somente a mudança do perfil epidemiológico que tem causado o aumento da demanda por cuidados domiciliares, algumas mudanças socioculturais como a fragmentação da unidade familiar tradicional, sua configuração reduzida e o aumento da participação das mulheres no mercado de trabalho também têm contribuído (15).

Goshima e Mello (24) realizaram levantamento das características da AD no período de 2002 e 2012 em uma Unidade de Saúde da Família no interior do Estado de São Paulo e mostraram prevalência geral de $2 \%$ de VD em todas as unidades avaliadas. Com relação ao perfil sociodemográfico da população visitada, encontrou-se que $73,3 \%$ dos que necessitaram deste serviço eram mulheres e a média geral de idade foi de 74,7 (15,36 anos). Quanto à divisão por microáreas, que são as unidades operacionais do agente comunitário de saúde formadas por conjuntos de família, a maior média de idade foi na microárea 1 [83 anos (6,4 anos)] e a menor média de idade na microárea 3 [67,2 anos (21,4 anos)]. Observou-se também que 36,7\% apresentavam dificuldade de deambulação, 46,7\% solicitaram as visitas por alguma queixa 
relacionada à saúde e $16,7 \%$ por outros motivos. Uma importante dificuldade apontada pela equipe foi a falta de objetividade na solicitação da $\mathrm{AD}$, referida em $26,7 \%$ dos casos.

A análise do perfil da Atenção Domiciliar revelou que, coerentemente, a modalidade mais utilizada foi a AD1, já que é a modalidade que, segundo o Ministério da Saúde, se enquadra no atendimento de pacientes com menor nível de complexidade e que estejam dentro da capacidade de atendimento das UBS. Os tipos de atenção domiciliar realizados foram somente Atendimento Domiciliar e Acompanhamento Domiciliar, não sendo realizados atendimentos de busca ativa dos grupos prioritários nem de puérperas e recém-nascidos.

Entre as mulheres, 31,8\% retornaram para atendimentos na Unidade e 68,2\% continuaram o acompanhamento domiciliar. Entre os homens, 37,5\% tiveram a atenção domiciliar encerrada e 62,5\% mantiveram acompanhamento domiciliar. Os idosos foram os que mais receberam $\mathrm{AD}$ e as solicitações foram motivadas, em sua maioria, por queixas associadas ao próprio processo de envelhecimento. Porém, outras demandas foram identificadas e as queixas envolvendo pós-operatórios e queixas súbitas também foram causas frequentes de solicitação de VD. Observou-se ainda a falta de objetividade nas solicitações de AD que foi apontada como fator que dificultou a assistência tanto do ponto de vista do profissional quanto do atendimento da demanda (resolutividade) (24). O estudo mostrou que as AD se realizavam de forma quase intuitiva, não sistematizada, certamente em decorrência da alta demanda por assistência tanto na Unidade como no domicílio. Este dado reforça a necessidade de que a AD se baseie em roteiros sistematizados que favoreçam a execução deste tipo de atendimento.

A proposta da $\mathrm{AD}$ é complementar ou até mesmo substituir outras ações de saúde (25). A implantação sistematizada da $\mathrm{AD}$ pode melhorar os indicadores de qualidade de vida de portadores de doenças crônicas ou de enfermidades agudas graves, minimizar o desconforto físico e emocional dos pacientes e seus familiares causados por estas condições, diminuir a necessidade e, consequentemente, os custos decorrentes de hospitalizações, bem como favorecer a proximidade das equipes de saúdes com os pacientes, humanizando o atendimento (26).

Um estudo publicado no Canadá avaliou a recuperação clínica dos pacientes que receberam cuidados domiciliares depois de procedimentos cirúrgicos (varizes, herniorrafia, colecistectomia, cirurgias anal e retal e histerectomia abdominal) e de pacientes que receberam cuidados no ambiente hospitalar, concluindo que o programa de $\mathrm{AD}$ funcionou eficientemente, pois não houve diferença nas taxas de eventos adversos (desconforto, infecção, cicatrização demorada ou complicações) entre os dois grupos (27). 
Já um estudo na Turquia mostrou que o apoio à amamentação no pós-parto em ambiente domiciliar foi eficaz para aumentar a duração do aleitamento materno e o conhecimento da mãe sobre a amamentação (28).

Em outro estudo realizado em Passo Fundo/RS (Brasil) com VD's a pacientes pós alta hospitalar realizadas com a finalidade de orientar sobre possíveis dúvidas frente sua nova realidade, os autores observaram maior satisfação e segurança dos pacientes e seus familiares, além da redução no número de reinternações, que foram atribuídas às orientações recebidas, consideradas personalizadas e adaptadas à realidade de cada um (5).

Assim, diante deste contexto, o presente estudo teve como finalidade avaliar as ações de Atenção Domiciliar realizadas nos Núcleos de Saúde da Família ligados à Faculdade de Medicina de Ribeirão Preto da Universidade de São Paulo, identificar o perfil dos pacientes assistidos em domicílio pelas equipes e nortear estratégias de aprimoramento e sistematização das diferentes modalidades de Atenção Domiciliar à Saúde realizadas nas unidades. 


\section{JUSTIFICATIVA}

Segundo dados relacionados à assistência a pacientes oncológicos, as práticas de diferentes modalidades de Atenção Domiciliar vêm reduzindo os custos com atendimentos ambulatorial e hospitalar, diminuindo as internações (29) e garantindo o bem-estar de grande número de pessoas (29).

Um estudo realizado na Espanha revelou que o modelo de gerenciamento de pacientes crônicos em AD agiliza o acesso aos serviços e recursos de saúde, impacta positivamente na capacidade funcional dos pacientes, diminui a sobrecarga dos cuidadores e aumenta os níveis de satisfação da assistência prestada $(15,30)$.

Entretanto, os resultados positivos destas ações dependem da integração dos diferentes níveis de atenção à saúde, através de equipes de profissionais bem preparadas para a atuação nos domicílios e, neste contexto, a ESF - atuando no nível primário de Atenção à Saúde - é a instância adequada para garantir assistência continuada e integrada aos pacientes crônicos ou agudamente enfermos no seu território de abrangência. Além disso, o apoio dos gestores é essencial para assegurar aos profissionais de $\mathrm{AD}$ condições adequadas de trabalho.

No Distrito Oeste de Saúde de Ribeirão Preto, os Núcleos de Saúde da Família ligados à Faculdade de Medicina de Ribeirão Preto da Universidade de São Paulo realizam assistência em nível primário de atenção para a sua população adscrita, incluindo ações no domicílio, através do trabalho de equipes multiprofissionais.

Desta forma, em decorrência da grande heterogeneidade do território, conhecer o perfil dos pacientes atendidos em Atenção Domiciliar e entender como as ações vêm sendo realizadas pelos NSF's é fundamental para que se possa elaborar um plano sistematizado de Atenção Domiciliar adaptado às demandas locais e que venha a contribuir efetivamente para a integração de toda a rede de atenção à saúde no que se refere à Atenção Domiciliar, já que não há muitos trabalhos sobre o tema e nem instrumentos específicos. 


\section{OBJETIVOS}

\subsection{Objetivo geral}

Avaliar a Atenção Domiciliar realizada pelas equipes de profissionais dos Núcleos de Saúde do Município de Ribeirão Preto/SP no período de janeiro de 2015 a dezembro de 2016 e sistematizar o atendimento aos usuários da APS com vistas a planejar e organizar o trabalho do profissional da APS que realizará a AD.

\subsection{Objetivos Específicos}

- Caracterizar o grupo de usuários da $\mathrm{AD}$ quanto à faixa etária, gênero, estado civil, nível de escolaridade, profissão e à etapa do ciclo de vida em que se encontram;

- Identificar as doenças mais frequentemente associadas às solicitações de $A D$, considerando-se diagnóstico principal (CID-10) e doenças associadas;

- Caracterizar a Atenção Domiciliar quanto ao tipo de solicitação, modalidade de Assistência Domiciliar realizada e principais dificuldades encontradas.

- Avaliar os desfechos mais frequentes das AD;

- Apresentar sugestões para o aprimoramento do atendimento domiciliar dos moradores da área de abrangência do NSF. 


\section{MÉTODOS}

\subsection{Tipo de Estudo e local da coleta dos dados}

Conduziu-se um estudo transversal com o propósito de descrever a Atenção Domiciliar realizada pelas equipes de profissionais dos Núcleos de Saúde da Família ligados à Faculdade de Medicina de Ribeirão Preto da Universidade de São Paulo localizados no Distrito de Saúde Oeste do Município de Ribeirão Preto/SP e sistematizar, através de instrumentos padronizados (fichas - apêndices B e C), a solicitação (Ficha 1 - Apêndice B) e a realização (Ficha 2 Apêndice C) das Visitas Domiciliares. Os NSF's foram escolhidos como local de coleta do estudo pois são espaços destinados a implementar a Estratégia de Saúde da Família, são responsáveis pela cobertura da área básica do bairro Sumarezinho do Distrito Oeste de Ribeirão Preto. Constituem a rede de saúde local e são mantidas por um convênio entre a Prefeitura Municipal de Ribeirão Preto e a Universidade de São Paulo. Cada NSF tem uma população de referência de aproximadamente 3000 habitantes e possui uma equipe mínima de um médico de família e comunidade, uma enfermeira, três auxiliares de enfermagem e cinco agentes comunitários de saúde. Desenvolvem assistência primária à saúde à população adstrita de acordo com a gestão municipal e as diretrizes do Ministério da Saúde. Por serem gerenciados pela FMRP-USP, desenvolvem ensino e pesquisa para os alunos de graduação e pós-graduação da FMRP e das demais unidades de ensino da área da Saúde do Campus da USP Ribeirão Preto e dos Médicos Residentes do HCFMRP.

A coleta dos dados foi realizada no período de março de 2015 a março de 2016, iniciada com o treinamento dos profissionais das equipes participantes para utilizarem os instrumentos - Ficha 1 e Ficha 2 (Apêndices B e C), que foram elaborados pela pesquisadora e sua orientadora com base na literatura atual sobre Atenção Domiciliar. A finalidade dos referidos instrumentos foi coletar informações essenciais sobre como se dá a AD na área de abrangência dos Núcleos de Saúde da Família da FMRP (NSF-FMRP) e propor a sistematização do procedimento através do planejamento e organização do trabalho do profissional executor da VD, favorecendo maior resolutividade da(s) demanda(s) e, consequentemente, maior satisfação por parte do usuário.

As fichas de solicitação (Ficha 1 - Apêndice B) foram preenchidas pelo profissional da equipe dos NSF's que recebeu o pedido do paciente ou familiar/responsável para a realização da VD ou pelo profissional que identificou a necessidade da realização da mesma durante um atendimento ou visita de rotina. Ficha consta de dados de identificação do paciente e do cuidador, endereço, telefone, número de familia e microárea, qual o tipo de solicitação, o 
motivo da solicitação, a conduta frente a esta demanda, tipo de atenção domiciliar e a conclusão do caso.A ficha de VD propriamente dita (Ficha 2 - Apêndice C) foi preenchida pela pesquisadora, que é médica de família, e é composta de dados de identidicação do paciente, anamnese, uso de medicamentos, exames checados, antecedentes pessoais, mobilidade, seguimento em outros serviços, exame físico, hipóteses diagnósticas e condutas. No domicílio, a pesquisadora informou detalhadamente o usuário solicitante sobre a pesquisa. Após aceitar participar do estudo, foi solicitado ao usuário a leitura e assinatura do Termo de Consentimento Livre e Esclarecido (TCLE - Apêndice A). Ressalta-se que ao usuário que não concordou em participar da pesquisa não sofreu nenhum prejuízo, pois teve sua solicitação atendida pelo profissional da equipe naquele mesmo momento.

\subsection{Cálculo do tamanho amostral}

O tamanho da amostra foi calculado levando-se em consideração a prevalência de $2 \%$ de visitas domiciliares com erro absoluto tolerável de 0,05 , população acessível de aproximadamente 3.000 moradores cadastrados, admitindo-se um erro amostral máximo de 5\% e um coeficiente de confiança de $95 \%$, segundo a fórmula:

$$
\mathrm{n}=\frac{Z^{2}(1-y) / 2 N p(1-p)}{d^{2}(N-1)+Z^{2}(1-y) / 2 p(1-p)}
$$

Desta forma, foi estimado um tamanho amostral mínimo de 150 visitas domiciliares. Foram consideradas 30 visitas domiciliares por unidade de saúde da família, selecionadas de forma sistematizada em que a primeira solicitação de visita da semana de cada núcleo foi incluída. Assim, a cada semana, a pesquisadora realizou cinco visitas domiciliares (uma por núcleo) durante aproximadamente 30 semanas até completar 30 visitas por cada NSF-FMRP. A prevalência utilizada no cálculo do tamanho da amostra (150 visitas domiciliares sendo 30 por núcleo) foi baseada em dados de um estudo anteriormente realizado pela pesquisadora em que se constatou a frequencia de $2 \%$ de solicitações de algum tipo de $\mathrm{AD}$, variando entre os NSF-FMRP e ao longo do ano.

Após a fase de coleta, os dados obtidos foram analisados com a finalidade de identificar as principais características clínico-epidemiológicas, de ciclo de vida e demandas mais 
frequentes, além dos aspectos relacionados ao tipo de solicitação e modalidade de Assistência Domiciliar mais frequente.

\subsection{Critérios de inclusão}

Foram elegíveis para o estudo as primeiras solicitações de visita da semana em cada núcleo, de modo que foram 5 visitas domiciliares (uma por núcleo) a cada semana, até completar 30 visitas por NSF-FMRP. Foram incluídos apenas os Núcleos de Saúde da Família ligados à Faculdade de Medicina de Ribeirão Preto da Universidade de São Paulo que concordaram em participar do estudo. Com relação aos instrumentos - de solicitação (Apêndice B - Ficha 1) e de realização (Apêndice C - Ficha 2), foram considerados apenas aqueles adequadamente preenchidos no período de coleta dos dados (março de 2015 a março de 2016) e que continham informações claras e consistentes.

\subsection{Critérios de exclusão}

Não foram considerados os Núcleos de Saúde da Família que não concordaram em participar do estudo, assim como as informações obtidas por instrumentos preenchidos fora do período de coleta dos dados (março de 2015 a março de 2016), com informações inadequadas, duvidosas ou inconsistentes, de paciente que não aceitaram participar da pesquisa e daqueles que não faziam parte da área de abrangência dos NSF's.

\subsection{Fonte de dados}

Foram utilizados no presente estudo os dados primários obtidos a partir do preenchimento das Fichas 1 e 2 (Apêndices B e C). Os dados foram avaliados quanto aos critérios de inclusão e exclusão e então registrados para a análise.

Foram consideradas variáveis de interesse a faixa etária, gênero, estado civil, nível de escolaridade, profissão, ciclo de vida (31), doença principal (CID-10) e associada e etapa do ciclo de vida em que se encontrava o indivíduo. Também foi avaliado o tipo de solicitação (caso novo ou seguimento) e a conduta frente à solicitação inicial (VD agendada ou VD eventual). Outras variáveis foram o tipo de atendimento realizado, se era um atendimento domiciliar 
pontual, acompanhamento domiciliar contínuo ou busca ativa de pacientes de grupos prioritários faltosos, a modalidade de $\mathrm{AD}$ e a conclusão da $\mathrm{AD}$.

Os dados coletados foram dispostos em planilhas e submetidos à análise estatística.

\subsection{Análise estatística}

Inicialmente, realizou-se a análise descritiva dos dados através das frequências absolutas e relativas das variáveis qualitativas e medidas de tendência central para as variáveis contínuas. Esta metodologia tem como objetivo básico sintetizar uma série de valores de mesma natureza, permitindo uma visão global da variação desses valores, organizando e descrevendo os dados de três maneiras: por meio de tabelas, de gráficos e de medidas descritivas (32).

Para verificar a associação entre as variáveis qualitativas, os dados foram submetidos ao Teste Exato de Fisher (33). Todas as análises estatísticas foram realizadas com a utilização do software estatístico SAS® 9. Valores de $\mathrm{p}$ menores que 0,05 foram considerados significativos.

\subsection{Aspectos éticos}

O projeto foi submetido ao Comitê de Ética em Pesquisa do Centro de Saúde Escola (CEP-CSE) da Faculdade de Medicina de Ribeirão Preto/USP e aprovado de acordo com o parecer $n^{\circ} 54670$ (Anexo A). O desenvolvimento da pesquisa contemplou o cumprimento da Resolução 466/12 do Conselho Nacional de Saúde.

O estudo proposto previu a participação de membros das equipes de APS dos Núcleos de Saúde da Família ligados à FMRP e a utilização das informações registradas nas Fichas 1 e 2. As equipes foram convidadas a participar do estudo e cada interessado foi informado sobre a pesquisa, sendo solicitada a leitura e assinatura do Termo de Consentimento Livre e Esclarecido (TCLE). Os usuários que solicitaram a visita também foram informados do estudo e a cada um deles foi oferecido o TCLE.

\subsection{Resultados}

Foram realizadas 150 visitas domiciliares, 30 em cada Núcleo de Saúde da Família (NSF) - número baseado na demanda (prevalência de 2\%) de visitas domiciliares de um NSF 
observado em estudo anterior (24). Dos pacientes visitados, 106 (70,7\%) eram mulheres, sendo o NSF2 com maior quantidade de mulheres [23 (15,3\%)] e o NSF4 com maior número de homens $[13(8,7 \%)]$ (Tabela 1 e Gráfico 1$)$.

Tabela 1 - Distribuição dos pacientes por NSF segundo gênero

\begin{tabular}{|c|c|c|c|c|c|c|c|c|c|c|c|c|c|}
\hline \multirow[t]{2}{*}{ VARIÁVEIS } & \multicolumn{6}{|c|}{$\begin{array}{c}\text { Masculino } \\
\text { n (\%) }\end{array}$} & \multicolumn{6}{|c|}{$\begin{array}{c}\text { Feminino } \\
\mathrm{n}(\%)\end{array}$} & \multirow[t]{2}{*}{$\mathrm{N}(\%)$} \\
\hline & NSF 1 & NSF 2 & NSF 3 & NSF 4 & NSF 5 & Total & NSF 1 & NSF 2 & NSF 3 & NSF 4 & NSF 5 & Total & \\
\hline$N(\%)$ & $9(6 \%)$ & $7(4,67 \%)$ & $9(6 \%)$ & $13(8,67 \%)$ & $6(4 \%)$ & $\begin{array}{c}44 \\
(29,33 \%)\end{array}$ & $21(14 \%)$ & $\begin{array}{c}23 \\
(15,33 \%)\end{array}$ & $21(14 \%)$ & $\begin{array}{c}17 \\
(11,33 \%)\end{array}$ & $\begin{array}{c}24 \\
(22,64 \%)\end{array}$ & $\begin{array}{c}106 \\
(70,67 \%)\end{array}$ & $150(100)$ \\
\hline
\end{tabular}

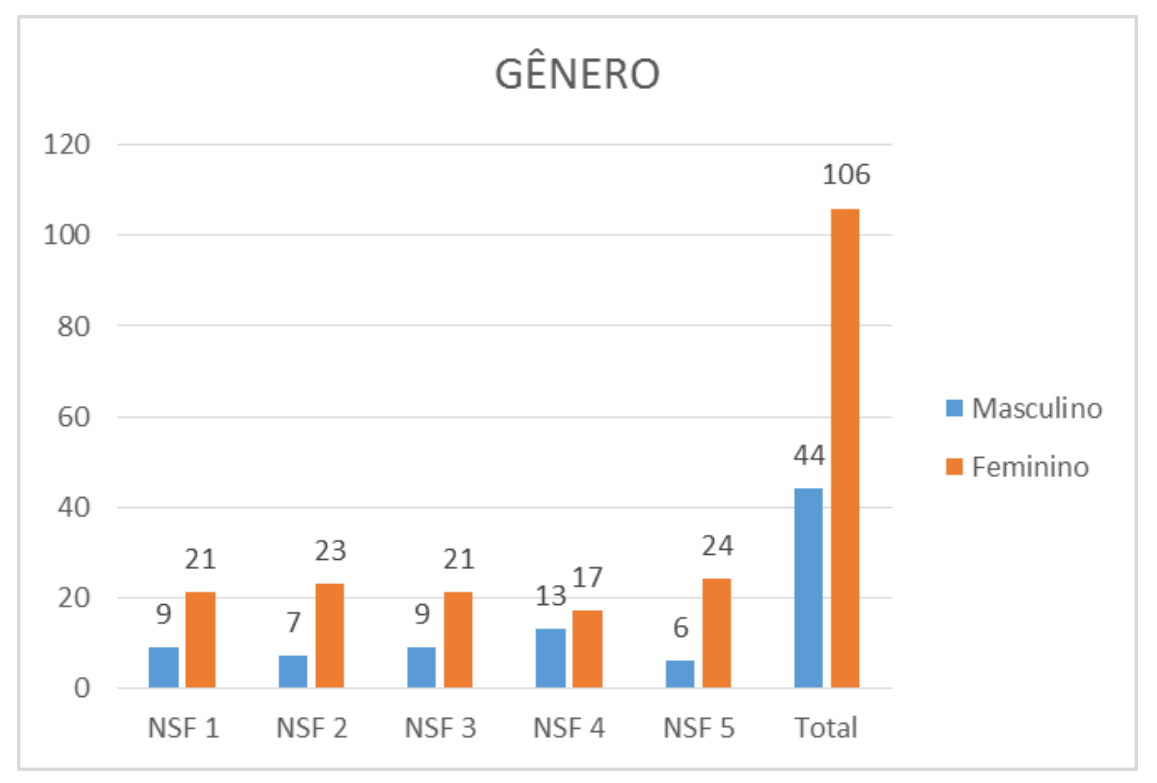

Gráfico 1 - Distribuição dos pacientes por NSF segundo gênero

O NSF 2 também obteve a maior média de idade observada [72,5 $(17,1)$ anos] e o NSF 5 a menor média $[59,9(21,4)$ anos] (Tabela 2$)$.

Tabela 2 - Idade média, mediana, idade mínima e máxima dos pacientes que receberam visitas domiciliares por NSF

\begin{tabular}{cccccc} 
VARIÁVEIS & NSF $\mathbf{1}$ & NSF 2 & NSF 3 & NSF 4 & NSF5 \\
\hline Idade - Média (DP) & $68.33(21,3)$ & $72.50(17,11)$ & $69.16(23,96)$ & $66.13(21,32)$ & $59.91(21,44)$ \\
Mediana & 74 & 77 & 79 & 73 & 64.50 \\
Mínimo & 0.00 & 30 & 0.67 & 0.00 & 0.33 \\
Máximo & 93 & 95 & 93 & 92 & 89 \\
\hline
\end{tabular}


A maioria dos pacientes eram casados [66(44\%)] (Gráfico 2), aposentados [84 (56\%)] (Gráfico 3), pertenciam a famílias anciãs [101 (67,3\%)] (Gráfico 4), possuíam ensino fundamental ( $1^{\mathrm{a}}$ a $4^{\mathrm{a}}$ série) [84 (56\%)] (Gráfico 5) e tinham cuidadores [102 (68\%)] (Gráfico 6) (Tabela 3).

\section{ESTADO CIVIL}

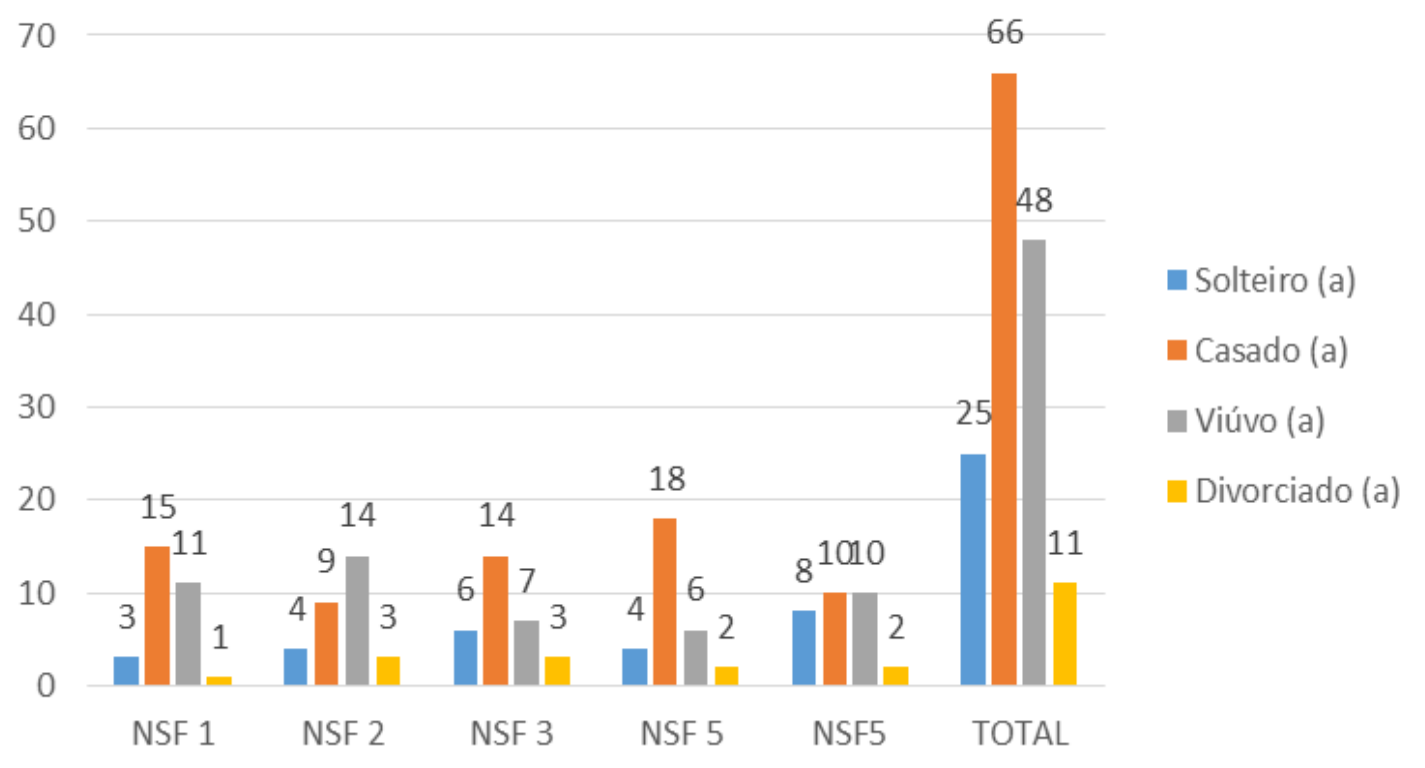

Gráfico 2 - Distribuição dos pacientes por NSF segundo o estado civil

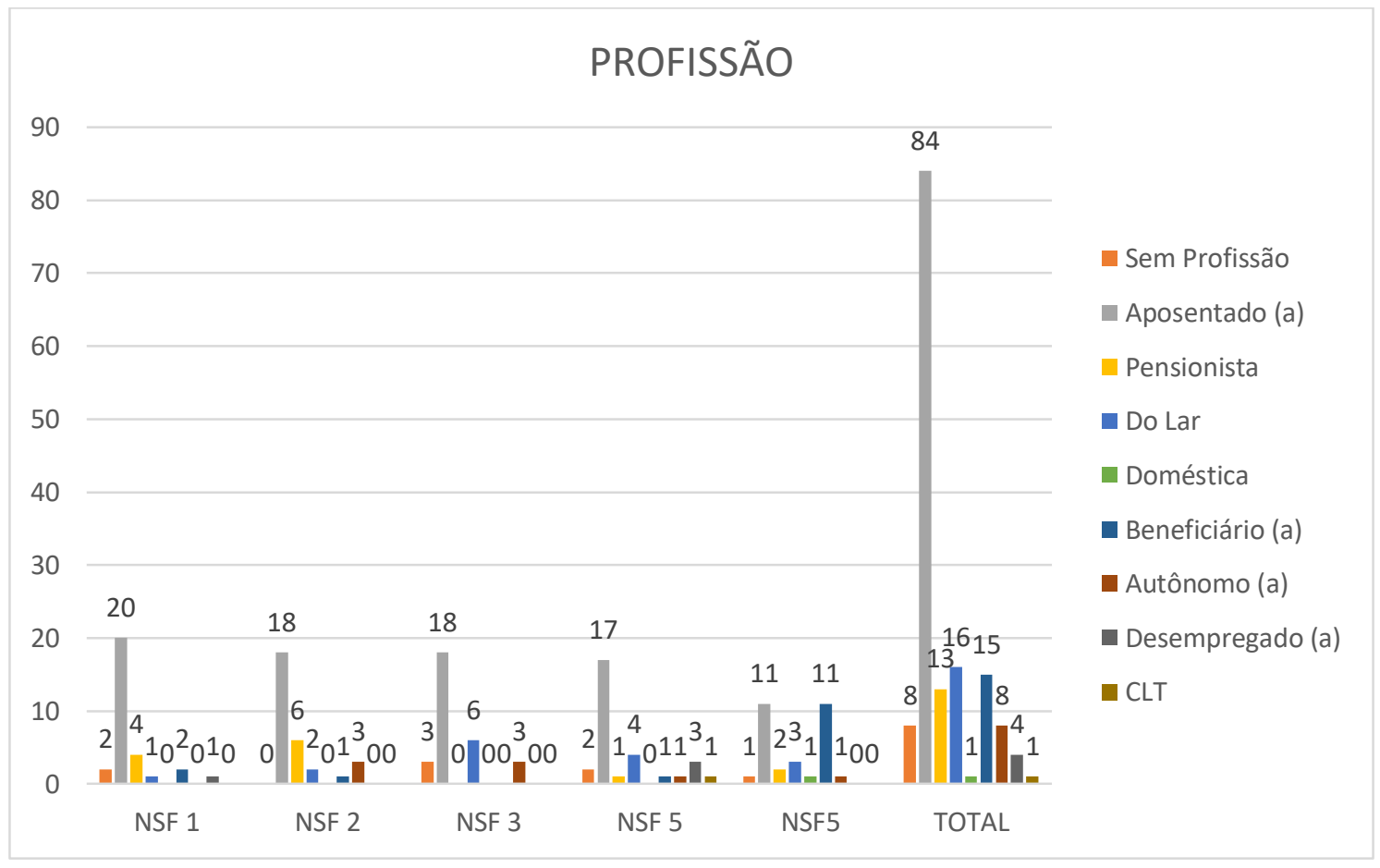

Gráfico 3 - Distribuição dos pacientes por NSF segundo a profissão 


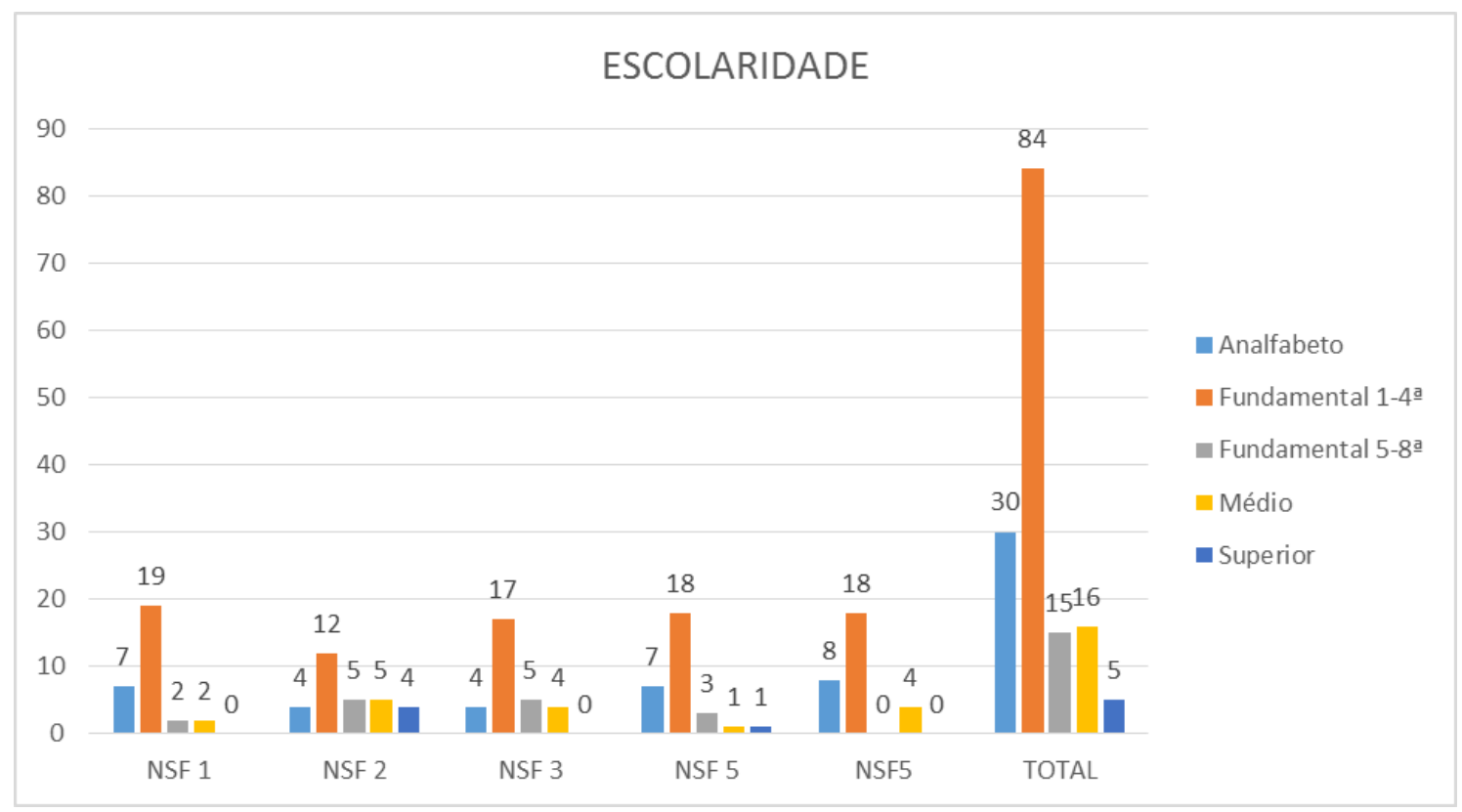

Gráfico 5 - Distribuição dos pacientes por NSF segundo a escolaridade

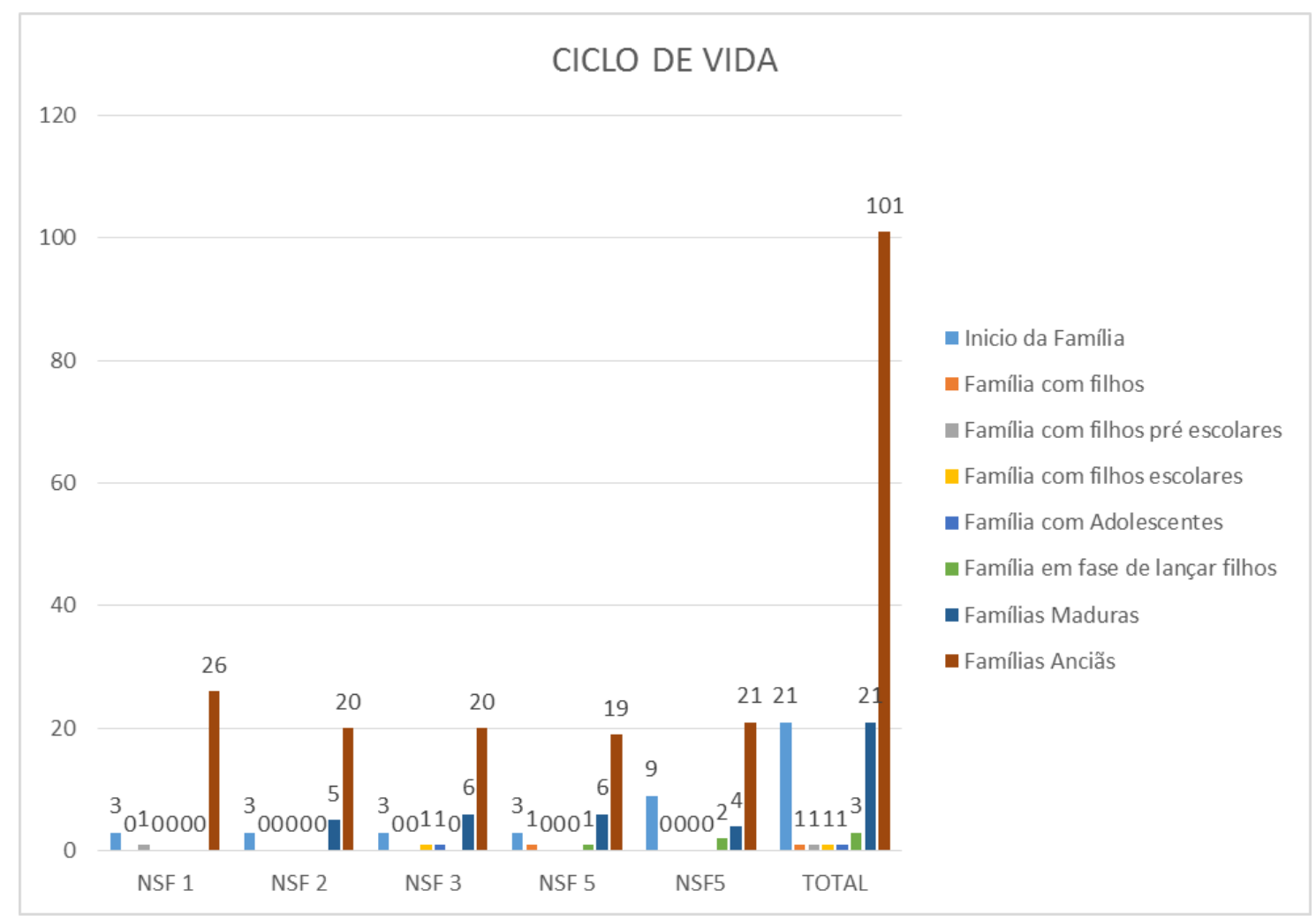

Gráfico 4- Distribuição dos pacientes por NSF segundo o ciclo de vida 


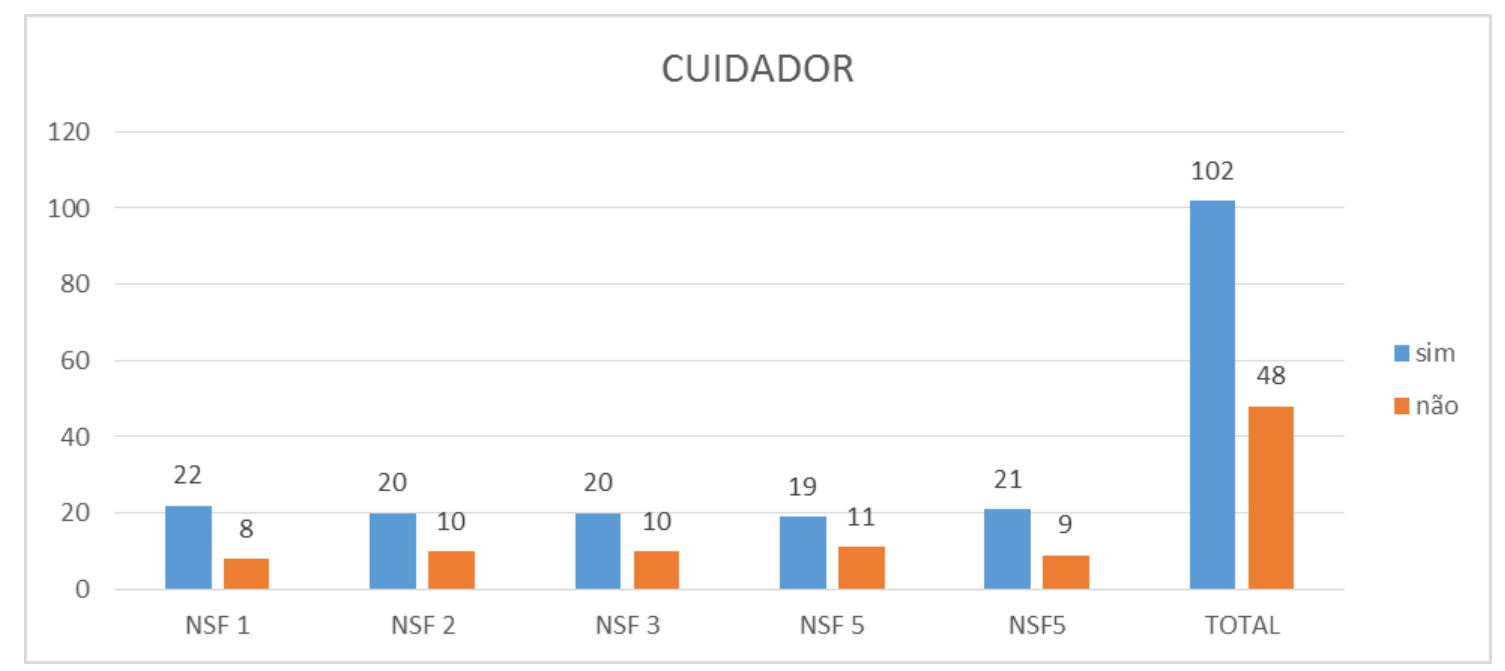

Gráfico 6 - Distribuição dos pacientes por NSF segundo a presença de cuidador 
Tabela 3 - Distribuição dos pacientes por NSF segundo as variáveis sociodemográficas

\begin{tabular}{|c|c|c|c|c|c|c|c|}
\hline \multicolumn{2}{|c|}{ VARIÁVEIS } & NSF 1 & NSF 2 & NSF 3 & NSF 4 & NSF5 & TOTAL \\
\hline \multirow{5}{*}{$\begin{array}{c}\text { Escolarida } \\
\text { de }\end{array}$} & Analfabeto & $7(4,67 \%)$ & $4(2,67 \%)$ & $4(2,67 \%)$ & $7(4,67 \%)$ & $8(5,33 \%)$ & $30(20 \%)$ \\
\hline & $\begin{array}{c}\text { Fundamenta } \\
11-4^{a}\end{array}$ & $\begin{array}{c}19 \\
(12,97 \%)\end{array}$ & $12(8 \%)$ & $\begin{array}{c}17 \\
(11,33 \%)\end{array}$ & $18(12 \%)$ & $18(12 \%)$ & $84(56 \%)$ \\
\hline & $\begin{array}{c}\text { Fundamenta } \\
15-8^{a}\end{array}$ & $2(1,33 \%)$ & $5(3,33 \%)$ & $5(3,33 \%)$ & $3(2 \%)$ & $0(0 \%)$ & $15(10 \%)$ \\
\hline & Médio & $2(1,33 \%)$ & $5(3,33 \%)$ & $4(2,67 \%)$ & $1(0,67 \%)$ & $4(2,67 \%)$ & $\begin{array}{c}16 \\
(10,67 \%)\end{array}$ \\
\hline & Superior & $0(0 \%)$ & $4(2,67 \%)$ & $0(0 \%)$ & $1(0,67 \%)$ & $0(0 \%)$ & $5(3,33 \%)$ \\
\hline \multirow{8}{*}{$\begin{array}{c}\text { Estado } \\
\text { Civil } \\
\text { Casado (a) }\end{array}$} & Solteiro (a) & $3(2 \%)$ & $4(2,67 \%)$ & $6(4 \%)$ & $4(2,67 \%)$ & $8(5,33 \%)$ & $\begin{array}{c}25 \\
(16,67 \%)\end{array}$ \\
\hline & $15(10 \%)$ & $9(6 \%)$ & $14(9,33 \%)$ & $18(12 \%)$ & $10(6,67 \%)$ & $66(44 \%)$ & \\
\hline & Viúvo (a) & $11(7,33 \%)$ & $14(9,33 \%)$ & $7(4,67 \%)$ & $6(4 \%)$ & $10(6,67 \%)$ & $48(32 \%)$ \\
\hline & $\begin{array}{l}\text { Divorciado } \\
\text { (a) }\end{array}$ & $1(0,67 \%)$ & $3(2 \%)$ & $3(2 \%)$ & $2(1,33 \%)$ & $291,33 \%$ ) & $11(7,33 \%)$ \\
\hline & $\begin{array}{c}\text { Sem } \\
\text { Profissão }\end{array}$ & $2(1,33 \%)$ & $0(0 \%)$ & $3(2 \%)$ & $2(1,33 \%)$ & $1(0,67 \%)$ & $8(5,33 \%)$ \\
\hline & $\begin{array}{l}\text { Aposentado } \\
\text { (a) }\end{array}$ & $\begin{array}{c}20 \\
(13,33 \%)\end{array}$ & $18(12 \%)$ & $18(12 \%)$ & $\begin{array}{c}17 \\
(11,33 \%)\end{array}$ & $11(7,33 \%)$ & $84(56 \%)$ \\
\hline & Pensionista & $4(2,67 \%)$ & $6(4 \%)$ & $0(0 \%)$ & $1(0,67 \%)$ & $2(1,33 \%)$ & $13(8,67 \%)$ \\
\hline & Do Lar & $1(0,67 \%)$ & $2(1,33 \%)$ & $6(4 \%)$ & $4(2,67 \%)$ & $3(2 \%)$ & $\begin{array}{c}16 \\
(10,67 \%)\end{array}$ \\
\hline \multirow[t]{5}{*}{ Profissão } & Doméstica & $0(0 \%)$ & $0(0 \%)$ & $0(0 \%)$ & $0(0 \%)$ & $1(0,67 \%)$ & $1(0,67 \%)$ \\
\hline & $\begin{array}{l}\text { Beneficiário } \\
\text { (a) }\end{array}$ & $2(1,33 \%)$ & $1(0,67 \%)$ & $0(0 \%)$ & $1(0,67 \%)$ & $11(7,33 \%)$ & $15(10 \%)$ \\
\hline & $\begin{array}{l}\text { Autônomo } \\
\text { (a) }\end{array}$ & $0(0 \%)$ & $3(2 \%)$ & $3(2 \%)$ & $1(0,67 \%)$ & $1(0,67 \%)$ & $8(5,33 \%)$ \\
\hline & $\begin{array}{l}\text { Desempreg } \\
\text { ado (a) }\end{array}$ & $1(0,67 \%)$ & $0(0 \%)$ & $0(0 \%)$ & $3(2 \%)$ & $0(0 \%)$ & $4(2,67 \%)$ \\
\hline & CLT & $0(0 \%)$ & $0(0 \%)$ & $0(0 \%)$ & $1(0,67 \%)$ & $0(0 \%)$ & $1(0,67 \%)$ \\
\hline \multirow[t]{6}{*}{ Cuidador } & $\operatorname{sim}$ & $\begin{array}{c}22 \\
(14,67 \%)\end{array}$ & $\begin{array}{c}20 \\
(13,33 \%)\end{array}$ & $\begin{array}{c}20 \\
(13,33 \%)\end{array}$ & $\begin{array}{c}19 \\
(12,67 \%)\end{array}$ & $21(14 \%)$ & $102(68 \%)$ \\
\hline & não & $8(5,33 \%)$ & $10(6,67 \%)$ & $10(6,67 \%)$ & $11(7,33 \%)$ & $9(6 \%)$ & $48(68 \%)$ \\
\hline & $\begin{array}{l}\text { Inicio da } \\
\text { Familia }\end{array}$ & $3(2 \%)$ & $3(2 \%)$ & $3(2 \%)$ & $3(2 \%)$ & $9(6 \%)$ & $21(14 \%)$ \\
\hline & $\begin{array}{l}\text { Família com } \\
\text { filhos }\end{array}$ & $0(0 \%)$ & $0(0 \%)$ & $0(0 \%)$ & $1(0,67 \%)$ & $0(0 \%)$ & $1(0,67 \%)$ \\
\hline & $\begin{array}{l}\text { Familia com } \\
\text { filhos pré } \\
\text { escolares }\end{array}$ & $1(0,67 \%)$ & $0(0 \%)$ & $0(0 \%)$ & $0(0 \%)$ & $0(0 \%)$ & $1(0,67 \%)$ \\
\hline & $\begin{array}{l}\text { Familia com } \\
\text { filhos } \\
\text { escolares }\end{array}$ & $0(0 \%)$ & $0(0 \%)$ & $1(0,67 \%)$ & $0(0 \%)$ & $0(0 \%)$ & $1(0,67 \%)$ \\
\hline \multirow{5}{*}{$\begin{array}{l}\text { Ciclo de } \\
\text { Vida }\end{array}$} & Família com & & & & & & \\
\hline & $\begin{array}{c}\text { Adolescente } \\
\mathrm{s}\end{array}$ & $0(0 \%)$ & $0(0 \%)$ & $1(0,67 \%)$ & $0(0 \%)$ & $0(0 \%)$ & $1(0,67 \%)$ \\
\hline & $\begin{array}{c}\text { Família em } \\
\text { fase de } \\
\text { lançar filhos }\end{array}$ & $0(0 \%)$ & $0(0 \%)$ & $0(0 \%)$ & $1(0,67 \%)$ & $2(1,33 \%)$ & $3(2 \%)$ \\
\hline & $\begin{array}{l}\text { Famílias } \\
\text { Maduras }\end{array}$ & $0(0 \%)$ & $5(3,33 \%)$ & $6(4 \%)$ & $6(4 \%)$ & $4(2,67 \%)$ & $21(14 \%)$ \\
\hline & $\begin{array}{l}\text { Famílias } \\
\text { Anciãs }\end{array}$ & $26(17,33 \%)$ & $20(13,33 \%)$ & $20(13,33 \%)$ & $19(12,67 \%)$ & $21(14 \%)$ & $101(67,33 \%)$ \\
\hline
\end{tabular}


A higiene do domicílio foi avaliada pela pesquisadora através de observação utilizandose uma escala de 5 categorias e notou-se que a maioria das casas visitadas possuíam boa higiene [62 (41,3\%)], embora algumas casas visitadas no território do NSF1 tivessem higiene regular [8 (5,3\%)]. A higiene da cama, corporal e bucal dos pacientes analisados mostrou-se boa [74 $(49,3 \%), 88(58,7 \%)$ e $63(42 \%)]$, respectivamente (Tabela 4$).$

Tabela 4 - Distribuição dos pacientes por NSF segundo a higiene

\begin{tabular}{|c|c|c|c|c|c|c|}
\hline HIGIENE & NSF 1 & NSF 2 & NSF 3 & NSF 4 & NSF 5 & n (\%) \\
\hline \multicolumn{7}{|l|}{ CASA } \\
\hline EXCELENTE & $2(1,33 \%)$ & $0(0 \%)$ & $4(2,67 \%)$ & $0(0 \%)$ & $0(0 \%)$ & $6(4 \%)$ \\
\hline MUITO BOA & $6(4 \%)$ & $2(1,33 \%)$ & $3(2 \%)$ & $6(4 \%)$ & $11(7,33 \%)$ & $28(18,66 \%)$ \\
\hline $\mathrm{BOA}$ & $7(4,67 \%)$ & $10(6,67 \%)$ & $10(6,67 \%)$ & $20(13,33 \%)$ & $15(10 \%)$ & $62(41,33 \%)$ \\
\hline REGULAR & $8(5,33 \%)$ & $8(5,33 \%)$ & $8(5,33 \%)$ & $2(1,33 \%)$ & $3(2 \%)$ & $29(19,33 \%)$ \\
\hline PÉSSIMA & $7(4,67 \%)$ & $10(6,67 \%)$ & $5(3,33 \%)$ & $2(1,33 \%)$ & $1(0,67 \%)$ & $25(16,67 \%)$ \\
\hline \multicolumn{7}{|l|}{ CAMA } \\
\hline EXCELENTE & $2(1,33 \%)$ & $0(0 \%)$ & $3(2 \%)$ & $0(0 \%)$ & $0(0 \%)$ & $5(3,33 \%)$ \\
\hline MUITO BOA & $4(2,67 \%)$ & $2(3,33 \%)$ & $6(4 \%)$ & $8(5,33 \%)$ & $12(8 \%)$ & $32(21,33 \%)$ \\
\hline $\mathrm{BOA}$ & $14(9,33 \%)$ & $12(8 \%)$ & $12(8 \%)$ & $19(12,67 \%)$ & $17(11,33 \%)$ & $74(49,33 \%)$ \\
\hline REGULAR & $5(3,33 \%)$ & $8(5,33 \%)$ & $6(4 \%)$ & $1(0,67 \%)$ & $1(0,67 \%)$ & $21(14 \%)$ \\
\hline PÉSSIMA & $5(3,33 \%)$ & $8(5,33 \%)$ & $3(2 \%)$ & $2(1,33 \%)$ & $0(0 \%)$ & $18(12 \%)$ \\
\hline \multicolumn{7}{|l|}{ CORPORAL } \\
\hline EXCELENTE & $1(0,67 \%)$ & $0(0 \%)$ & $2(1,33 \%)$ & $0(0 \%)$ & $1(0,67 \%)$ & $4(2,67 \%)$ \\
\hline MUITO BOA & $2(1,33 \%)$ & $1(0,67 \%)$ & $2(1,33 \%)$ & $9(6 \%)$ & $8(5,33 \%)$ & $22(14,67 \%)$ \\
\hline BOA & $19(12,67 \%)$ & $15(10 \%)$ & $18(12 \%)$ & $17(11,33 \%)$ & $19(12,67 \%)$ & $88(58,67 \%)$ \\
\hline REGULAR & $4(2,67 \%)$ & $6(4 \%)$ & $5(3,33 \%)$ & $3(2 \%)$ & $2(1,33 \%)$ & $20(13,33 \%)$ \\
\hline PÉSSIMA & $4(2,67 \%)$ & $8(5,33 \%)$ & $3(2 \%)$ & $1(0,67 \%)$ & $0(0 \%)$ & $16(10,67 \%)$ \\
\hline \multicolumn{7}{|l|}{ BUCAL } \\
\hline EXCELENTE & $1(0,67 \%)$ & $1(0,67 \%)$ & $2(1,33 \%)$ & $1(0,67 \%)$ & $1(0,67 \%)$ & $6(4 \%)$ \\
\hline MUITO BOA & $10(6,67 \%)$ & $6(4 \%)$ & $11(7,33 \%)$ & $12(8 \%)$ & $22(14,67 \%)$ & $61(40,67 \%)$ \\
\hline BOA & $13(8,67 \%)$ & $15(10 \%)$ & $12(8 \%)$ & $16(10,67 \%)$ & $7(4,66 \%)$ & $63(42 \%)$ \\
\hline REGULAR & $2(1,33 \%)$ & $5(3,33 \%)$ & $3(2 \%)$ & $1(0,67 \%)$ & $0(0 \%)$ & $11(7,33 \%)$ \\
\hline PÉSSIMA & $4(2,66 \%)$ & $3(2 \%)$ & $2(1,33 \%)$ & $0(0 \%)$ & $0(0 \%)$ & $9(6 \%)$ \\
\hline
\end{tabular}

A avaliação da condição de mobilização mostrou que $140(93,3 \%)$ pacientes se movimentavam de forma ativa e $117(78 \%)$ se mobilizavam fora do leito. Com relação à mobilização passiva, 33 (22\%) estavam restritos ao leito e $10(6,7 \%)$ somente se movimentavam com auxílio. Observou-se também que 32 (21,3\%) pacientes utilizavam cadeira de rodas, $20(13,3 \%)$ utilizavam andador, $11(7,3 \%)$ usavam bengalas e somente $5(3,3 \%)$ se movimentavam apoiando-se em móveis ou pessoas (Tabela 5). 
Tabela 5 - Distribuição dos pacientes por NSF segundo a mobilização e presença de sondas, estomias e úlceras

\begin{tabular}{|c|c|c|c|c|c|c|}
\hline VARIÁVEIS & NSF 1 & NSF 2 & NSF 3 & NSF 4 & NSF 5 & n (\%) \\
\hline \multicolumn{7}{|l|}{ MOBILIZAÇÃO } \\
\hline LEITO & $11(7,33 \%)$ & $7(4,67 \%)$ & $7(4,67 \%)$ & $3(2 \%)$ & $5(3,33 \%)$ & $33(22 \%)$ \\
\hline FORA DO LEITO & $19(12,67 \%)$ & $23(15,33 \%)$ & $23(15,33 \%)$ & $27(18 \%)$ & $25(16,67 \%)$ & $117(78 \%)$ \\
\hline PASSIVA & $3(2 \%)$ & $2(1,33 \%)$ & $3(2 \%)$ & $0(0 \%)$ & $2(1,33 \%)$ & $10(6,67 \%)$ \\
\hline ATIVA & $27(18 \%)$ & $28(18,67 \%)$ & $27(18 \%)$ & $30(20 \%)$ & $28(18,67 \%)$ & $140(93,33 \%)$ \\
\hline \multicolumn{7}{|l|}{ EQUIPAMENTO } \\
\hline BENGALA & $3(2 \%)$ & $2(1,33 \%)$ & $3(2 \%)$ & $1(0,67 \%)$ & $2(1,33 \%)$ & $11(7,33 \%)$ \\
\hline MULETA & $0(0 \%)$ & $0(0 \%)$ & $0(0 \%)$ & $0(0 \%)$ & $0(0 \%)$ & $0(0 \%)$ \\
\hline CADEIRAS RODAS & $10(6,67 \%)$ & $7(4,67 \%)$ & $7(4,67 \%)$ & $5(3,33 \%)$ & $3(2 \%)$ & $32(21,33 \%)$ \\
\hline ANDADOR & $5(3,33 \%)$ & $5(3,33 \%)$ & $5(3,33 \%)$ & $3(2 \%)$ & $2(1,33 \%)$ & $20(13,33 \%)$ \\
\hline APOIO PESSOAS & $1(0,67 \%)$ & $0(0 \%)$ & $1(0,67 \%)$ & $1(0,67 \%)$ & $0(0 \%)$ & $3(2 \%)$ \\
\hline APOIO MÓVEIS & $0(0 \%)$ & $0(0 \%)$ & $0(0 \%)$ & $0(0 \%)$ & $2(1,33 \%)$ & $2(1,33 \%)$ \\
\hline SONDAS & $1(0,67 \%)$ & $1(0,67 \%)$ & $2(1,33 \%)$ & $1(0,67 \%)$ & $1(0,67 \%)$ & $6(4 \%)$ \\
\hline ESTOMIAS & $1(0,67 \%)$ & $1(0,67 \%)$ & $1(0,67 \%)$ & $1(0,67 \%)$ & $0(0 \%)$ & $4(2,67 \%)$ \\
\hline TROCA & $2(1,37 \%)$ & $1(0,67 \%)$ & $2(1,37 \%)$ & $1(0,67 \%)$ & $2(1,33 \%)$ & $8(5,33 \%)$ \\
\hline FUNCIONAMENTO ADEQUADO & $2,(1,33 \%)$ & $1(0,67 \%)$ & $2(1,33 \%)$ & $1(0,67 \%)$ & $2(1,33 \%)$ & $8(5,33 \%)$ \\
\hline ÚLCERAS & $3(2 \%)$ & $5(3,33 \%)$ & $2(1,33 \%)$ & $1(0,67 \%)$ & $1(0,67 \%)$ & $12(8 \%)$ \\
\hline CALCÂNEO & $1(0,67 \%)$ & $0(0 \%)$ & $0(0 \%)$ & $0(0 \%)$ & $0(0 \%)$ & $1(0,67 \%)$ \\
\hline FALANGE & $1(0,67 \%)$ & $0(0 \%)$ & $0(0 \%)$ & $0(0 \%)$ & $0(0 \%)$ & $1(0,67 \%)$ \\
\hline INGUINAL & $0(0 \%)$ & $1(0,67 \%)$ & $0(0 \%)$ & $0(0 \%)$ & $0(0 \%)$ & $1(0,67 \%)$ \\
\hline JOELHO & $1(0,67 \%)$ & $0(0 \%)$ & $0(0 \%)$ & $0(0 \%)$ & $0(0 \%)$ & $1(0,67 \%)$ \\
\hline MALÉOLO & $2(1,33 \%)$ & $1(0,67 \%)$ & $0(0 \%)$ & $0(0 \%)$ & $0(0 \%)$ & $3(2 \%)$ \\
\hline PÉ & $0(0 \%)$ & $0(0 \%)$ & $0(0 \%)$ & $1(0,67 \%)$ & $0(0 \%)$ & $1(0,67 \%)$ \\
\hline PANTURRILHA & $1(0,67 \%)$ & $0(0 \%)$ & $0(0 \%)$ & $0(0 \%)$ & $0(0 \%)$ & $1(0,67 \%)$ \\
\hline PERNA & $2(1,33 \%)$ & $1(0,67 \%)$ & $0(0 \%)$ & $0(0 \%)$ & $0(0 \%)$ & $3(2 \%)$ \\
\hline TROCANTER & $0(0 \%)$ & $1(0,67 \%)$ & $0(0 \%)$ & $0(0 \%)$ & $0(0 \%)$ & $1(0,67 \%)$ \\
\hline SACRAL & $0(0 \%)$ & $2(1,33 \%)$ & $2(1,33 \%)$ & $0(0 \%)$ & $1(0,67 \%)$ & $5(3,33 \%)$ \\
\hline TECIDO GRANULAÇÃO & $1(0,67 \%)$ & $4(2,67 \%)$ & $1(0,67 \%)$ & $1(0,67 \%)$ & $0(0 \%)$ & $7(4,67 \%)$ \\
\hline FIBRINA & $0(0 \%)$ & $2(1,33 \%)$ & $0(0 \%)$ & $1(0,67 \%)$ & $0(0 \%)$ & $3(2 \%)$ \\
\hline NECROSE & $1(0,67 \%)$ & $0(0 \%)$ & $0(0 \%)$ & $0(0 \%)$ & $1(0,67 \%)$ & $2(1,33 \%)$ \\
\hline SECREÇÃO PURULENTA & $1(0,67 \%)$ & $1(0,67 \%)$ & $0(0 \%)$ & $0(0 \%)$ & $1(0,67 \%)$ & $3(2 \%)$ \\
\hline TECIDO CICATRIZAÇÃO & $0(0 \%)$ & $1(0,67 \%)$ & $2(1,33 \%)$ & $0(0 \%)$ & $0(0 \%)$ & $3(2 \%)$ \\
\hline TRAUMÁTICA & $0(0 \%)$ & $1(0,67 \%)$ & $0(0 \%)$ & $0(0 \%)$ & $0(0 \%)$ & $1(0,67 \%)$ \\
\hline PARANEOPLÁSICA & $1(0,67 \%)$ & $0(0 \%)$ & $0(0 \%)$ & $0(0 \%)$ & $0(0 \%)$ & $1(0,67 \%)$ \\
\hline PRESSÃO & $1(0,67 \%)$ & $2(1,33 \%)$ & $2(1,33 \%)$ & $1(0,67 \%)$ & $1(0,67 \%)$ & $7(4,67 \%)$ \\
\hline VENOSA & $1(0,67 \%)$ & $2(1,33 \%)$ & $0(0 \%)$ & $0(0 \%)$ & $0(0 \%)$ & $3(2 \%)$ \\
\hline SF $0,9 \%$ & $2(1,33 \%)$ & $2(1,33 \%)$ & $2(1,33 \%)$ & $0(0 \%)$ & $1,(0,67 \%)$ & $7(4,67 \%)$ \\
\hline AGE & $2(1,33 \%)$ & $1(0,67 \%)$ & $2(1,33 \%)$ & $0(0 \%)$ & $1(0,67 \%)$ & $6(4 \%)$ \\
\hline PAPAÍNA & $1(0,67 \%)$ & $1(0,67 \%)$ & $0(0 \%)$ & $0(0 \%)$ & $1(0,67 \%)$ & $3(2 \%)$ \\
\hline BARBATIMÃO & $0(0 \%)$ & $1(0,67 \%)$ & $0(0 \%)$ & $0(0 \%)$ & $0(0 \%)$ & $1(0,67 \%)$ \\
\hline CALÊNDULA & $0(0 \%)$ & $1(0,67 \%)$ & $0(0 \%)$ & $0(0 \%)$ & $1(0,67 \%)$ & $2(1,33 \%)$ \\
\hline HIDROGEL & $0(0 \%)$ & $1(0,67 \%)$ & $0(0 \%)$ & $0(0 \%)$ & $0(0 \%)$ & $1(0,67 \%)$ \\
\hline \multicolumn{7}{|l|}{ ADAPTAÇÃO } \\
\hline CORRIMÃO & $2(1,33 \%)$ & $4(2,67 \%)$ & $4(2,67 \%)$ & $0(0 \%)$ & $1(0,67 \%)$ & $11(7,33 \%)$ \\
\hline TAPETES & $9(6 \%)$ & $7(4,67 \%)$ & $12(8 \%)$ & $18(12 \%)$ & $16(10,67 \%)$ & $62(41,33 \%)$ \\
\hline DEGRAUS & $29(19,33 \%)$ & $25(16,67 \%)$ & $23(15,33 \%)$ & $25(16,67 \%)$ & $30(20 \%)$ & $132(88 \%)$ \\
\hline PISOS & $24(16 \%)$ & $28(18,67 \%)$ & $22(14,67 \%)$ & $21(14 \%)$ & $24(16 \%)$ & $119(79,33 \%)$ \\
\hline ILUMINAÇÃO ADEQUADA & $25(16,67 \%)$ & $28(18,67 \%)$ & $25(16,67 \%)$ & $28(18,67 \%)$ & $23(15,33 \%)$ & $129(86 \%)$ \\
\hline INTERRUPTOR DE FÁCIL DE ACESSO & $27(18 \%)$ & $30(20 \%)$ & $27(18 \%)$ & $28(18,67 \%)$ & $25(16,67 \%)$ & $137(91,33 \%)$ \\
\hline ESPAÇO FLUXO QUARTO & $17(11,33 \%)$ & $23(15,33 \%)$ & $18(12 \%)$ & $22(14,67 \%)$ & $21(14 \%)$ & $101(67,33 \%)$ \\
\hline VENTILAÇÃO ADEQUADA & $22(14,67 \%)$ & $22(14,67 \%)$ & $22(14,67 \%)$ & $17(11,33 \%)$ & $22(14,67 \%)$ & $105(70 \%)$ \\
\hline
\end{tabular}


Também foi avaliada a presença de sondas e estomias, tendo observado que 6 (4\%) pacientes utilizavam algum tipo de sonda e 4 (2,7\%) apresentavam estomias que são características de pacientes com quadros clínicas de nível de complexidade maior (Tabela 5).

Avaliou-se a presença de úlceras, tendo encontrado $12(8 \%)$ pacientes com algum tipo de úlcera, sendo as regiões sacral [5 (3,3\%)] e maleolar [3 (2\%)] as mais acometidas, o que, consequentemente, colocou as úlceras de pressão como prevalentes [7 (4,7\%)]. Os tratamentos tópicos mais utilizados foram, respectivamente, soro fisiológico [7 (4,7\%)] e AGE (ácidos graxos essenciais) $[6(4 \%)]$ (Tabela 5).

Quanto à locomoção dos pacientes, avaliaram-se as possíveis adaptações presentes nos domicílios e observou-se que somente $11(7,3 \%)$ ] casas possuíam corrimão. Com relação às outras variáveis como presença de piso, iluminação adequada, interruptor de fácil acesso, espaço para fluxo no quarto e ventilação adequada foram notados na maioria dos domicílios visitados (Tabela 6). Por outro lado, em 62 (41,3\%) domicílios foi observada a presença de tapetes não antiderrapantes, com maior destaque para o NSF 4 [18 (12\%) e NSF 5 [16 (10,7\%)] e a presença de algum tipo de desnível (degrau) em 132 (88\%) casas (Tabela 5).

Com relação à ingesta alimentar, pôde-se observar que a maioria dos pacientes se alimentavam por via oral, [147 (98\%)] e somente [7 (4,7\%)] faziam uso de algum tipo de suplemento alimentar. Quanto à ingesta hídrica observou-se que 61 (40,7\%) pacientes tomavam em média 1-2 litros de líquido por dia, sendo os pacientes dos NSF 4 [12(8\%)] e NSF 5 [15(10\%)] os que ingeriram menor quantidade de líquidos, apenas 500ml a 1 litro por dia (Tabela 6). 
Tabela 6 - Distribuição dos pacientes por NSF segundo a alimentação, ingesta hídrica, e qualidade dos órgãos do sentido

\begin{tabular}{|c|c|c|c|c|c|c|}
\hline VARIÁVEIS & NSF 1 & NSF 2 & NSF 3 & NSF 4 & NSF 5 & $\mathrm{n}(\%)$ \\
\hline \multicolumn{7}{|l|}{ ALIMENTAÇÃO } \\
\hline VIA ORAL - NÃO & $0(0 \%)$ & $1(0,67 \%)$ & $1(0,67 \%)$ & $0(0 \%)$ & $1(0,67 \%)$ & $3(2 \%)$ \\
\hline VIA ORAL - SIM & $30(20 \%)$ & $29(19,33 \%)$ & $29(19,33 \%)$ & $30(20 \%)$ & $29(19,33 \%)$ & $147(98 \%)$ \\
\hline \multicolumn{7}{|l|}{ LÍQUIDOS } \\
\hline$<500 \mathrm{ML}$ & $3(2 \%)$ & $5(3,33 \%)$ & $6(4 \%)$ & $9(6 \%)$ & $6(4 \%)$ & $29(19,33 \%)$ \\
\hline $500 \mathrm{ML}-1 \mathrm{~L}$ & $9(6 \%)$ & $6(4 \%)$ & $10(6,67 \%)$ & $12(8 \%)$ & $15(10 \%)$ & $52(34,67 \%)$ \\
\hline $1-2 L$ & $17(11,33 \%)$ & $17(11,33 \%)$ & $11(7,33 \%)$ & $8(5,33 \%)$ & $8(5,33 \%)$ & $61(40,67 \%)$ \\
\hline$>2 \mathrm{~L}$ & $1(0,67 \%)$ & $2(1,33 \%)$ & $3(2 \%)$ & $1(0,67 \%)$ & $1(0,67 \%)$ & $8(5,33 \%)$ \\
\hline SUPLEMENTAÇÃO & $1(0,67 \%)$ & $0(0 \%)$ & $5(3,33 \%)$ & $1(0,67 \%)$ & $0(0 \%)$ & $7(4,67 \%)$ \\
\hline PRÓTESE DENTÁRIA & $20(13,33 \%)$ & $18(12 \%)$ & $22(14,67 \%)$ & $17(11,33 \%)$ & $11(7,33 \%)$ & $88(58,67 \%)$ \\
\hline FRALDA & $10(6,67 \%)$ & $8(5,33 \%)$ & $9(6 \%)$ & $5(3,33 \%)$ & $6(4 \%)$ & $38(25,33 \%)$ \\
\hline COLETOR & $0(0 \%)$ & $2(1,33 \%)$ & $3(2 \%)$ & $0(0 \%)$ & $1(0,67 \%)$ & $6(4 \%)$ \\
\hline VACINAÇÃO ATRASADA & $0(0 \%)$ & $2(1,33 \%)$ & $3(2 \%)$ & $0(0 \%)$ & $1(0,67 \%)$ & $6(4 \%)$ \\
\hline ALTERAÇÃO SONO & $3(2 \%)$ & $6(4 \%)$ & $6(4 \%)$ & $1(0,67 \%)$ & $1(0,67 \%)$ & $17(11,33 \%)$ \\
\hline \multicolumn{7}{|l|}{ AUDIÇÃO } \\
\hline PÉSSIMA & $0(0 \%)$ & $0(0 \%)$ & $0(0 \%)$ & $1(0,67 \%)$ & $1(0,67 \%)$ & $2(1,33 \%)$ \\
\hline REGULAR & $5(3,33 \%)$ & $5(3,33 \%)$ & $7(4,67 \%)$ & $4(2,67 \%)$ & $2(1,33 \%)$ & $23(15,33 \%)$ \\
\hline BOA & $16(10,67 \%)$ & $13(8,67 \%)$ & $14(9,33 \%)$ & $20(13,33)$ & $23(15,33 \%)$ & $86(57,33 \%)$ \\
\hline MUITO BOA & $7(4,67 \%)$ & $9(6 \%)$ & $7(4,67 \%)$ & $4(2,67 \%)$ & $4(2,67 \%)$ & $31(20,67 \%)$ \\
\hline EXCELENTE & $2(1,33 \%)$ & $3(2 \%)$ & $2(1,33 \%)$ & $1(0,67 \%)$ & $0(0 \%)$ & $8(5,33 \%)$ \\
\hline \multicolumn{7}{|l|}{ VISÃO } \\
\hline PÉSSIMA & $4(2,67 \%)$ & $0(0 \%)$ & $3(2 \%)$ & $1(0,67 \%)$ & $3(2 \%)$ & $11(7,33 \%)$ \\
\hline REGULAR & $8(5,33 \%)$ & $4(2,67 \%)$ & $9(6 \%)$ & $10(6,67 \%)$ & $7(4,67 \%)$ & $39(25,33 \%)$ \\
\hline $\mathrm{BOA}$ & $16(10,67 \%)$ & $18(12 \%)$ & $14(9,33 \%)$ & $15(10 \%)$ & $15(10 \%)$ & $78(52 \%)$ \\
\hline MUITO BOA & $2(1,33 \%)$ & $6(4 \%)$ & $3(2 \%)$ & $3(2 \%)$ & $5(3,33 \%)$ & $19(12,67 \%)$ \\
\hline EXCELENTE & $0(0 \%)$ & $2(1,33 \%)$ & $1(0,67 \%)$ & $1(0,67 \%)$ & $0(0 \%)$ & $4(2,67 \%)$ \\
\hline
\end{tabular}

Com relação às outras variáveis, encontrou-se uso de prótese em $88(58,7 \%)$ pacientes, uso de fralda em $38(25,3 \%)$ pessoas, uso de coletor e vacinação atrasada em 6 (4\%) e alguma alteração no sono e relação familiar ruim em 17 (11,3\%) pacientes (Tabela 6).

Analisando-se os órgãos do sentido, notou-se que a maioria considerava que sua audição [86 (57,3\%)] e visão [78 (52\%)] eram boas, mas entre os moradores da área do NSF 3 um número significativo de pacientes consideravam sua audição regular $[7(4,7 \%)]$ e na área do NSF 4 um expressivo número considerava regular sua condição para enxergar [10 $(6,7 \%)]$ (Tabela 6).

Identificou-se que $79(52,7 \%)$ pacientes relataram realizar alguma atividade de lazer, sendo que assistir TV [62 (41,3\%)], ler [16 (10,7\%)] e conversar com os amigos [16 (10,7\%)] 
foram as atividades mais destacadas. Notou-se também que 71 (47,3\%) possuíam algum animal de estimação, sendo predomínio de cachorro em 46 (30,7\%) domicílios, gatos em 21 (14\%), aves em $20(13,3 \%)$ e somente $1(0,7 \%)$ possuía tartaruga. O NSF 1 foi o que apresentou maior número de pacientes com algum tipo de animal doméstico [20 (13,3\%)]. A maioria dos entrevistados possuía apenas um animal [33 (22\%)], porém, em 4 (2,7\%) domicílios encontrouse um número incomum de animais por domicílio (mais de 15 animais) e a maioria em locais inadequados (dentro do domicílio) [115(76,7\%)] (Tabela 7).

Tabela 7 - Distribuição dos pacientes por NSF segundo a relação familiar, atividade de lazer e animais domésticos

\begin{tabular}{|c|c|c|c|c|c|c|}
\hline VARIÁVEIS & NSF 1 & NSF 2 & NSF 3 & NSF 4 & NSF 5 & n (\%) \\
\hline RELAÇÃO FAMILIAR RUIM & $4(2,67 \%)$ & $0(0 \%)$ & $5(3,33 \%)$ & $2(1,33 \%)$ & $6(4 \%)$ & $17(11,33 \%)$ \\
\hline ATIVIDADES DE LAZER & $14(9,33 \%)$ & $18(12 \%)$ & $17(11,33 \%)$ & $11(7,33 \%)$ & $19(12,67 \%)$ & $79(52,67 \%)$ \\
\hline ATIVIDADE FÍSICA & $1(0,67 \%)$ & $1(0,67 \%)$ & $1(0,67 \%)$ & $1(0,67 \%)$ & $0(0 \%)$ & $4(2,67 \%)$ \\
\hline ARTESANATO & $1(0,67 \%)$ & $5(3,33 \%)$ & $3(2 \%)$ & $0(0 \%)$ & $1(0,67 \%)$ & $10(6,67 \%)$ \\
\hline BINGO & $1(0,67 \%)$ & $1(0,67 \%)$ & $0(0 \%)$ & $0(0 \%)$ & $0(0 \%)$ & $2(1,33 \%)$ \\
\hline CONVERSA COM AMIGAS & $4(2,67 \%)$ & $3(2 \%)$ & $1(0,67 \%)$ & $1(0,67 \%)$ & $7(4,67 \%)$ & $16(10,67 \%)$ \\
\hline INTERNET & $1(0,67 \%)$ & $2(1,33 \%)$ & $0(0 \%)$ & $0(0 \%)$ & $0(0 \%)$ & $3(2 \%)$ \\
\hline IR AO MERCADO & $1(0,67 \%)$ & $0(0 \%)$ & $1(0,67 \%)$ & $0(0 \%)$ & $0(0 \%)$ & $2(1,33 \%)$ \\
\hline JARDINAGEM & $0(0 \%)$ & $1(0,67 \%)$ & $1(0,67 \%)$ & $0(0 \%)$ & $0(0 \%)$ & $2(1,33 \%)$ \\
\hline ORGANIZAR A CASA & $1(0,67 \%)$ & $1(0,67 \%)$ & $3(2 \%)$ & $0(0 \%)$ & $1(0,67 \%)$ & $6(4 \%)$ \\
\hline LER & $1(0,67 \%)$ & $4(2,67 \%)$ & $5(3,33 \%)$ & $0(0 \%)$ & $1(0,67 \%)$ & $11(7,33 \%)$ \\
\hline RADIO & $0(0 \%)$ & $1(0,67 \%)$ & $0(0 \%)$ & $0(0 \%)$ & $0(0 \%)$ & $1(0,67 \%)$ \\
\hline TV & $13(8,67 \%)$ & $15(10 \%)$ & $14(9,33 \%)$ & $9(6 \%)$ & $11(7,33 \%)$ & $62(41,33 \%)$ \\
\hline \multicolumn{7}{|l|}{ FREQUÊNCIA } \\
\hline SEMANAL & $0(0 \%)$ & $0(0 \%)$ & $1(0,67 \%)$ & $1(0,67 \%)$ & $0(0 \%)$ & $2(1,33 \%)$ \\
\hline DIÁRIA & $14(9,33 \%)$ & $18(12 \%)$ & $16(10,67 \%)$ & $10(6,67 \%)$ & $19(12,67 \%)$ & $77(51,33 \%)$ \\
\hline \multicolumn{7}{|l|}{ DURAÇÃO } \\
\hline $1-2 \mathrm{H}$ & $5(3,33 \%)$ & $7(4,67 \%)$ & $5(3,33 \%)$ & $2(1,33 \%)$ & $2(1,33 \%)$ & $21(14 \%)$ \\
\hline $2 \mathrm{H}$ & $9(6 \%)$ & $11(7,33 \%)$ & $12(8 \%)$ & $9(6 \%)$ & $17(11,33 \%)$ & $58(38,67 \%)$ \\
\hline ANIMAS DOMÉSTICOS & $20(13,33 \%)$ & $11(7,33 \%)$ & $16(10,67 \%)$ & $13(8,67 \%)$ & $11(7,33 \%)$ & $71(47,33 \%)$ \\
\hline CACHORRO & $14(9,33 \%)$ & $8(5,33 \%)$ & $10(6,67 \%)$ & $9(6 \%)$ & $5(3,33 \%)$ & $46(30,67 \%)$ \\
\hline GATO & $3(2 \%)$ & $4(2,67 \%)$ & $7(4,67 \%)$ & $3(2 \%)$ & $4(2,67 \%)$ & $21(14 \%)$ \\
\hline AVE & $6(4 \%)$ & $2(1,33 \%)$ & $3(2 \%)$ & $5(3,33 \%)$ & $4(2,67 \%)$ & $20(13,33 \%)$ \\
\hline TARTARUGA & $0(0 \%)$ & $0(0 \%)$ & $0(0 \%)$ & $0(0 \%)$ & $1(0,67 \%)$ & $1(0,67 \%)$ \\
\hline \multicolumn{7}{|l|}{ QUANTIDADE } \\
\hline UM & $9(6 \%)$ & $4(2,67 \%)$ & $8(5,33 \%)$ & $6(4 \%)$ & $6(4 \%)$ & $33(22 \%)$ \\
\hline DOIS & $7(4,67 \%)$ & $2(1,33 \%)$ & $4(2,67 \%)$ & $2(1,33 \%)$ & $3(2 \%)$ & $18(12 \%)$ \\
\hline TRÊS & $0(0 \%)$ & $4(2,67 \%)$ & $1(0,67 \%)$ & $1(0,67 \%)$ & $2(1,33 \%)$ & $8(5,33 \%)$ \\
\hline QUATRO & $0(0 \%)$ & $0(0 \%)$ & $2(1,33 \%)$ & $0(0 \%)$ & $0(0 \%)$ & $2(1,33 \%)$ \\
\hline CINCO & $1(0,67 \%)$ & $0(0 \%)$ & $0(0 \%)$ & $1(0,67 \%)$ & $0(0 \%)$ & $2(1,33 \%)$ \\
\hline SEIS & $2(1,33 \%)$ & $0(0 \%)$ & $0(0 \%)$ & $0(0 \%)$ & $0(0 \%)$ & $2(1,33 \%)$ \\
\hline SETE & $0(0 \%)$ & $1(0,67 \%)$ & $0(0 \%)$ & $0(0 \%)$ & $0(0 \%)$ & $1(0,67 \%)$ \\
\hline DEZ & $0(0 \%)$ & $0(0 \%)$ & $0(0 \%)$ & $1(0,67 \%)$ & $0(0 \%)$ & $1(0,67 \%)$ \\
\hline$>15$ & $1(0,67 \%)$ & $0(0 \%)$ & $1(0,67 \%)$ & $2(1,33 \%)$ & $0(0 \%)$ & $4(2,67 \%)$ \\
\hline VACINAÇÃO ATRASADA & $0(0 \%)$ & $0(0 \%)$ & $2(1,33 \%)$ & $1(0,67 \%)$ & $1(0,67 \%)$ & $4(2,67 \%)$ \\
\hline LOCAL INADEQUADO & $18(12 \%)$ & $29(19,33 \%)$ & $21(14 \%)$ & $22(14,67 \%)$ & $25(16,67 \%)$ & $115(76,67 \%)$ \\
\hline
\end{tabular}


Quanto aos exames solicitados, notou-se que o colesterol HDL [34 (22,7\%)], o colesterol total [33 (22\%)] e o triglicérides [32 (21,3\%)] foram os mais checados durante as visitas domiciliares seguido da glicemia de jejum [31 (20,7\%)], creatinina [30 (20\%)] e hemograma [30 (20\%)]. Os exames que foram solicitados para uma parcela menor da população foram cálcio, CKMB, desidrogenase láctica, FSH, Lipase, Parasitológico de Fezes, Prolactina, tempo de coagulação, tempo de sangramento, troponina, ultrassom e vitamina D [1 $(0,7 \%)]$ (Tabela 8). 
Tabela 8 - Distribuição dos exames checados durante as VDs por NSF

\begin{tabular}{|c|c|c|c|c|c|c|}
\hline EXAMES & NSF 1 & NSF 2 & NSF 3 & NSF 4 & NSF 5 & n (\%) \\
\hline ALBUMINA & $1(0,67 \%)$ & $0(0 \%)$ & $0(0 \%)$ & $2(1,33 \%)$ & $0(0 \%)$ & $3(2 \%)$ \\
\hline AMILASE & $1(0,67 \%)$ & $1(0,67 \%)$ & $2(1,33 \%)$ & $0(0 \%)$ & $0(0 \%)$ & $4(2,67 \%)$ \\
\hline BILIRRUBINA DIRETA & $2(1,33 \%)$ & $0(0 \%)$ & $2(1,33 \%)$ & $1(0,67 \%)$ & $1(0,67 \%)$ & $6(4 \%)$ \\
\hline BILIRRUBINA TOTAL & $2(1,33 \%)$ & $0(0 \%)$ & $2(1,33 \%)$ & $2(1,33 \%)$ & $1(0,67 \%)$ & $7(4,67 \%)$ \\
\hline CÁLCIO & $0(0 \%)$ & $1(0,67 \%)$ & $0(0 \%)$ & $0(0 \%)$ & $0(0 \%)$ & $1(0,67 \%)$ \\
\hline CPK & $3(2 \%)$ & $3(2 \%)$ & $6(4 \%)$ & $2(1,33 \%)$ & $5(3,33 \%)$ & $19(12,67 \%)$ \\
\hline CKMB & $0(0 \%)$ & $1(0,67 \%)$ & $0(0 \%)$ & $0(0 \%)$ & $0(0 \%)$ & $1(0,67 \%)$ \\
\hline COLESTEROL TOTAL & $9(6 \%)$ & $6(4 \%)$ & $9(6 \%)$ & $3(2 \%)$ & $6(4 \%)$ & $33(22 \%)$ \\
\hline CREATININA & $6(4 \%)$ & $7(4,67 \%)$ & $7(4,67 \%)$ & $5(3,33 \%)$ & $5(3,33 \%)$ & $30(20 \%)$ \\
\hline $\begin{array}{l}\text { DESIDROGENASE } \\
\text { LACTICA }\end{array}$ & $1(, 067 \%)$ & $0(0 \%)$ & $0(0 \%)$ & $0(0 \%)$ & $0(0 \%)$ & $1(0,67 \%)$ \\
\hline ECG & $0(0 \%)$ & $1(0,67 \%)$ & $0(0 \%)$ & $0(0 \%)$ & $1(0,67 \%)$ & $2(1,33 \%)$ \\
\hline $\mathrm{FSH}$ & $0(0 \%)$ & $0(0 \%)$ & $0(0 \%)$ & $0(0 \%)$ & $1(0,67 \%)$ & $1(0,67 \%)$ \\
\hline FERRO & $2(1,33 \%)$ & $0(0 \%)$ & $3(2 \%)$ & $1(0,67 \%)$ & $0(0 \%)$ & $6(4 \%)$ \\
\hline FERRITINA & $2(1,33 \%)$ & $0(0 \%)$ & $1(0,67 \%)$ & $1(0,67 \%)$ & $0(0 \%)$ & $4(2,67 \%)$ \\
\hline FOSFATASE ALCALINA & $0(0 \%)$ & $1(0,67 \%)$ & $1(0,67 \%)$ & $1(0,67 \%)$ & $0(0 \%)$ & $3(2 \%)$ \\
\hline GAMA GT & $1(0,67 \%)$ & $2(1,33 \%)$ & $1(0,67 \%)$ & $2(1,33 \%)$ & $0(0 \%)$ & $6(4 \%)$ \\
\hline GLICEMIA JEJUM & $7(4,67 \%)$ & $4(2,67 \%)$ & $10(6,67 \%)$ & $4(2,67 \%)$ & $6(4 \%)$ & $31(20,67 \%)$ \\
\hline GLICEMIA PÓS PRANDIAL & $3(2 \%)$ & $1(0,67 \%)$ & $3(2 \%)$ & $1(0,67 \%)$ & $0(0 \%)$ & $8(5,33 \%)$ \\
\hline GTT & $1(0,67 \%)$ & $0(0 \%)$ & $0(0 \%)$ & $0(0 \%)$ & $1(0,67 \%)$ & $2(1,33 \%)$ \\
\hline HEMOGLOBINA GLICADA & $4(2,67 \%)$ & $2(1,33 \%)$ & $4(2,67 \%)$ & $3(2 \%)$ & $6(4 \%)$ & $19(12,67 \%)$ \\
\hline $\mathrm{HDL}$ & $9(6 \%)$ & $6(4 \%)$ & $9(6 \%)$ & $4(2,67 \%)$ & $6(4 \%)$ & $34(22,67 \%)$ \\
\hline HEMOGRAMA & $4(2,67 \%)$ & $7(4,67 \%)$ & $12(8 \%)$ & $3(2 \%)$ & $4(2,67 \%)$ & $30(20 \%)$ \\
\hline INR & $1(0,67 \%)$ & $0(0 \%)$ & $0(0 \%)$ & $1(0,67 \%)$ & $0(0 \%)$ & $2(1,33 \%)$ \\
\hline POTÁSSIO & $6(4 \%)$ & $5(3,33 \%)$ & $7(4,67 \%)$ & $4(2,67 \%)$ & $4(2,67 \%)$ & $26(17,33 \%)$ \\
\hline LIPASE & $0(0 \%)$ & $1(0,67 \%)$ & $0(0 \%)$ & $0(0 \%)$ & $0(0 \%)$ & $1(0,67 \%)$ \\
\hline NA (SÓDIO) & $3(2 \%)$ & $5(3,33 \%)$ & $2(1,33 \%)$ & $3(2 \%)$ & $4(2,67 \%)$ & $17(11,33 \%)$ \\
\hline PARASITOLÓGICO FEZES & $0(0 \%)$ & $0(0 \%)$ & $1(0,67 \%)$ & $0(0 \%)$ & $0(0 \%)$ & $1(0,67 \%)$ \\
\hline PROTEINA C REATIVA & $0(0 \%)$ & $1(0,67 \%)$ & $0(0 \%)$ & $1(0,67 \%)$ & $0(0 \%)$ & $2(1,33 \%)$ \\
\hline PROLACTINA & $0(0 \%)$ & $0(0 \%)$ & $0(0 \%)$ & $0(0 \%)$ & $1(0,67 \%)$ & $1(0,67 \%)$ \\
\hline $\begin{array}{l}\text { PESQUISA SANGUE } \\
\text { OCULTO NAS FEZES }\end{array}$ & $1(0,67 \%)$ & $0(0 \%)$ & $2(1,33 \%)$ & $1(0,67 \%)$ & $0(0 \%)$ & $4(2,67 \%)$ \\
\hline PROTEINAS TOTAIS & $1(0,67 \%)$ & $0(0 \%)$ & $0(0 \%)$ & $2(1,33 \%)$ & $0(0 \%)$ & $3(2 \%)$ \\
\hline RAIO $X$ & $0(0 \%)$ & $0(0 \%)$ & $1(0,67 \%)$ & $1(0,67 \%)$ & $0(0 \%)$ & $2(1,33 \%)$ \\
\hline SOROLOGIAS & $0(0 \%)$ & $0(0 \%)$ & $2(1,33 \%)$ & $0(0 \%)$ & $2(1,33 \%)$ & $4(2,67 \%)$ \\
\hline TESTOSTERONA & $0(0 \%)$ & $0(0 \%)$ & $0(0 \%)$ & $0(0 \%)$ & $2(1,33 \%)$ & $2(1,33 \%)$ \\
\hline TIBC & $2(1,33 \%)$ & $0(0 \%)$ & $3(2 \%)$ & $1(0,67 \%)$ & $0(0 \%)$ & $6(4 \%)$ \\
\hline TEMPO COAGULAÇÃO & $1(0,67 \%)$ & $0(0 \%)$ & $0(0 \%)$ & $0(0 \%)$ & $0(0 \%)$ & $1(0,67 \%)$ \\
\hline TEMPO SANGRAMENTO & $1(0,67 \%)$ & $0(0 \%)$ & $0(0 \%)$ & $0(0 \%)$ & $0(0 \%)$ & $1(0,67 \%)$ \\
\hline TRIGLICERIDES & $8(5,33 \%)$ & $6(4 \%)$ & $9(" \%)$ & $4(2,67 \%)$ & $5(3,33 \%)$ & $32(21,33 \%)$ \\
\hline TGO & $5(3,33 \%)$ & $6(4 \%)$ & $7(4,67 \%)$ & $4(2,67 \%)$ & $5(3,33 \%)$ & $27(18 \%)$ \\
\hline TGP & $5(3,33 \%)$ & $6(4 \%)$ & $7(4,67 \%)$ & $4(2,67 \%)$ & $5(3,33 \%)$ & $27(18 \%)$ \\
\hline TROPONINA & $0(0 \%)$ & $1(0,67 \%)$ & $0(0 \%)$ & $0(0 \%)$ & $0(0 \%)$ & $1(0,67 \%)$ \\
\hline TSH & $3(2 \%)$ & $3(2 \%)$ & $7(4,67 \%)$ & $3(2 \%)$ & $5(3,33 \%)$ & $21(14 \%)$ \\
\hline T4 LIVRE & $1(0,67 \%)$ & $0(0 \%)$ & $1(0,67 \%)$ & $0(0 \%)$ & $1(0,67 \%)$ & $3(2 \%)$ \\
\hline ULTRA SOM & $0(0 \%)$ & $0(0 \%)$ & $1(0,67 \%)$ & $0(0 \%)$ & $0(0 \%)$ & $1(0,67 \%)$ \\
\hline UREIA & $4(2,67 \%)$ & $4(2,67 \%)$ & $1(0,67 \%)$ & $4(2,67 \%)$ & $3(2 \%)$ & $16(10,67 \%)$ \\
\hline UROCULTURA & $0(0 \%)$ & $1(0,67 \%)$ & $0(0 \%)$ & $0(0 \%)$ & $10,67 \%)$ & $2(1,33 \%)$ \\
\hline URINA I & $1(0,67 \%)$ & $4(2,67 \%)$ & $7(4,67 \%)$ & $1(0,67 \%)$ & $3(2 \%)$ & $16(10,67 \%)$ \\
\hline VITAMINA B12 & $1(0,67 \%)$ & $2(1,33 \%)$ & $8(5,33 \%)$ & $2(1,33 \%)$ & $0(0 \%)$ & $13(8,67 \%)$ \\
\hline VITAMINA D & $0(0 \%)$ & $1(0,67 \%)$ & $0(0 \%)$ & $0(0 \%)$ & $0(0 \%)$ & $1(0,67 \%)$ \\
\hline
\end{tabular}


Com relação ao seguimento desses pacientes em outras especialidades, observou-se que $35(23,3 \%)$ faziam seguimento na Cardiologia, 17 (11,3\%) na Geriatria e Neurologia, 16 $(10,7 \%)$ na Psiquiatria e Ortopedia, 14 (9,3\%) na Oftalmologia, $11(7,3 \%)]$ na Nefrologia e 10 $(6,7 \%)]$ na Gastroenterologia (Tabela 9 e Gráfico 7). Os diagnósticos principais mais encontrados foram Acidentes Vasculares Cerebrais (CID 10: G 45) [21 (14\%)] e Demência (CID 10: F 02) [16 (10,7\%)] (Tabela 10 e Gráfico 8). Já as classes de medicamentos mais utilizadas foram anti-hipertensivos [93 (62\%)], antiulcerosos [58 (38,7\%)], hipolipimiante [57 (38\%)], antiagregante [55(36,7\%)], antidepressivo [41(27,3\%)], hipoglicemiante [40(26,7\%)], suplemento vitamínico [39(26\%)], ansiolítico [26(17,3\%)], antipsicótico [23 (15,3\%)], anticonvulsivante e analgésico [20 (13,3\%)], antitireoidiano [18 (12\%)] e anticoagulante [12 (8\%)] (Tabela 11 e Gráfico 9).

Tabela 9 - Distribuição dos seguimentos dos pacientes por NSF segundo a especialidade

\begin{tabular}{|c|c|c|c|c|c|c|}
\hline VARIÁVEIS & NSF 1 & NSF 2 & NSF 3 & NSF 4 & NSF 5 & n (\%) \\
\hline \multicolumn{7}{|l|}{ ESPECIALIDADES } \\
\hline CARDIOLOGIA & $9(6 \%)$ & $7(4,67 \%)$ & $7(4,67 \%)$ & $3(2 \%)$ & $9(6 \%)$ & $35(23,33 \%)$ \\
\hline CIRURGIA & $0(0 \%)$ & $1(0,67 \%)$ & $2(1,33 \%)$ & $0(0 \%)$ & $2(1,33 \%)$ & $5(3,33 \%)$ \\
\hline DERMATOLOGIA & $0(0 \%)$ & $3(2 \%)$ & $1(0,67 \%)$ & $0(0 \%)$ & $0(0 \%)$ & $4(2,67 \%)$ \\
\hline ENDOCRINOLOGIA & $1(0,67 \%)$ & $3(2 \%)$ & $0(0 \%)$ & $1(0,67 \%)$ & $3(2 \%)$ & $8(5,33 \%)$ \\
\hline FISIATRIA & $0(0 \%)$ & $1(0,67 \%)$ & $0(0 \%)$ & $0(0 \%)$ & $1(0,67 \%)$ & $2(1,33 \%)$ \\
\hline FISIOTERAPIA & $0(0 \%)$ & $0(0 \%)$ & $2(1,33 \%)$ & $0(0 \%)$ & $0(0 \%)$ & $2(1,33 \%)$ \\
\hline FONOAUDIOLOGIA & $0(0 \%)$ & $0(0 \%)$ & $1(0,67 \%)$ & $0(0 \%)$ & $0(0 \%)$ & $1(0,67 \%)$ \\
\hline GASTROLOGIA & $0(0 \%)$ & $4(2,67 \%)$ & $4(2,67 \%)$ & $2(1,33 \%)$ & $0(0 \%)$ & $10(6,67 \%)$ \\
\hline GERIATRIA & $4(2,67 \%)$ & $3(2 \%)$ & $7(4,67 \%)$ & $1(0,67 \%)$ & $2(1,33 \%)$ & $17(11,33 \%)$ \\
\hline GO & $2(1,33 \%)$ & $1(0,67 \%)$ & $2(1,33 \%)$ & $0(0 \%)$ & $0(0 \%)$ & $5(3,33 \%)$ \\
\hline HEMATOLOGIA & $0(0 \%)$ & $0(0 \%)$ & $2(1,33 \%)$ & $0(0 \%)$ & $1(0,67 \%)$ & $3(2 \%)$ \\
\hline INTEGRADO & $1(0,67 \%)$ & $0(0 \%)$ & $0(0 \%)$ & $0(0 \%)$ & $0(0 \%)$ & $1(0,67 \%)$ \\
\hline NEFROLOGIA & $6(4 \%)$ & $0(0 \%)$ & $1(0,67 \%)$ & $3(2 \%)$ & $1(0,67 \%)$ & $11(7,33 \%)$ \\
\hline MOLÉSTIAS INFECCIOSAS & $0(0 \%)$ & $0(0 \%)$ & $1(0,67 \%)$ & $0(0 \%)$ & $1(0,67 \%)$ & $2(1,33 \%)$ \\
\hline NEUROLOGIA & $2(1,33 \%)$ & $6(4 \%)$ & $4(2,67 \%)$ & $2(1,33 \%)$ & $3(2 \%)$ & $17(11,33 \%)$ \\
\hline NUTROLOGIA & $0(0 \%)$ & $0(0 \%)$ & $0(0 \%)$ & $0(0 \%)$ & $1(0,67 \%)$ & $1(0,67 \%)$ \\
\hline OFTALMOLOGIA & $2(1,33 \%)$ & $2(1,33 \%)$ & $6(4 \%)$ & $0(0 \%)$ & $4(2,67 \%)$ & $14(9,33 \%)$ \\
\hline ONCOLOGIA & $4(2,67 \%)$ & $2(1,33 \%)$ & $1(0,67 \%)$ & $1(0,67 \%)$ & $1(0,67 \%)$ & $9(6 \%)$ \\
\hline ORTOPEDIA & $4(2,67 \%)$ & $1(0,67 \%)$ & $4(2,67 \%)$ & $4(2,67 \%)$ & $3(2 \%)$ & $16(10,67 \%)$ \\
\hline PNEUMOLOGIA & $2(1,33 \%)$ & $1(0,67 \%)$ & $3(2 \%)$ & $0(0 \%)$ & $4(2,67 \%)$ & $10(6,67 \%)$ \\
\hline PSIQUIATRIA & $4(2,67 \%)$ & $1(0,67 \%)$ & $2(1,33 \%)$ & $1(0,67 \%)$ & $8(5,33 \%)$ & $16(10,67 \%)$ \\
\hline PSICOLOGIA & $0(0 \%)$ & $0(0 \%)$ & $0(0 \%)$ & $1(0,67 \%)$ & $0(0 \%)$ & $1(0,67 \%)$ \\
\hline RADIOLOGIA & $0(0 \%)$ & $1(0,67 \%)$ & $0(0 \%)$ & $0(0 \%)$ & $0(0 \%)$ & $1(0,67 \%)$ \\
\hline REUMATOLOGIA & $0(0 \%)$ & $2(1,33 \%)$ & $0(0 \%)$ & $0(0 \%)$ & $1(0,67 \%)$ & $3(2 \%)$ \\
\hline SAD & $2(1,33 \%)$ & $1(0,67 \%)$ & $0(0 \%)$ & $0(0 \%)$ & $0(0 \%)$ & $3(2 \%)$ \\
\hline UROLOGIA & $2(1,33 \%)$ & $1(0,67 \%)$ & $1(0,67 \%)$ & $4(2,67 \%)$ & $1(0,67 \%)$ & $9(6 \%)$ \\
\hline VASCULAR & $3(2 \%)$ & $1(0,67 \%)$ & $1(0,67 \%)$ & $0(0 \%)$ & $3(2 \%)$ & $8(5,33 \%)$ \\
\hline CER/CIR & $1(0,67 \%)$ & $2(1,33 \%)$ & $1(0,67 \%)$ & $0(0 \%)$ & $0(0 \%)$ & $4(2,67 \%)$ \\
\hline
\end{tabular}




\section{TOTAL}

35

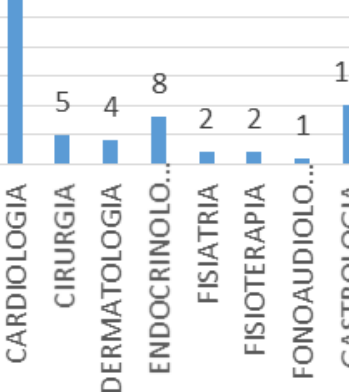

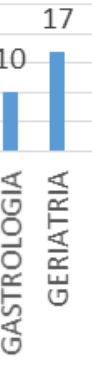

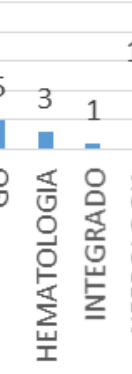
11

$17 \quad 14 \quad 16 \quad 16$

\begin{tabular}{l|c|c|ccccccc}
9 & 10 & & & & & & 9 & 8 & 4 \\
\hline & & 1 & 1 & 3 & 3 & & & 4 \\
\hline
\end{tabular}

n (\%)

Gráfico 7 - Distribuição dos seguimentos dos pacientes nas especialidades

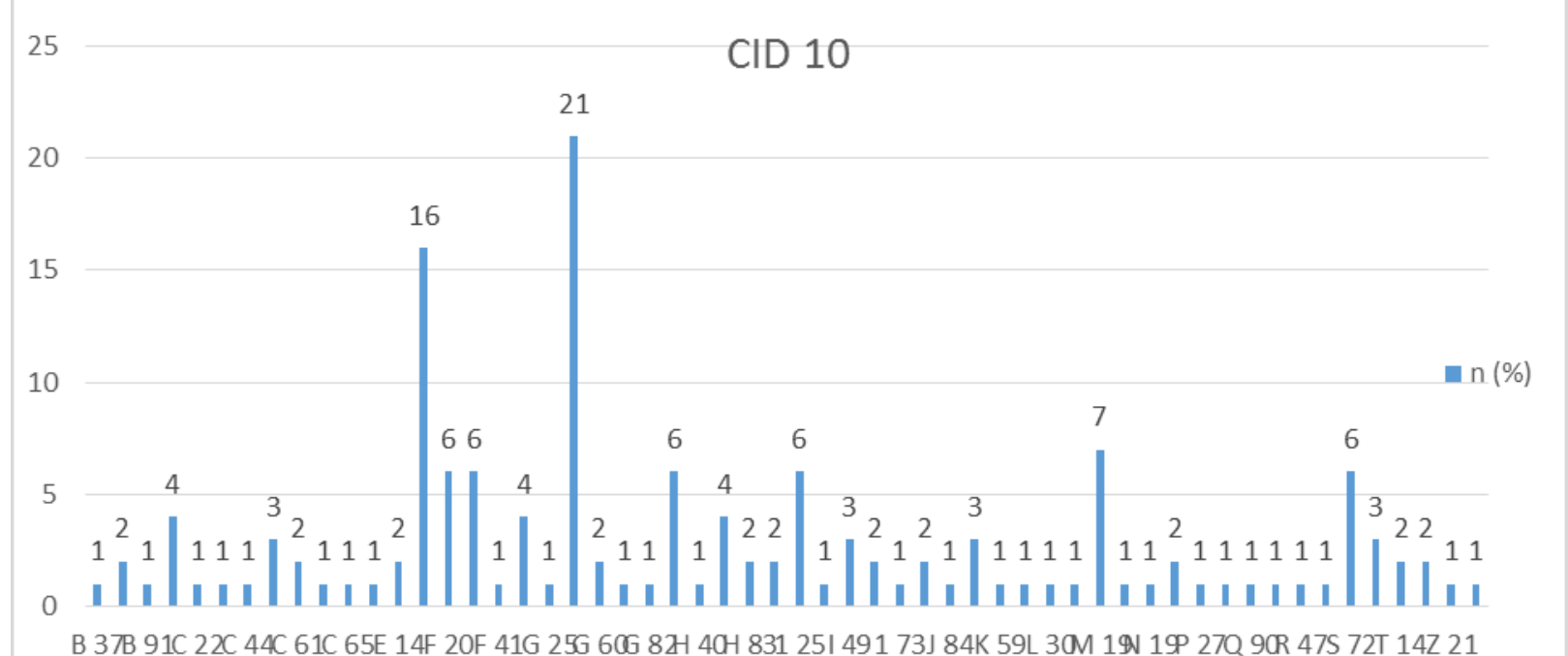

Gráfico 8 - Distribuição dos diagnósticos por CID 10 
Tabela 10 - Distribuição por NSF segundo diagnósticos principais (CID 10)

\begin{tabular}{|c|c|c|c|c|c|c|c|}
\hline \multicolumn{2}{|r|}{$\begin{array}{c}\text { DIAGNÓSTICO } \\
\text { PRINCIPAL (CID 10) }\end{array}$} & NSF 1 & NSF 2 & NSF 3 & NSF 4 & NSF 5 & n (\%) \\
\hline & B 37 & $0(0 \%)$ & $0(0 \%)$ & $0(0 \%)$ & $1(0,67 \%)$ & $0(0 \%)$ & $1(0,67 \%)$ \\
\hline & В 57 & $1(0,67 \%)$ & $0(0 \%)$ & $0(0 \%)$ & $0(0 \%)$ & $1(0,67 \%)$ & $2(1,33 \%)$ \\
\hline & В 91 & $0(0 \%)$ & $0(0 \%)$ & $0(0 \%)$ & $0(0 \%)$ & $1(0,67 \%)$ & $1(0,67 \%)$ \\
\hline & C 18 & $1(0,67 \%)$ & $1(0,67 \%)$ & $0(0 \%)$ & $291,33 \%$ ) & $0(0 \%)$ & $4(2,67 \%)$ \\
\hline & C 22 & $1(0,67 \%)$ & $0(0 \%)$ & $0(0 \%)$ & $0(0 \%)$ & $0(0 \%)$ & $1(0,67 \%)$ \\
\hline & C 34 & $0(0 \%)$ & $1(0,67 \%)$ & $0(0 \%)$ & $0(0 \%)$ & $0(0 \%)$ & $1(0,67 \%)$ \\
\hline & C 44 & $0(0 \%)$ & $1(0,67 \%)$ & $0(0 \%)$ & $0(0 \%)$ & $0(0 \%)$ & $1(0,67 \%)$ \\
\hline & C 50 & $1(0,67 \%)$ & $1(0,67 \%)$ & $1(0,67 \%)$ & $0(0 \%)$ & $0(0 \%)$ & $3(2 \%)$ \\
\hline & C 61 & $1(0,67 \%)$ & $1(0,67 \%)$ & $0(0 \%)$ & $0(0 \%)$ & $0(0 \%)$ & $2(1,33 \%)$ \\
\hline & C 64 & $1(0,67 \%)$ & $0(0 \%)$ & $0(0 \%)$ & $0(0 \%)$ & $0(0 \%)$ & $1(0,67 \%)$ \\
\hline & C 65 & $0(0 \%)$ & $0(0 \%)$ & $1(0,67 \%)$ & $0(0 \%)$ & $0(0 \%)$ & $1(0,67 \%)$ \\
\hline & E 07 & $0(0 \%)$ & $0(0 \%)$ & $0(0 \%)$ & $1(0,67 \%)$ & $0(0 \%)$ & $1(0,67 \%)$ \\
\hline & E 14 & $0(0 \%)$ & $0(0 \%)$ & $2(1,33 \%)$ & $0(0 \%)$ & $0(0 \%)$ & $2(1,33 \%)$ \\
\hline & F 02 & $4(2,67 \%)$ & $3(2 \%)$ & $6(4 \%)$ & $2(1,33 \%)$ & $1(0,67 \%)$ & $16(10,67 \%)$ \\
\hline & F 20 & $0(0 \%)$ & $0(0 \%)$ & $0(0 \%)$ & $0(0 \%)$ & $6(4 \%)$ & $6(4 \%)$ \\
\hline & F 32 & $2(1,33 \%)$ & $1(0,67 \%)$ & $2(1,33 \%)$ & $1(0,67 \%)$ & $0(0 \%)$ & $6(4 \%)$ \\
\hline & F 41 & $0(0 \%)$ & $0(0 \%)$ & $0(0 \%)$ & $0(0 \%)$ & $1(0,67 \%)$ & $1(0,67 \%)$ \\
\hline & F 72 & $0(0 \%)$ & $1(0,67 \%)$ & $0(0 \%)$ & $1(0,67 \%)$ & $2(1,33 \%)$ & $4(2,67 \%)$ \\
\hline & G 25 & $0(0 \%)$ & $0(0 \%)$ & $0(0 \%)$ & $1(0,67 \%)$ & $0(0 \%)$ & $1(0,67 \%)$ \\
\hline & G 45 & $4(2,67 \%)$ & $5(3,33 \%)$ & $4(2,67 \%)$ & $5(3,33 \%)$ & $3(2 \%)$ & $21(14 \%)$ \\
\hline & G 60 & $0(0 \%)$ & $1(0,67 \%)$ & $0(0 \%)$ & $1(0,67 \%)$ & $0(0 \%)$ & $2(1,33 \%)$ \\
\hline & G 80 & $0(0 \%)$ & $1(0,67 \%)$ & $0(0 \%)$ & $0(0 \%)$ & $0(0 \%)$ & $1(0,67 \%)$ \\
\hline & G 82 & $1(0,67 \%)$ & $0(0 \%)$ & $0(0 \%)$ & $0(0 \%)$ & $0(0 \%)$ & $1(0,67 \%)$ \\
\hline & H 28 & $0(0 \%)$ & $2(1,33 \%)$ & $1(0,67 \%)$ & $3(2 \%)$ & $0(0 \%)$ & $6(4 \%)$ \\
\hline & $\mathrm{H} 40$ & $0(0 \%)$ & $0(0 \%)$ & $1(0,67 \%)$ & $0(0 \%)$ & $0(0 \%)$ & $1(0,67 \%)$ \\
\hline & H 54 & $1(0,67 \%)$ & $0(0 \%)$ & $3(2 \%)$ & $0(0 \%)$ & $0(0 \%)$ & $4(2,67 \%)$ \\
\hline & H 83 & $0(0 \%)$ & $0(0 \%)$ & $0(0 \%)$ & $0(0 \%)$ & $2(1,33 \%)$ & $2(1,33 \%)$ \\
\hline & I 10 & $0(0 \%)$ & $1(0,67 \%)$ & $1(0,67 \%)$ & $0(0 \%)$ & $0(0 \%)$ & $2(1,33 \%)$ \\
\hline$\nabla$ & 125 & $2(1,33 \%)$ & $1(0,67 \%)$ & $0(0 \%)$ & $1(0,67 \%)$ & $2(1,33 \%)$ & $6(4 \%)$ \\
\hline & I 48 & $0(0 \%)$ & $1(0,67 \%)$ & $0(0 \%)$ & $0(0 \%)$ & $0(0 \%)$ & $1(0,67 \%)$ \\
\hline & I 49 & $2(1,33 \%)$ & $0(0 \%)$ & $0(0 \%)$ & $1(0,67 \%)$ & $0(0 \%)$ & $3(2 \%)$ \\
\hline & 150 & $0(0 \%)$ & $1(0,67 \%)$ & $1(0,67 \%)$ & $0(0 \%)$ & $0(0 \%)$ & $2(1,33 \%)$ \\
\hline$F$ & 173 & $0(0 \%)$ & $0(0 \%)$ & $0(0 \%)$ & $0(0 \%)$ & $1(0,67 \%)$ & $1(0,67 \%)$ \\
\hline & J 44 & $1(0,67 \%)$ & $1(0,67 \%)$ & $0(0 \%)$ & $0(0 \%)$ & $0(0 \%)$ & $2(1,33 \%)$ \\
\hline & J 84 & $0(0 \%)$ & $0(0 \%)$ & $1(0,67 \%)$ & $0(0 \%)$ & $0(0 \%)$ & $1(0,67 \%)$ \\
\hline & K 30 & $1(0,67 \%)$ & $1(0,67 \%)$ & $0(0 \%)$ & $0(0 \%)$ & $1(0,67 \%)$ & $3(2 \%)$ \\
\hline & K 59 & $0(0 \%)$ & $0(0 \%)$ & $0(0 \%)$ & $0(0 \%)$ & $1(0,67 \%)$ & $1(0,67 \%)$ \\
\hline & K 72 & $0(0 \%)$ & $1(0,67 \%)$ & $0(0 \%)$ & $0(0 \%)$ & $0(0 \%)$ & $1(0,67 \%)$ \\
\hline & L 30 & $0(0 \%)$ & $0(0 \%)$ & $0(0 \%)$ & $1(0,67 \%)$ & $0(0 \%)$ & $1(0,67 \%)$ \\
\hline & M 06 & $0(0 \%)$ & $0(0 \%)$ & $0(0 \%)$ & $0(0 \%)$ & $1(0,67 \%)$ & $1(0,67 \%)$ \\
\hline & M 19 & $1(0,67 \%)$ & $1(0,67 \%)$ & $1(0,67 \%)$ & $1(0,67 \%)$ & $3(2 \%)$ & $7(4,67 \%)$ \\
\hline & M 81 & $1(0,67 \%)$ & $0(0 \%)$ & $0(0 \%)$ & $0(0 \%)$ & $0(0 \%)$ & $1(0,67 \%)$ \\
\hline & N 19 & $0(0 \%)$ & $0(0 \%)$ & $0(0 \%)$ & $1(0,67 \%)$ & $0(0 \%)$ & $1(0,67 \%)$ \\
\hline & O 90 & $1(0,67 \%)$ & $0(0 \%)$ & $0(0 \%)$ & $1(0,67 \%)$ & $0(0 \%)$ & $2(1,33 \%)$ \\
\hline & P 27 & $0(0 \%)$ & $0(0 \%)$ & $1(0,67 \%)$ & $0(0 \%)$ & $0(0 \%)$ & $1(0,67 \%)$ \\
\hline & P 91 & $0(0 \%)$ & $0(0 \%)$ & $0(0 \%)$ & $1(0,67 \%)$ & $0(0 \%)$ & $1(0,67 \%)$ \\
\hline & Q 90 & $0(0 \%)$ & $0(0 \%)$ & $1(0,67 \%)$ & $0(0 \%)$ & $0(0 \%)$ & $1(0,67 \%)$ \\
\hline & R 26 & $0(0 \%)$ & $0(0 \%)$ & $0(0 \%)$ & $1(0,67 \%)$ & $0(0 \%)$ & $1(0,67 \%)$ \\
\hline & $\mathrm{R} 47$ & $0(0 \%)$ & $1(0,67 \%)$ & $0(0 \%)$ & $0(0 \%)$ & $0(0 \%)$ & $1(0,67 \%)$ \\
\hline & S 42 & $0(0 \%)$ & $0(0 \%)$ & $1(0,67 \%)$ & $0(0 \%)$ & $0(0 \%)$ & $1(0,67 \%)$ \\
\hline & S 72 & $1(0,67 \%)$ & $1(0,67 \%)$ & $1(0,67 \%)$ & $0(0 \%)$ & $3(2 \%)$ & $6(4 \%)$ \\
\hline & S 88 & $0(0 \%)$ & $1(0,67 \%)$ & $0(0 \%)$ & $1(0,67 \%)$ & $1(0,67 \%)$ & $3(2 \%)$ \\
\hline & T 14 & $0(0 \%)$ & $0(0 \%)$ & $0(0 \%)$ & $2(1,33 \%)$ & $0(0 \%)$ & $2(1,33 \%)$ \\
\hline & T 90 & $1(0,67 \%)$ & $0(0 \%)$ & $0(0 \%)$ & $1(0,67 \%)$ & $0(0 \%)$ & $2(1,33 \%)$ \\
\hline & Z 21 & $0(0 \%)$ & $0(0 \%)$ & $1(0,67 \%)$ & $0(0 \%)$ & $0(0 \%)$ & $1(0,67 \%)$ \\
\hline & Z 94 & $1(0,67 \%)$ & $0(0 \%)$ & $0(0 \%)$ & $0(0 \%)$ & $0(0 \%)$ & $1(0,67 \%)$ \\
\hline
\end{tabular}


Tabela 11 - Distribuição das classes de medicamentos utilizados pelos pacientes por NSF

\begin{tabular}{|c|c|c|c|c|c|c|}
\hline MEDICAMENTOS & NSF 1 & NSF 2 & NSF 3 & NSF 4 & NSF 5 & $\mathrm{n}(\%)$ \\
\hline AINES & $0(0 \%)$ & $1(0,67 \%)$ & $0(0 \%)$ & $0(0 \%)$ & $0(0 \%)$ & $1(0,67 \%)$ \\
\hline ANALGÉSICO & $4(2,67 \%)$ & $7(4,67 \%)$ & $3(2 \%)$ & $3(2 \%)$ & $3(2 \%)$ & $20(13,33 \%)$ \\
\hline ANSIOLÍTICO & $6(4 \%)$ & $7(4,67 \%)$ & $5(3,33 \%)$ & $3(2 \%)$ & $5(3,33 \%)$ & $26(17,33 \%)$ \\
\hline ANTIÁCIDO & $0(0 \%)$ & $1(0,67 \%)$ & $0(0 \%)$ & $0(0 \%)$ & $0(0 \%)$ & $1(0,67 \%)$ \\
\hline ANTIAGREGANTE & $9(6 \%)$ & $10(6,67 \%)$ & $14(9,33 \%)$ & $9(6 \%)$ & $13(8,67 \%)$ & $55(36,67 \%)$ \\
\hline ANTIANGINOSO & $0(0 \%)$ & $2(1,33 \%)$ & $1(0,67 \%)$ & $1(0,67 \%)$ & $3(2 \%)$ & $7(4,67 \%)$ \\
\hline ANTIARRITIMICO & $0(0 \%)$ & $1(0,67 \%)$ & $2(1,33 \%)$ & $1(0,67 \%)$ & $2(1,33 \%)$ & $6(4 \%)$ \\
\hline ANTIBIÓTICO & $0(0 \%)$ & $2(1,33 \%)$ & $1(0,67 \%)$ & $0(0 \%)$ & $0(0 \%)$ & $3(2 \%)$ \\
\hline ANTICOAGULANTE & $2(1,33 \%)$ & $4(2,67 \%)$ & $1(0,67 \%)$ & $1(0,67 \%)$ & $4(2,67 \%)$ & $12(8 \%)$ \\
\hline ANTICOLINESTERASE & $1(0,67 \%)$ & $2(1,33 \%)$ & $3(2 \%)$ & $0(0 \%)$ & $1(0,67 \%)$ & $7(4,67 \%)$ \\
\hline ANTICONVULSIVANTE & $3(2 \%)$ & $7(4,67 \%)$ & $3(2 \%)$ & $0(0 \%)$ & $7(4,67 \%)$ & $20(13,33 \%)$ \\
\hline ANTIDEPRESSIVO & $10(6,67 \%)$ & $6(4 \%)$ & $14(9,33 \%)$ & $4(2,67 \%)$ & $7(4,67 \%)$ & $41(27,33 \%)$ \\
\hline ANTIEMÉTICO & $2(1,33 \%)$ & $3(2 \%)$ & $1(0,67 \%)$ & $0(0 \%)$ & $1(0,67 \%)$ & $7(4,67 \%)$ \\
\hline ANTIESPASMÓDICO & $1(0,67 \%)$ & $0(0 \%)$ & $0(0 \%)$ & $0(0 \%)$ & $0(0 \%)$ & $1(0,67 \%)$ \\
\hline ANTIFÚNGICO & $0(0 \%)$ & $1(0,67 \%)$ & $0(0 \%)$ & $0(0 \%)$ & $1(0,67 \%)$ & $2(1,33 \%)$ \\
\hline ANTIGOTOSO & $1(0,67 \%)$ & $1(0,67 \%)$ & $0(0 \%)$ & $3(2 \%)$ & $1(0,67 \%)$ & $6(4 \%)$ \\
\hline ANTIHIPERTENSIVO & $17(11,33 \%)$ & $19(12,67 \%)$ & $18(12 \%)$ & $17(11,33 \%)$ & $22(14,67 \%)$ & $93(62 \%)$ \\
\hline ANTIHISTAMÍNICO & $1(0,67 \%)$ & $1(0,67 \%)$ & $0(0 \%)$ & $0(0 \%)$ & $6(4 \%)$ & $8(5,33 \%)$ \\
\hline ANTIMETABÓLICO & $0(0 \%)$ & $1(0,67 \%)$ & $0(0 \%)$ & $0(0 \%)$ & $0(0 \%)$ & $1(0,67 \%)$ \\
\hline ANTIPARKINSONIANO & $0(0 \%)$ & $0(0 \%)$ & $0(0 \%)$ & $0(0 \%)$ & $3(2 \%)$ & $3(2 \%)$ \\
\hline ANTIPROSTÁTICO & $2(1,33 \%)$ & $0(0 \%)$ & $1(0,67 \%)$ & $1(0,67 \%)$ & $1(0,67 \%)$ & $5(3,33 \%)$ \\
\hline ANTIPSICÓTICO & $1(0,67 \%)$ & $4(2,67 \%)$ & $6(4 \%)$ & $3(2 \%)$ & $9(6 \%)$ & $23(15,33 \%)$ \\
\hline ANTIRETROVIRAL & $0(0 \%)$ & $0(0 \%)$ & $1(0,67 \%)$ & $0(0 \%)$ & $0(0 \%)$ & $1(0,67 \%)$ \\
\hline ANTIREUMÁTICO & $0(0 \%)$ & $1(0,67 \%)$ & $1(0,67 \%)$ & $0(0 \%)$ & $0(0 \%)$ & $2(1,33 \%)$ \\
\hline ANTITIREOIDIANO & $3(2 \%)$ & $3(2 \%)$ & $5(3,33 \%)$ & $0(0 \%)$ & $7(4,67 \%)$ & $18(12 \%)$ \\
\hline ANTIULCEROSO & $8(5,33 \%)$ & $15(10 \%)$ & $14(9,33 \%)$ & $7(4,67 \%)$ & $14(9,33 \%)$ & $58(38,67 \%)$ \\
\hline ANTIVARICOSO & $2(1,33 \%)$ & $1(0,67 \%)$ & $0(0 \%)$ & $0(0 \%)$ & $1(0,67 \%)$ & $4(2,67 \%)$ \\
\hline ANTIVERTIGINOSO & $1(0,67 \%)$ & $0(0 \%)$ & $0(0 \%)$ & $0(0 \%)$ & $1(0,67 \%)$ & $2(1,33 \%)$ \\
\hline BIFOSFONATO & $1(0,67 \%)$ & $2(1,33 \%)$ & $1(0,67 \%)$ & $0(0 \%)$ & $4(2,67 \%)$ & $8(5,33 \%)$ \\
\hline BRONCODILATADOR & $2(1,33 \%)$ & $1(0,67 \%)$ & $4(2,67 \%)$ & $0(0 \%)$ & $3(2 \%)$ & $10(6,67 \%)$ \\
\hline CORTICÓIDE & $1(0,67 \%)$ & $2(1,33 \%)$ & $2(1,33 \%)$ & $0(0 \%)$ & $3(2 \%)$ & $8(5,33 \%)$ \\
\hline HIPOGLICEMIANTE & $7(4,67 \%)$ & $5(3,33 \%)$ & $8(5,33 \%)$ & $8(5,33 \%)$ & $12(8 \%)$ & $40(26,67 \%)$ \\
\hline HIPOLIPIMIANTE & $10(6,67 \%)$ & $14(9,33 \%)$ & $14(9,33 \%)$ & $6(4 \%)$ & $13(8,67 \%)$ & $57(38 \%)$ \\
\hline HORMÔNIO & $1(0,67 \%)$ & $1(0,67 \%)$ & $0(0 \%)$ & $3(2 \%)$ & $1(0,67 \%)$ & $6(4 \%)$ \\
\hline IMUNOSSUPRESSOR & $1(0,67 \%)$ & $0(0 \%)$ & $0(0 \%)$ & $0(0 \%)$ & $0(0 \%)$ & $1(0,67 \%)$ \\
\hline LAXANTE & $0(0 \%)$ & $1(0,67 \%)$ & $1(0,67 \%)$ & $0(0 \%)$ & $2(1,33 \%)$ & $4(2,67 \%)$ \\
\hline RELAXANTE MUSCULAR & $1(0,67 \%)$ & $2(1,33 \%)$ & $0(0 \%)$ & $0(0 \%)$ & $0(0 \%)$ & $3(2 \%)$ \\
\hline REPOSITOR HIDROELETROLÍTICO & $0(0 \%)$ & $1(0,67 \%)$ & $0(0 \%)$ & $0(0 \%)$ & $0(0 \%)$ & $1(0,67 \%)$ \\
\hline SUPLEMENTO & $4(6 \%)$ & $8(5,33 \%)$ & $9(6 \%)$ & $4(2,67 \%)$ & $12(8 \%)$ & $37(24,66 \%)$ \\
\hline VASODILATADOR & $1(0,67 \%)$ & $0(0 \%)$ & $0(0 \%)$ & $0(0 \%)$ & $0(0 \%)$ & $1(0.67 \%)$ \\
\hline
\end{tabular}




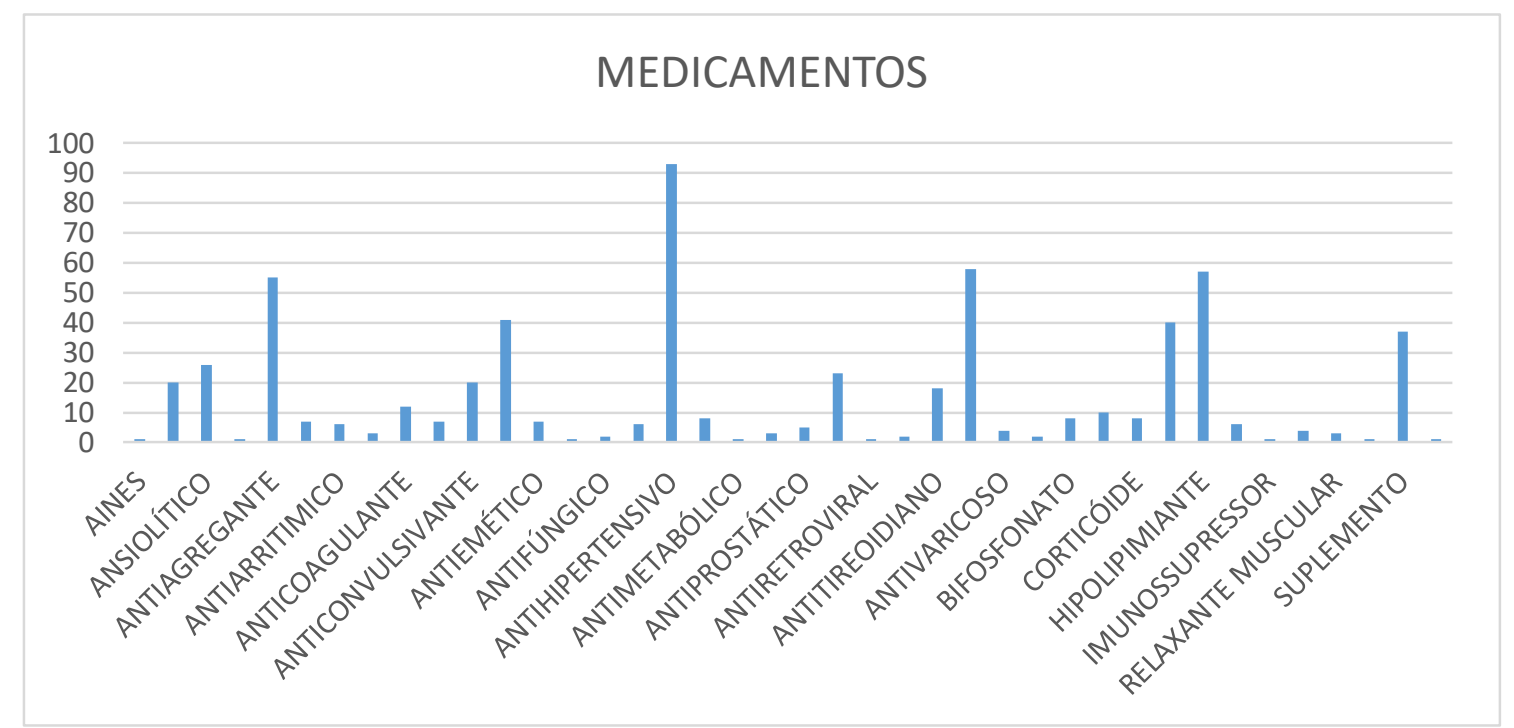

Gráfico 9 - Distribuição das classes de medicamentos

Observando o território - dividido por microáreas, unidades operacionais dos agentes comunitários de saúde -, formado por conjuntos de famílias que são delimitados com uma lógica da homogeneidade socioeconômica-sanitária, notou-se que a microárea 3 foi a que mais recebeu $\operatorname{VD}[39(26 \%)]$ e a microárea 6 foi a menos visitada [4(2,7\%)], provavelmente porque somente dois núcleos possuíam seis microáreas (Tabela 12 e Gráfico 10).

Tabela 12 - Distribuição das características da Atenção Domiciliar por NSF

\begin{tabular}{|c|c|c|c|c|c|c|c|}
\hline \multicolumn{2}{|c|}{ VARIÁVEIS } & NÚCLEO 1 & NÚCLEO 2 & NÚCLEO 3 & NÚCLEO 4 & NÚCLEO 5 & TOTAL \\
\hline \multirow{7}{*}{ Microárea } & 1 & $11(7,33 \%)$ & $2(1,33 \%)$ & $6(4 \%)$ & $6(4 \%)$ & $5(3,33 \%)$ & $30(20 \%)$ \\
\hline & 2 & $4(2,67 \%)$ & $9(6 \%)$ & $7(4,67 \%)$ & $8(5,33 \%)$ & $8(5,33 \%)$ & $36(24 \%)$ \\
\hline & 3 & $6(4 \%)$ & $8(5,33 \%)$ & $6(4 \%)$ & $7(4,67 \%)$ & 12 (8\%) & $39(26 \%)$ \\
\hline & 4 & $6(4 \%)$ & $3(2 \%)$ & $4(2,67 \%)$ & $6(4 \%)$ & $2(1,33 \%)$ & $21(14 \%)$ \\
\hline & 5 & $3(2 \%)$ & $8(5,33 \%)$ & $6(4 \%)$ & $3(2 \%)$ & $0(0 \%)$ & $20(13,33 \%)$ \\
\hline & 6 & $0(0 \%)$ & $0(0 \%)$ & $1(0,67 \%)$ & $0(0 \%)$ & $3(2 \%)$ & $4(67 \%)$ \\
\hline & AD1 & $26(17,33 \%)$ & $26(17,33 \%)$ & $23(15,33 \%)$ & $26(17,33 \%)$ & $27(18 \%)$ & $128(85,33 \%)$ \\
\hline \multirow[t]{2}{*}{ Modalidade $p=0,7909$} & AD2 & $3(2 \%)$ & $3(2 \%)$ & $3(2 \%)$ & $3(2 \%)$ & $1(0,67 \%)$ & $13(8,67 \%)$ \\
\hline & AD3 & $1(0,67 \%)$ & $1(0,67 \%)$ & $4(2,67 \%)$ & $1(0,67 \%)$ & $2(1,33 \%)$ & $9(6 \%)$ \\
\hline \multirow{2}{*}{ Solicitação } & Caso Novo & $19(12,67 \%)$ & $11(7,33 \%)$ & $20(13,33 \%)$ & $18(12 \%)$ & $14(9,33 \%)$ & $82(54,67 \%)$ \\
\hline & Seguimento & $11(7,33 \%)$ & $19(12,67 \%)$ & $10(6,67 \%)$ & $12(8 \%)$ & $16(10,67 \%)$ & $68(45,33 \%)$ \\
\hline \multirow{3}{*}{ Conduta } & VD Agendada & $27(18 \%)$ & $27(18 \%)$ & $27(18 \%)$ & $27(18 \%)$ & $29(19,33 \%)$ & $137(91,33 \%)$ \\
\hline & VD Eventual & $3(2 \%)$ & $3(2 \%)$ & $3(2 \%)$ & $3(2 \%)$ & $1(0,67 \%)$ & $13(8,67 \%)$ \\
\hline & Atendimento Domiciliar & $17(11,33 \%)$ & $6(4 \%)$ & $16(10,67 \%)$ & $11(7,33 \%)$ & $5(3,33 \%)$ & $55(36,67 \%)$ \\
\hline \multirow[t]{3}{*}{ Tipo de Atendimento } & Acompanhamento Domiciliar & $10(6,67 \%)$ & $19(12,67 \%)$ & $10(6,67 \%)$ & $10(6,67 \%)$ & $16(10,67 \%)$ & $65(43,33 \%)$ \\
\hline & Busca Ativa & $3(2 \%)$ & $5(3,33 \%)$ & $4(2,67 \%)$ & $9(6 \%)$ & $9(6 \%)$ & $30(20 \%)$ \\
\hline & AD Encerrada/Acomp Unidade & $10(6,67 \%)$ & $11(7,33 \%)$ & $13(8,67 \%)$ & $16(10,67 \%)$ & $15(10 \%)$ & $65(43,33 \%)$ \\
\hline \multirow[t]{2}{*}{ Conclusão } & Acompanhamento Domiciliar & $20(13,33 \%)$ & $19(12,67 \%)$ & $17(11,33 \%)$ & $14(9,33 \%)$ & $13(8,67 \%)$ & $83(55,33 \%)$ \\
\hline & Óbito & $0(0 \%)$ & $0(0 \%)$ & $0(0 \%)$ & $0(0 \%)$ & $2(1,33 \%)$ & $2(1,33 \%)$ \\
\hline
\end{tabular}




\section{MICROÁREA}

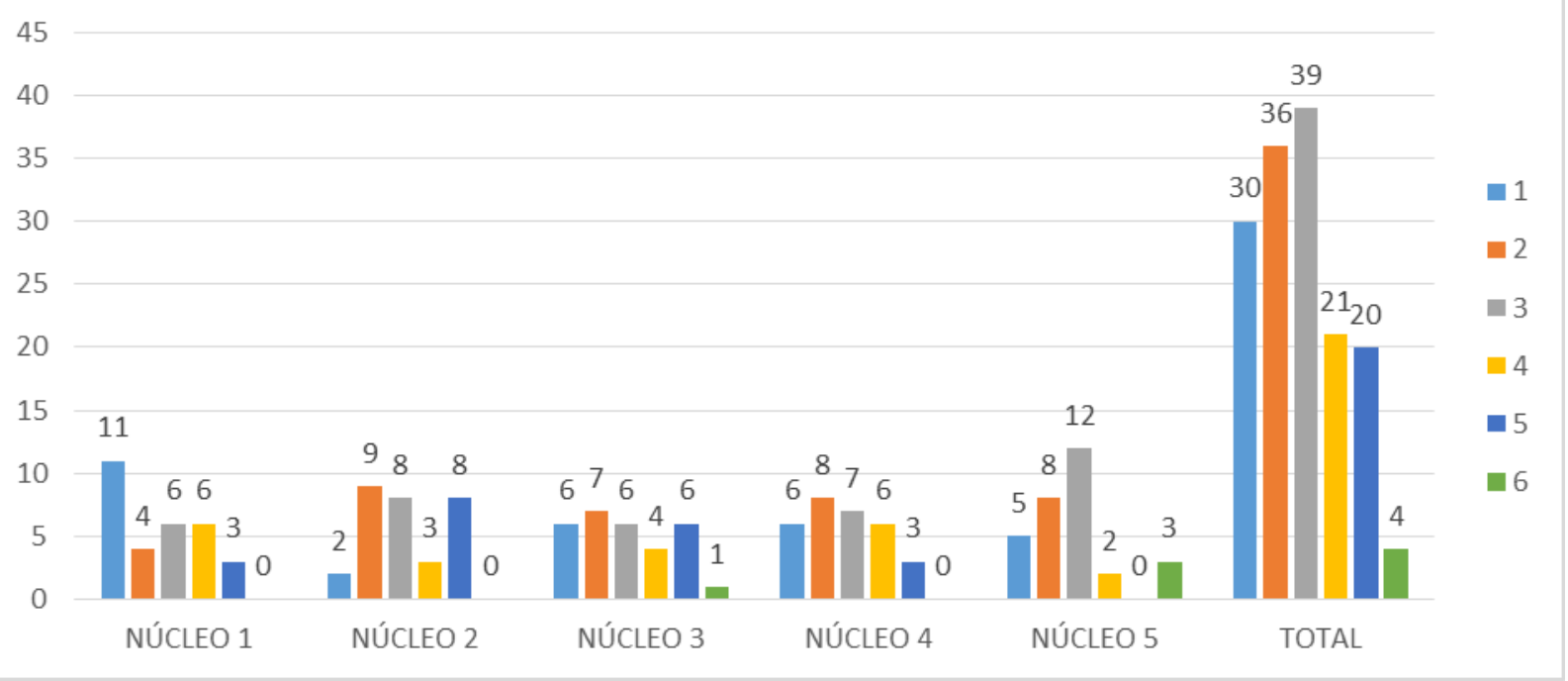

Gráfico 10 - Distribuição dos pacientes por NSF segundo a microárea

Com relação às modalidades de $\mathrm{AD}, 128$ (85,3\%) visitas foram classificadas como $\mathrm{AD} 1$, $13(8,7 \%)$ como AD2 e somente $9(6 \%)$ como AD3, com destaque para o NSF 3 que apresentou número maior de VD em AD3 [4(2,7\%)] e, portanto, maior nível de complexidade (Tabela 12 e Gráfico 11).

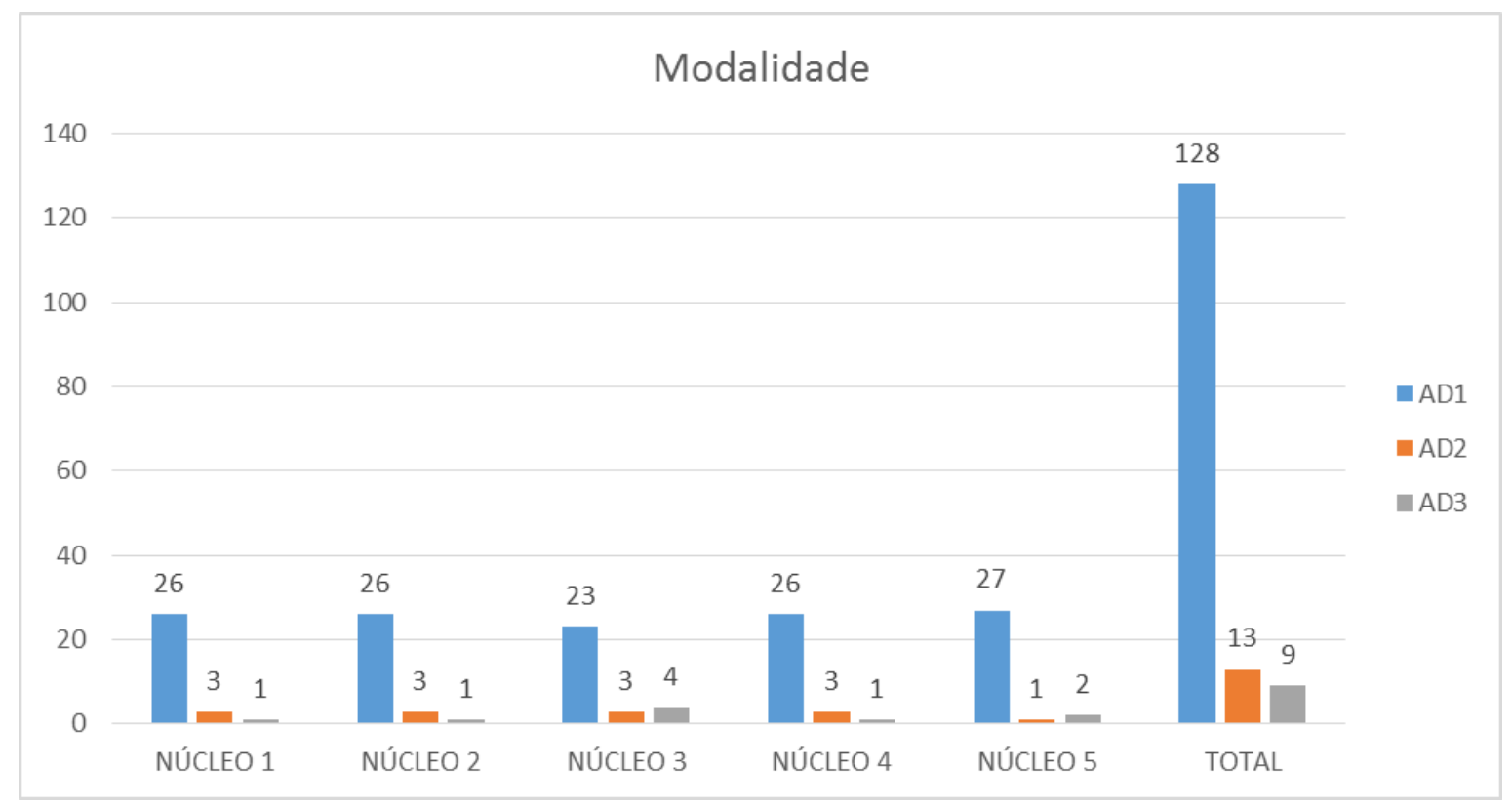

Gráfico 11 - Distribuição dos pacientes por NSF segundo a modalidade de Atenção Domiciliar 
Quanto ao tipo de solicitação, a maioria foi de casos novos [82(54,7\%)]. Somente o NSF 2 [19(12,7\%)] e o NSF 5 [16(10,7\%)] apresentaram número maior de pacientes em seguimento (Tabela 12 e Gráfico 12).

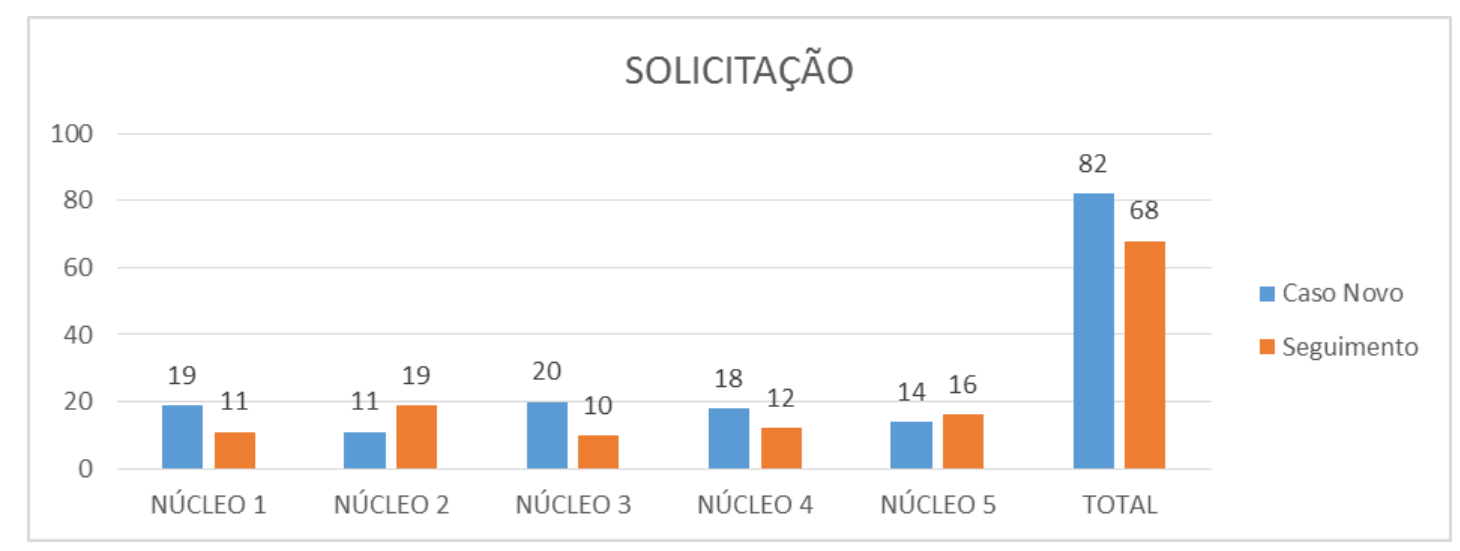

\section{Gráfico 12 - Distribuição dos pacientes por NSF segundo o tipo de solicitação}

Também foram avaliadas outras características da AD e foi observado que $137(91,3 \%)$ das VD's realizadas foram agendadas (Gráfico 13), 65 (43,3\%) estavam em acompanhamento domiciliar e somente 30 (20\%) foram busca ativa (Gráfico 14). Após as VD’s, 83 (55,3\%) pacientes mantiveram-se em acompanhamento domiciliar e $65(43,3 \%)$ pacientes retornaram para seguimento na Unidade (Gráfico 15) (Tabela 12).

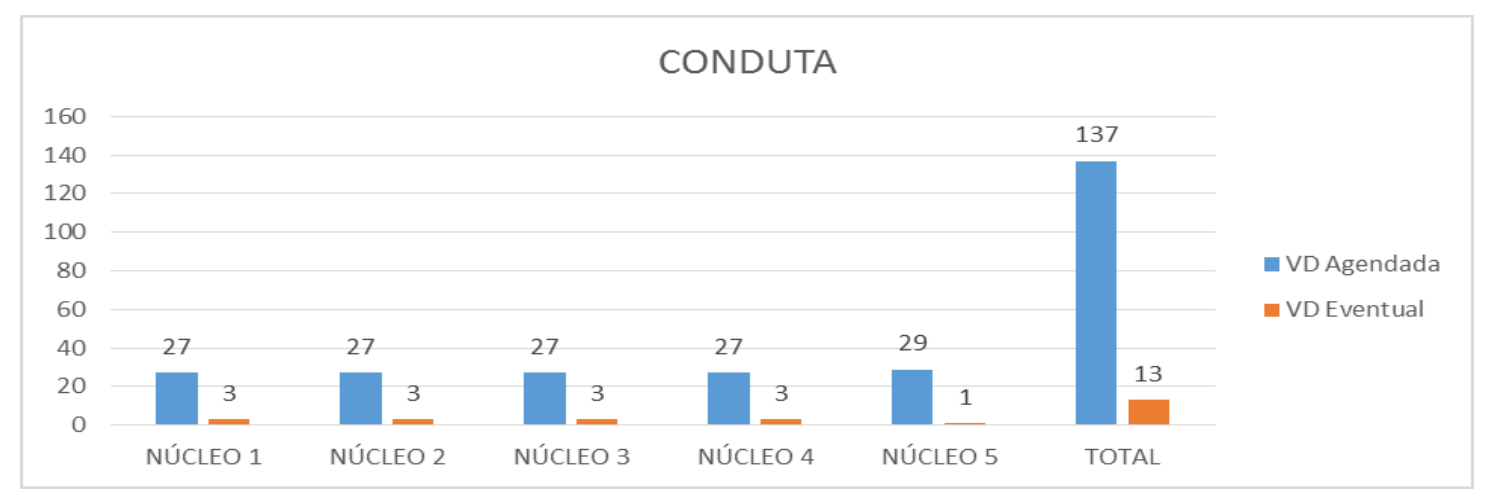

Gráfico 13 - Distribuição dos pacientes por NSF segundo a conduta tomada frente a solicitação de visita domiciliar 


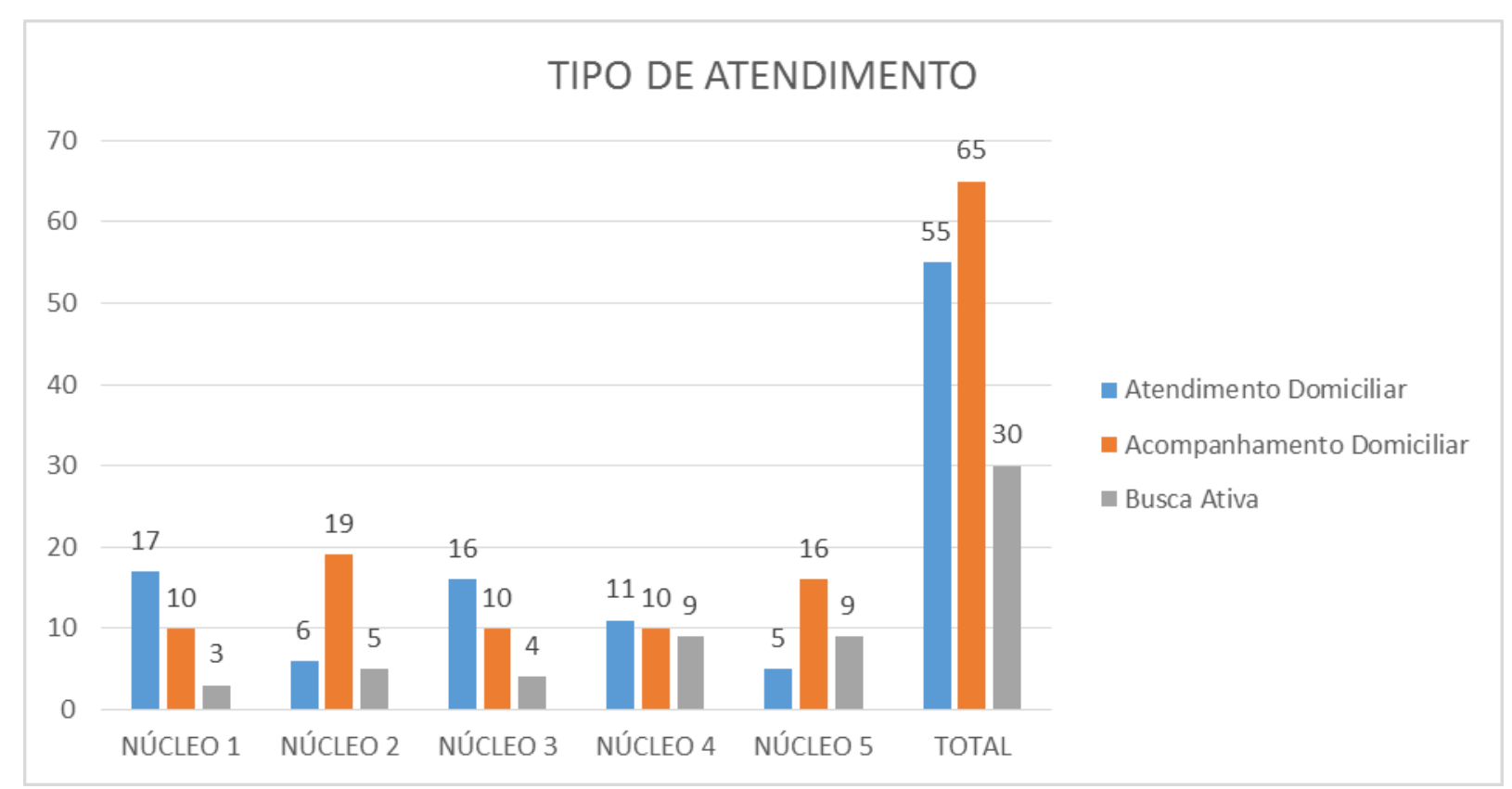

Gráfico 14 - Distribuição dos pacientes por NSF segundo o tipo de atendimento realizado

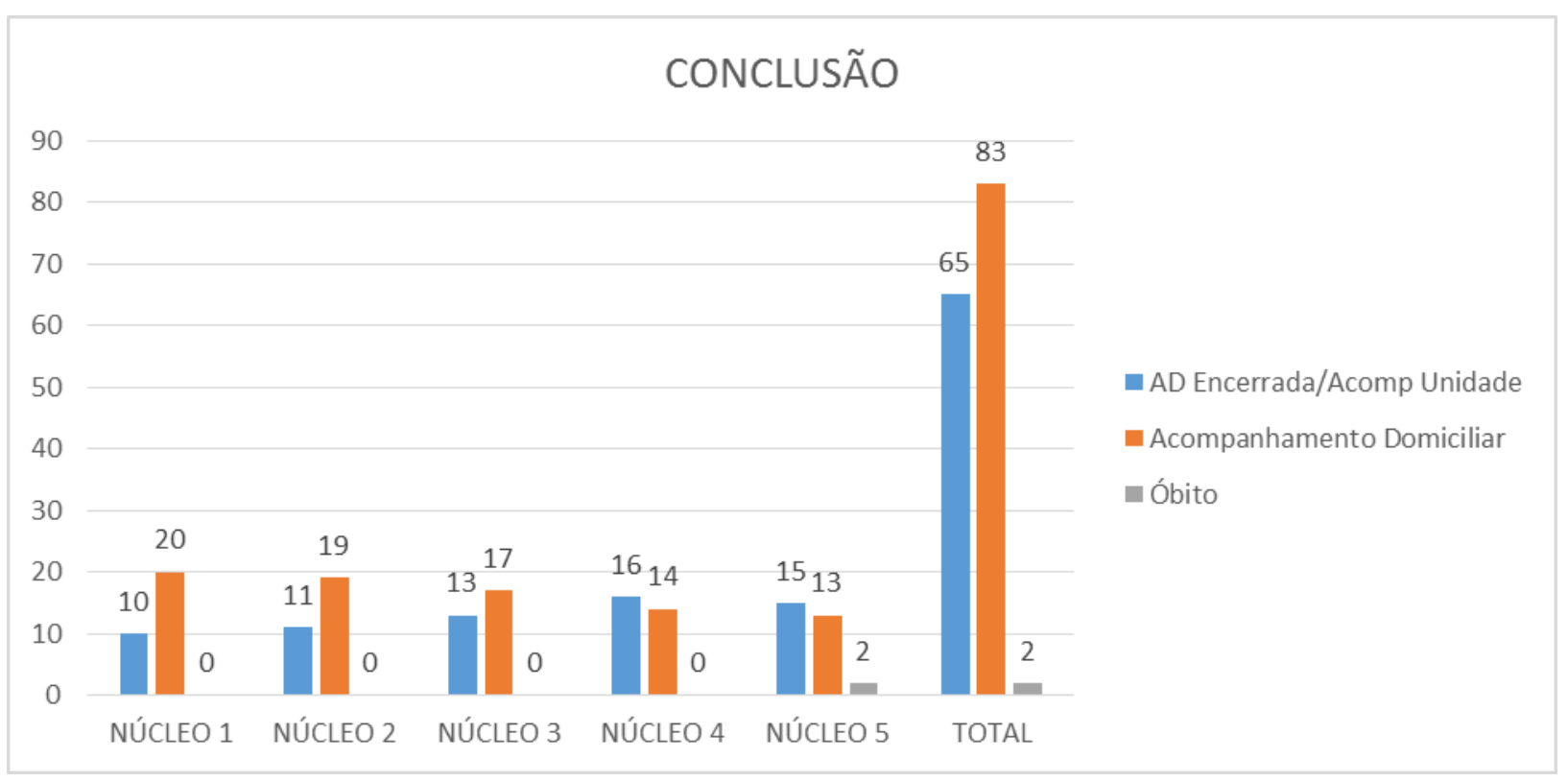

Gráfico 15 - Distribuição dos pacientes por NSF segundo a conclusão ou desfecho da Atenção Domiciliar 
Dentre as variáveis comparadas quanto aos tipos de modalidade, somente a variável demência apresentou relevância $(\mathrm{p}=0,0071)$. Dezesseis $(10,7 \%)$ pacientes possuíam diagnóstico de demência, sendo 10 (6,7\%) destes em AD1 (Tabela 13).

Tabela 13 - Perfil demográfico, epidemiológico e clínico dos pacientes visitados segundo as modalidades de Atenção Domiciliar:

\begin{tabular}{|c|c|c|c|c|c|c|}
\hline \multicolumn{3}{|c|}{ VARIÁVEIS } & AD1 & AD2 & AD3 & TOTAL \\
\hline \multirow{4}{*}{ Idade } & \multirow{4}{*}{$p=0,4854$} & 0-60 anos & $31(20,67 \%)$ & $1(0,67 \%)$ & $2(1,33 \%)$ & $34(22,67 \%)$ \\
\hline & & $>61$ anos & $97(64,67 \%)$ & $12(8 \%)$ & $7(4,67 \%)$ & $116(77,3 \%)$ \\
\hline & & Total & $128(85,33 \%)$ & $13(8,67 \%)$ & $9(6 \%)$ & $150(100 \%)$ \\
\hline & & Feminino & $92(61,33 \%)$ & $10(6,67 \%)$ & $4(2,67 \%)$ & $106(70,67 \%)$ \\
\hline \multirow[t]{3}{*}{ Gênero } & \multirow[t]{3}{*}{$p=0,2331$} & Masculino & $36(24 \%)$ & $3(2 \%)$ & $5(3,33 \%)$ & $44(29,33 \%)$ \\
\hline & & Total & $128(85,33 \%)$ & $13(8,67 \%)$ & $9(6 \%)$ & $150(100 \%)$ \\
\hline & & Analfabeto & $26(17,33 \%)$ & $1(0,67 \%)$ & $3(2 \%)$ & $30(20 \%)$ \\
\hline \multirow{4}{*}{ Escolaridade } & \multirow{4}{*}{$p=0,7077$} & Ensino Fundamental & $84(56 \%)$ & $10(6,67 \%)$ & $5(3,33 \%)$ & $99(66 \%)$ \\
\hline & & Ensino Médio e Superior & $18(12 \%)$ & $2(1,33 \%)$ & $1(0,67 \%)$ & $21(14 \%)$ \\
\hline & & Total & $128(85,33 \%)$ & $13(8,67 \%)$ & $9(6 \%)$ & $150(100 \%)$ \\
\hline & & Solteiro, Viúvo e Divorciado & $73(48,67 \%)$ & $5(3,33 \%)$ & $6(4 \%)$ & $84(56 \%)$ \\
\hline \multirow[t]{3}{*}{ Estado Civil } & \multirow[t]{3}{*}{$p=0,3937$} & Casado & $55(36,67 \%)$ & $8(5,33 \%)$ & $3(2 \%)$ & $66(44 \%)$ \\
\hline & & Total & $128(85,33 \%)$ & $13(8,67 \%)$ & $9(6 \%)$ & $150(100 \%)$ \\
\hline & & Começo familia até fase lançar filhos & $25(16,67 \%)$ & $1(0,67 \%)$ & $2(1,33 \%)$ & $28(18,67 \%)$ \\
\hline \multirow{4}{*}{ Ciclo de Vida } & \multirow{4}{*}{$p=0,8409$} & Familias Maduras & $19(12,67 \%)$ & $1(0,67 \%)$ & $1(0,67 \%)$ & $21(14 \%)$ \\
\hline & & Familias Anciãs & $84(56 \%)$ & $11(7,33 \%)$ & $6(4 \%)$ & $101(67,33 \%)$ \\
\hline & & Total & $128(85,33 \%)$ & $13(8,67 \%)$ & $9(6 \%)$ & $150(100 \%)$ \\
\hline & & Não & $43(28,67 \%)$ & $4(2,67 \%)$ & $1(0,67 \%)$ & $48(32 \%)$ \\
\hline \multirow[t]{2}{*}{ Cuidador } & \multirow[t]{2}{*}{$p=0,4281$} & Sim & $85(56,67 \%)$ & $9(6 \%)$ & $8(5,33 \%)$ & $102(68 \%)$ \\
\hline & & Total & $128(85,33 \%)$ & $13(8,67 \%)$ & $9(6 \%)$ & $150(100 \%)$ \\
\hline \multirow{2}{*}{ Demência } & \multirow{2}{*}{$p=0,0071$} & Não & $118(78,67 \%)$ & $8(5,33 \%)$ & $8(5,33 \%)$ & $134(89,33 \%)$ \\
\hline & & Sim & $10(6,67 \%)$ & $5(3,33 \%)$ & $1(0,67 \%)$ & $16(10,67 \%)$ \\
\hline \multirow{2}{*}{ AVC } & \multirow{2}{*}{$P=0,0758$} & Não & $110(73,33 \%)$ & $13(8,67 \%)$ & $6(4 \%)$ & $129(86 \%)$ \\
\hline & & Sim & $18(12 \%)$ & $0(0 \%)$ & $3(2 \%)$ & $21(14 \%)$ \\
\hline \multirow{2}{*}{ Artrose } & \multirow{2}{*}{$p=1$} & Não & $121(80,67 \%)$ & $13(8,67 \%)$ & $9(6 \%)$ & $143(95,33 \%)$ \\
\hline & & Sim & $7(4,67 \%)$ & $0(0 \%)$ & $0(0 \%)$ & $7(4,67 \%)$ \\
\hline \multirow{2}{*}{ Relação Familiar } & \multirow{2}{*}{$p=0,6314$} & Inadequada & $15(10 \%)$ & $2(1,33 \%)$ & $0(0 \%)$ & $17(11,33 \%)$ \\
\hline & & Adequada & $113(75,33 \%)$ & $11(7,33 \%)$ & $9(6 \%)$ & $133(88,67 \%)$ \\
\hline \multirow{2}{*}{ Antihipertensivo } & $n=0.5602$ & Não & $47(31,33 \%)$ & $5(3,33 \%)$ & $5(3,33 \%)$ & $57(38 \%)$ \\
\hline & & Sim & $81(54 \%)$ & $8(5,33 \%)$ & $4(2,67 \%)$ & $93(62 \%)$ \\
\hline Antidenressivo & $p=0.4979$ & Não & $95(63,33 \%)$ & $8(5,33 \%)$ & $6(4 \%)$ & $109(72,67 \%)$ \\
\hline Amtiuepressivo & p- & Sim & $33(22 \%)$ & $5(3,33 \%)$ & $3(2 \%)$ & $41(27,33 \%)$ \\
\hline & & Não & $94(62,67 \%)$ & $9(6 \%)$ & $8(5,33 \%)$ & $111(74 \%)$ \\
\hline suplemento & $p=0,5 / 28$ & Sim & $34(22,67 \%)$ & $4(2,67 \%)$ & $1(0,67 \%)$ & $39(26 \%)$ \\
\hline Hipoglicemiante & $p=0,4886$ & Não & $96(64 \%)$ & $8(5,33 \%)$ & $6(4 \%)$ & $110(73,33 \%)$ \\
\hline nipogiceminte & $p=0,4886$ & Sim & $32(21,33 \%)$ & $5(3,33 \%)$ & $3(2 \%)$ & $40(26,67 \%)$ \\
\hline Hinolinimiante & 4922 & Não & $78(52 \%)$ & $10(6,67 \%)$ & $5(3,33 \%)$ & $93(62 \%)$ \\
\hline 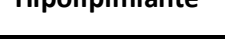 & $p-0,43<2$ & Sim & $50(33,33 \%)$ & $3(2 \%)$ & $4(2,67 \%)$ & $57(38 \%)$ \\
\hline
\end{tabular}

A comparação das variáveis núcleo, escolaridade, estado civil, demência, artrose, antidepressivo, suplemento e hipoglicemiante quanto ao tipo de solicitação (caso novo e seguimento) não apresentou relevância significativa. Contudo, notou-se relevância entre os idosos [116(77,3\%); $\mathrm{p}=0,0492]$, as mulheres [106(70,7\%); $\mathrm{p}=0,0124]$, as famílias anciãs 
[101(67,3\%); $\mathrm{p}=0,0014]$, as que possuíam cuidador [102(68\%); $\mathrm{p}=0,0027$ ] e relação familiar adequada [133(88,7\%); $\mathrm{p}=0,0448]$. Também apresentou relevância os pacientes que sofreram AVC [21(14\%); $\mathrm{p}=<0,001]$, os que utilizavam anti-hipertensivo [93(62\%); $\mathrm{p}=<0,001] \mathrm{e}$ hipolipemiante [57 (38\%); $\mathrm{p}=0,0024]$ (Tabela 14).

Tabela 14 - Perfil demográfico, epidemiológico e clínico dos pacientes visitados segundo os tipos de solicitação

\begin{tabular}{|c|c|c|c|c|c|}
\hline \multicolumn{3}{|c|}{ VARIÁVEIS } & CASO NOVO & SEGUIMENTO & TOTAL \\
\hline \multirow{6}{*}{ Núcleo } & \multirow{6}{*}{$p=0,1149$} & 1 & $19(12,67 \%)$ & $11(7,33 \%)$ & $30(20 \%)$ \\
\hline & & 2 & $11(7,33 \%)$ & $19(12,67 \%)$ & $30(20 \%)$ \\
\hline & & 3 & $20(13,33 \%)$ & $10(6,67 \%)$ & $30(20 \%)$ \\
\hline & & 4 & $18(12 \%)$ & $12(8 \%)$ & $30(20 \%)$ \\
\hline & & 5 & $14(9,33 \%)$ & $16(10,67 \%)$ & $30(20 \%)$ \\
\hline & & Total & $82(54,67 \%)$ & $68(45,33 \%)$ & $150(100 \%)$ \\
\hline \multirow{2}{*}{ Idade } & \multirow{2}{*}{$p=0,0492$} & $0-60$ anos & 24 (16\%) & $10(6,67 \%)$ & $34(22,67 \%)$ \\
\hline & & $>61$ anos & $58(38,67 \%)$ & $58(38,67 \%)$ & $116(77,33 \%)$ \\
\hline \multirow{3}{*}{ Gênero } & \multirow{2}{*}{$p=0,0124$} & Feminino & $65(43,33 \%)$ & $41(27,33 \%)$ & $106(70,67 \%)$ \\
\hline & & Masculino & $17(11,33 \%)$ & $27(18 \%)$ & $44(29,33 \%)$ \\
\hline & \multirow{3}{*}{$p=0,6898$} & Analafabeto & $15(10 \%)$ & $15(10 \%)$ & $30(20 \%)$ \\
\hline \multirow[t]{2}{*}{ Escolaridade } & & Ensino Fundamental & $54(36 \%)$ & $45(30 \%)$ & $99(66 \%)$ \\
\hline & & Ensino Médio e Superior & $13(8,67 \%)$ & $8(5,33 \%)$ & $21(14 \%)$ \\
\hline \multirow{2}{*}{ Estado Civil } & \multirow{2}{*}{$p=0,6205$} & Solteiro, Viúvo e Divorciado & $44(29,33 \%)$ & $40(26,67 \%)$ & $84(56 \%)$ \\
\hline & & Casado & $38(25,33 \%)$ & $28(18,67 \%)$ & $66(44 \%)$ \\
\hline \multirow{3}{*}{ Ciclo de Vida } & \multirow{3}{*}{$p=0,0014$} & Começo familia até fase lançar filhos & $22(14,67 \%)$ & $6(4 \%)$ & $28(18,67 \%)$ \\
\hline & & Familias Maduras & $15(10 \%)$ & $6(4 \%)$ & $21(14 \%)$ \\
\hline & & Familias Anciãs & $45(30 \%)$ & $56(37,33 \%)$ & $101(67,33 \%)$ \\
\hline \multirow{2}{*}{ Cuidador } & \multirow{2}{*}{$p=0,0027$} & Não & $35(23,33 \%)$ & $13(8,67 \%)$ & $48(32 \%)$ \\
\hline & & Sim & $47(31,33 \%)$ & $55(36,67 \%)$ & $102(68 \%)$ \\
\hline \multirow{2}{*}{ Demência } & \multirow{2}{*}{$p=1$} & Não & $73(48,67 \%)$ & $61(40,67 \%)$ & $134(89,33 \%)$ \\
\hline & & Sim & $9(6 \%)$ & $7(4,67 \%)$ & $16(10,67 \%)$ \\
\hline \multirow{2}{*}{ AVC } & \multirow{2}{*}{$p=<0,001$} & Não & $80(53,33 \%)$ & $49(32,67 \%)$ & $129(86 \%)$ \\
\hline & & Sim & $2(1,33)$ & $19(12,67 \%)$ & $21(14 \%)$ \\
\hline \multirow{2}{*}{ Artrose } & \multirow{2}{*}{$p=1$} & Não & $78(52 \%)$ & $65(43,33 \%)$ & $143(95,33 \%)$ \\
\hline & & Sim & $4(2,67 \%)$ & $3(2 \%)$ & $7(4,67 \%)$ \\
\hline \multirow{2}{*}{ Relação Familiar } & \multirow{2}{*}{$p=0,0448$} & Inadequada & $11(7,33 \%)$ & $6(4 \%)$ & $17(11,33 \%)$ \\
\hline & & Adequada & $71(47,33 \%)$ & $62(41,33 \%)$ & $133(88,67 \%)$ \\
\hline \multirow{2}{*}{ Antihipertensivo } & \multirow{2}{*}{$p=<0,001$} & Não & $42(28 \%)$ & $15(10 \%)$ & $57(38 \%)$ \\
\hline & & Sim & $40(26,67 \%)$ & $53(35,33 \%)$ & 93 (62\%) \\
\hline \multirow{2}{*}{ Antidepressivo } & \multirow{2}{*}{$p=0,7132$} & Não & $61(40,67 \%)$ & 48 (32\%) & $109(72,67 \%)$ \\
\hline & & Sim & $21(14 \%)$ & $20(13,33 \%)$ & $41(27,33 \%)$ \\
\hline Suplemento & $p=1$ & Não & $61(40,67 \%)$ & $50(33,33 \%)$ & $111(74 \%)$ \\
\hline & $p=1$ & Sim & $21(14 \%)$ & $18(12 \%)$ & 39 (26\%) \\
\hline Hipoglicemiante & & Não & $62(41,33 \%)$ & $48(32 \%)$ & $110(73,33 \%)$ \\
\hline Hipogilcemiante & $p=0,5 / 86$ & Sim & $20(13,33 \%)$ & $20(13,33 \%)$ & $40(26,67 \%)$ \\
\hline Hinolinimiante & & Não & $60(40 \%)$ & $33(22 \%)$ & $95(62 \%)$ \\
\hline HIpoirpImiante & $p=0,0024$ & Sim & $22(14,67 \%)$ & $35(23,33 \%)$ & $57(38 \%)$ \\
\hline
\end{tabular}


Quando as variáveis foram comparadas quanto ao tipo de conduta (VD agendada ou VD eventual), somente a variável demência mostrou diferença significativa [16 (10,7\%); $\mathrm{p}=0,0056]$, sendo que $11(7,3)$ destes foram acompanhados em VD agendada e 5 (3,3) em VD eventual (Tabela 15).

Tabela 15 - Perfil demográfico, epidemiológico e clínico dos pacientes visitados segundo as condutas

\begin{tabular}{|c|c|c|c|c|c|}
\hline \multicolumn{3}{|c|}{ VARIÁVEIS } & VD AGENDADA & VD EVENTUAL & TOTAL \\
\hline \multirow{6}{*}{ Núcleo } & \multirow{6}{*}{$P=0,8307$} & 1 & $27(18 \%)$ & $3(2 \%)$ & $30(20 \%)$ \\
\hline & & 2 & $27(18 \%)$ & $3(2 \%)$ & $30(20 \%)$ \\
\hline & & 3 & $27(18 \%)$ & $3(2 \%)$ & $30(20 \%)$ \\
\hline & & 4 & $27(18 \%)$ & $3(2 \%)$ & $30(20 \%)$ \\
\hline & & 5 & $29(19,33 \%)$ & $1(0,67 \%)$ & $30(20 \%)$ \\
\hline & & Total & $137(91,33 \%)$ & $13(8,67 \%)$ & $150(100 \%)$ \\
\hline \multirow{2}{*}{ Idade } & \multirow{2}{*}{$P=0,2992$} & $0-60$ anos & $33(22 \%)$ & $1(0,67 \%)$ & $34(22,67 \%)$ \\
\hline & & $>61$ anos & $104(69,33 \%)$ & $12(8 \%)$ & $116(77,33 \%)$ \\
\hline \multirow{3}{*}{ Gênero } & \multirow{3}{*}{$P=0,7564$} & Feminino & $96(64 \%)$ & $10(6,67 \%)$ & $106(70,67 \%)$ \\
\hline & & Masculino & $41(27,33 \%)$ & $3(2 \%)$ & $44(29,33 \%)$ \\
\hline & & Analafabeto & $29(19,33 \%)$ & $1(0,67 \%)$ & $30(20 \%)$ \\
\hline \multirow[t]{2}{*}{ Escolaridade } & \multirow[t]{2}{*}{$P=0,5675$} & Ensino Fundamental & $89(59,33 \%)$ & $10(6,67 \%)$ & $99(66 \%)$ \\
\hline & & Ensino Médio e Superior & $19(12,67 \%)$ & $2(1,33 \%)$ & $21(14 \%)$ \\
\hline \multirow{3}{*}{ Estado Civil } & \multirow{2}{*}{$p=0,2444$} & Solteiro, Viúvo e Divorciado & $79(52,67 \%)$ & $5(3,33 \%)$ & $84(56 \%)$ \\
\hline & & Casado & $58(38,67 \%)$ & $8(5,33 \%)$ & $66(44 \%)$ \\
\hline & \multirow{3}{*}{$p=0,5544$} & Começo familia até fase lançar filhos & $27(18 \%)$ & $1(0,67 \%)$ & $28(18,67 \%)$ \\
\hline \multirow[t]{2}{*}{ Ciclo de Vida } & & Familias Maduras & $20(13,33 \%)$ & $1(0,67 \%)$ & $21(14 \%)$ \\
\hline & & Familias Anciãs & $90(60 \%)$ & $11(7,33 \%)$ & $101(67,33 \%)$ \\
\hline \multirow{2}{*}{ Cuidador } & \multirow{2}{*}{$p=1$} & Não & $44(29,33 \%)$ & $4(2,67 \%)$ & $48(32 \%)$ \\
\hline & & Sim & $93(62 \%)$ & $9(6 \%)$ & $102(68 \%)$ \\
\hline \multirow{2}{*}{ Demência } & \multirow{2}{*}{$p=0,0056$} & Não & $126(84 \%)$ & $8(5,33 \%)$ & $134(89,33 \%)$ \\
\hline & & Sim & $11(7,33 \%)$ & $5(3,33 \%)$ & $16(10,67 \%)$ \\
\hline \multirow{2}{*}{ AVC } & \multirow{2}{*}{$p=0,2159$} & Não & $116(77,33 \%)$ & $13(8,67 \%)$ & $129(86 \%)$ \\
\hline & & Sim & $21(14 \%)$ & $0(0 \%)$ & $21(14 \%)$ \\
\hline \multirow{2}{*}{ Artrose } & \multirow{2}{*}{$p=1$} & Não & $130(86,67 \%)$ & $13(8,67 \%)$ & $143(95,33 \%)$ \\
\hline & & Sim & $7(4,67 \%)$ & $0(0 \%)$ & $7(4,67 \%)$ \\
\hline \multirow{2}{*}{ Relação Familiar } & \multirow{2}{*}{$p=0,6437$} & Inadequada & $15(10 \%)$ & $2(1,33 \%)$ & $17(11,33 \%)$ \\
\hline & & Adequada & $122(81,33 \%)$ & $11(7,33 \%)$ & $133(88,67 \%)$ \\
\hline \multirow{2}{*}{ Antihipertensivo } & \multirow{2}{*}{$p=1$} & Não & $52(34,67 \%)$ & $5(3,33 \%)$ & $57(38 \%)$ \\
\hline & & Sim & $85(56,67 \%)$ & $8(5,33 \%)$ & $97(62 \%)$ \\
\hline \multirow{2}{*}{ Antidepressivo } & \multirow{2}{*}{$p=0,3439$} & Não & $101(67,33 \%)$ & $8(5,33 \%)$ & $109(72,67 \%)$ \\
\hline & & Sim & $36(24 \%)$ & $5(3,33 \%)$ & $41(27,33 \%)$ \\
\hline Sunlemento & $n=0.7426$ & Não & $102(68 \%)$ & $9(6 \%)$ & $111(74 \%)$ \\
\hline & $p=0,14 \angle 0$ & Sim & $35(23,33 \%)$ & $4(2,67 \%)$ & $39(26 \%)$ \\
\hline Hinoglicemiante & $p=0,3333$ & Não & 102 (68\%) & $8(5,33 \%)$ & $110(73,33 \%)$ \\
\hline Hipogilcemiante & $p=0,3333$ & Sim & $35(23,33 \%)$ & $5(3,33 \%)$ & $40(26,67 \%)$ \\
\hline & & Não & $83(55,33 \%)$ & $10(6,67 \%)$ & $93(62 \%)$ \\
\hline Hipolipimiante & $p=0,3716$ & Sim & $54(36 \%)$ & $3(2 \%)$ & $57(38 \%)$ \\
\hline
\end{tabular}

Com relação ao tipo de atenção, identificou-se relevância entre as variáveis núcleo ( $\mathrm{p}=0,0052)$, idade $(\mathrm{p}=0,0126)$, gênero $(\mathrm{p}=0,0089)$, ciclo de vida $(\mathrm{p}=<0,001)$, cuidador $(\mathrm{p}=<0,001)$, demência $(\mathrm{p}=0,040)$, AVC $(\mathrm{p}=<0,001)$, anti-hipertensivos $(\mathrm{p}=0,0014)$ e 
hipolipemiante $(\mathrm{p}=0,0145)$ (Tabela 16). Dos $116(77,3 \%)$ idosos, $55(36,7 \%)$ receberam acompanhamento domiciliar e entre os 44 (29,3\%) homens, 26 (17,3\%) também receberam acompanhamento domiciliar. Com relação ao ciclo de vida, observou-se $101(67,3)$ famílias anciãs e, destas, 53 (35,3\%) receberam acompanhamento domiciliar. Dos 48 (32\%) pacientes que não possuíam cuidador, 18 (12\%) receberam atendimento domiciliar. Ao analisar as doenças, notou-se que dos $16(10,7 \%)$ pacientes com demência $9(6 \%)$ receberam atendimento domiciliar e dos 21 (14\%) com AVC 18 (12\%) receberam acompanhamento domiciliar. Com relação aos medicamentos, entre os 93 (62\%) pacientes que usavam anti-hipertensivos e 57 (38\%) que usavam hipolipemiantes, $50(33,3 \%)$ e 33 (22\%), respectivamente, estavam em acompanhamento domiciliar.

Tabela 16 - Perfil demográfico, epidemiológico e clínico dos pacientes visitados segundo os tipos de atenção domiciliar

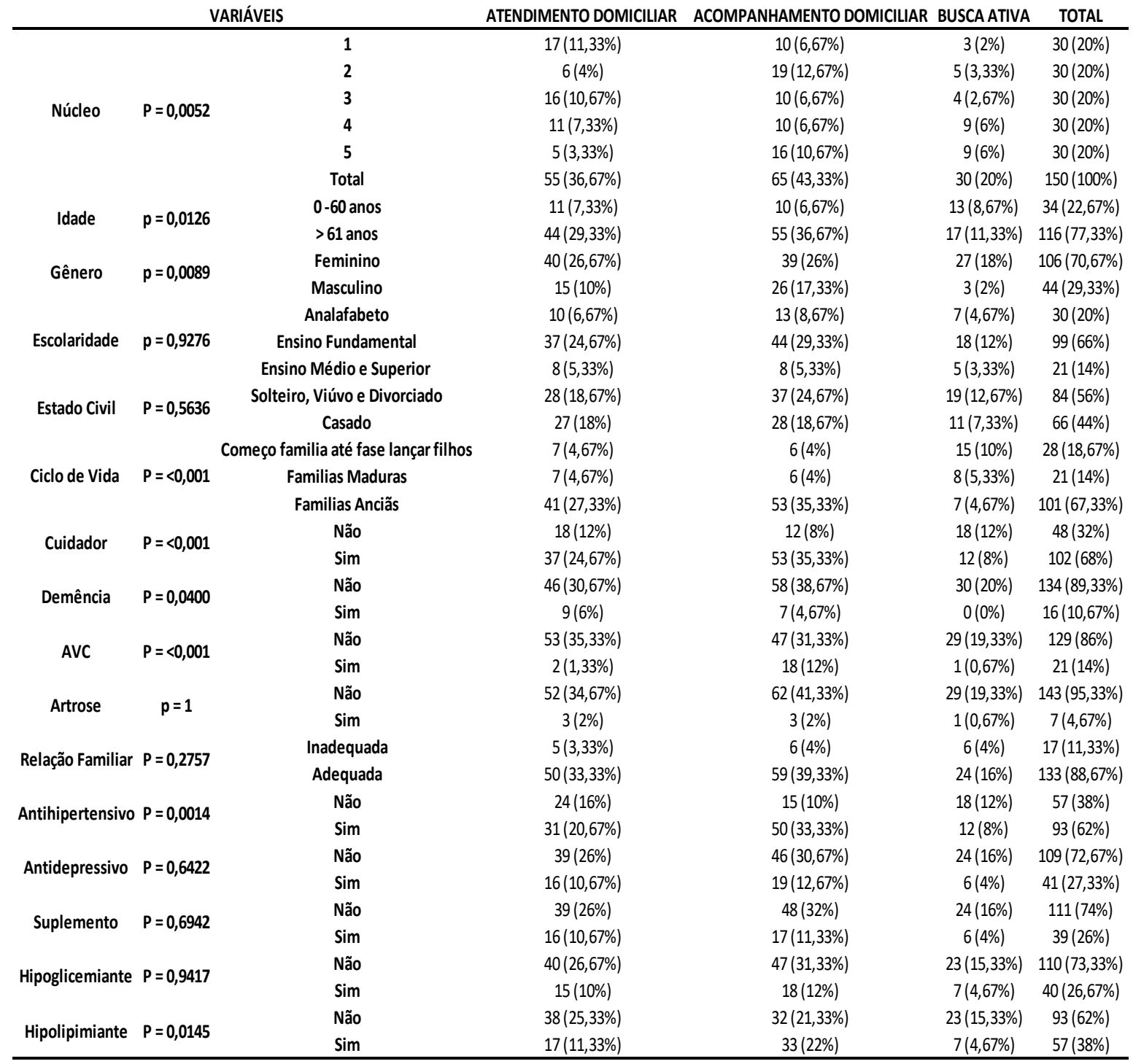


Por fim, quando os desfechos da $\mathrm{AD}$ foram comparados, notou-se que a idade ( $\mathrm{p}=0,0434)$, o gênero $(\mathrm{p}=0,0065)$, o estado civil $(\mathrm{p}=0,0131)$, o ciclo de vida $(\mathrm{p}=<0,001)$, o cuidador $(\mathrm{p}=<0,001)$, AVC $(\mathrm{p}=<0,001)$, uso de anti-hipertensivo $(\mathrm{p}=0,0265)$ e hipolipemiante $(\mathrm{p}=0,040)$ mostraram diferença significativa (Tabela 17). Entre os pacientes que prosseguiram em acompanhamento domiciliar após a VD, 70 (46,7\%) apresentavam idade acima de 61 anos, $32(21,3 \%)$ eram mulheres, $54(36 \%)$ eram solteiros, viúvos ou divorciados e pertenciam a famílias anciãs [69 (46\%)].

Tabela 17 - Perfil demográfico, epidemiológico e clínico dos pacientes visitados segundo a conclusão ou desfecho da AD

\begin{tabular}{|c|c|c|c|c|c|c|}
\hline \multicolumn{3}{|c|}{ VARIÁVEIS } & AD ENCERRADO & ACOMPANHAMENTO DOMICILIAR & ÓBITO & TOTAL \\
\hline \multirow{6}{*}{ Núcleo } & \multirow{6}{*}{$P=0,2668$} & 1 & $10(6,67 \%)$ & $20(13,33 \%)$ & $0(0 \%)$ & $30(20 \%)$ \\
\hline & & 2 & $11(7,33 \%)$ & $19(12,67 \%)$ & $0(0 \%)$ & $30(20 \%)$ \\
\hline & & 3 & $13(8,67 \%)$ & $17(11,33 \%)$ & $0(0 \%)$ & $30(20 \%)$ \\
\hline & & 4 & $16(10,67 \%)$ & $14(9,33 \%)$ & $0(0 \%)$ & $30(20 \%)$ \\
\hline & & 5 & $15(10 \%)$ & $13(8,67 \%)$ & $2(1,33 \%)$ & $30(20 \%)$ \\
\hline & & Total & $65(43,33 \%)$ & $83(55,33 \%)$ & $2(1,33 \%)$ & $150(100 \%)$ \\
\hline \multirow{2}{*}{ Idade } & \multirow{2}{*}{$P=0,0434$} & $0-60$ anos & $21(14 \%)$ & $13(8,67 \%)$ & $0(0 \%)$ & $34(22,67 \%)$ \\
\hline & & $>61$ anos & $44(29,33 \%)$ & $70(46,67 \%)$ & $2(1,33 \%)$ & $116(77,33 \%)$ \\
\hline \multirow{3}{*}{ Gênero } & \multirow{3}{*}{$P=0,0065$} & Feminino & $54(36 \%)$ & $51(34 \%)$ & $1(0,67 \%)$ & $106(70,67 \%)$ \\
\hline & & Masculino & $11(7,33 \%)$ & $32(21,33 \%)$ & $1(0,67 \%)$ & $44(29,33 \%)$ \\
\hline & & Analafabeto & $11(7,33 \%)$ & $19(12,67 \%)$ & $0(0 \%)$ & $30(20 \%)$ \\
\hline \multirow[t]{2}{*}{ Escolaridade } & \multirow[t]{2}{*}{$P=0,7738$} & Ensino Fundamental & $43(28,67 \%)$ & $54(36 \%)$ & $2(1,33 \%)$ & $99(66 \%)$ \\
\hline & & Ensino Médio e Superior & $11(7,33 \%)$ & $10(6,67 \%)$ & $0(0 \%)$ & $21(14 \%)$ \\
\hline \multirow{2}{*}{ Estado Civil } & \multirow{2}{*}{$P=0,0131$} & Solteiro, Viúvo e Divorciado & $30(20 \%)$ & $54(36 \%)$ & $0(0 \%)$ & $84(56 \%)$ \\
\hline & & Casado & $35(23,33 \%)$ & $29(19,33 \%)$ & $2(1,33 \%)$ & $66(44 \%)$ \\
\hline \multirow{3}{*}{ Ciclo de Vida } & \multirow{3}{*}{$P=<0,001$} & Começo familia até fase lançar filhos & $19(12,67 \%)$ & $9(6 \%)$ & $0(0 \%)$ & $28(18,67 \%)$ \\
\hline & & Familias Maduras & $15(10 \%)$ & $5(3,33 \%)$ & $1(0,67 \%)$ & $21(14 \%)$ \\
\hline & & Familias Anciãs & $31(20,67 \%)$ & $69(46 \%)$ & $1(0,67 \%)_{-}$ & $101(67,33 \%)$ \\
\hline \multirow{2}{*}{ Cuidador } & \multirow{2}{*}{$P=<0,001$} & Não & $33(22 \%)$ & $15(10 \%)$ & $0(0 \%)$ & $48(32 \%)$ \\
\hline & & Sim & $32(21,33 \%)$ & $68(45,33 \%)$ & $2(1,33 \%)$ & $102(68 \%)$ \\
\hline \multirow{2}{*}{ Demência } & \multirow{2}{*}{$P=0,1394$} & Não & $60(40 \%)$ & $73(48,67 \%)$ & $1(0,67 \%)$ & $134(89,33 \%)$ \\
\hline & & Sim & $5(3,33 \%)$ & $10(6,67 \%)$ & $1(0,67 \%)$ & $16(10,67 \%)$ \\
\hline \multirow{2}{*}{ AVC } & \multirow{2}{*}{$P=<0,001$} & Não & $64(42,67 \%)$ & $64(42,67 \%)$ & $1(0,67 \%)$ & $129(86 \%)$ \\
\hline & & Sim & $1(0,67 \%)$ & $19(12,67 \%)$ & $1(0,67 \%)$ & $21(14 \%)$ \\
\hline \multirow{2}{*}{ Artrose } & \multirow{2}{*}{$p=0,5156$} & Não & $63(42 \%)$ & $78(52 \%)$ & $2(1,33 \%)$ & $143(95,33 \%)$ \\
\hline & & Sim & $2(1,33 \%)$ & $5(3,33 \%)$ & $0(0 \%)$ & $7(4,67 \%)$ \\
\hline \multirow{2}{*}{ Relação Familiar } & \multirow{2}{*}{$p=0,3753$} & Inadequada & $10(6,67 \%)$ & $7(4,67 \%)$ & $0(0 \%)$ & $17(11,33 \%)$ \\
\hline & & Adequada & $55(36,67 \%)$ & $76(50,67 \%)$ & $2(1,33 \%)$ & $133(88,67 \%)$ \\
\hline \multirow{2}{*}{ Antihipertensivo } & \multirow{2}{*}{$p=0,0265$} & Não & $32(21,33 \%)$ & $25(16,67 \%)$ & $0(0 \%)$ & $57(38 \%)$ \\
\hline & & Sim & $33(22 \%)$ & $58(38,67 \%)$ & $2(1,33 \%)$ & $93(62 \%)$ \\
\hline \multirow{2}{*}{ Antidepressivo } & $p=0,1479$ & Não & $52(34,67 \%)$ & $55(36,67 \%)$ & $2(1,33 \%)$ & $109(72,67 \%)$ \\
\hline & $p=0,14 / 9$ & Sim & $13(8,67 \%)$ & $28(18,67 \%)$ & $0(0 \%)$ & $41(27,33 \%)$ \\
\hline & & Não & $48(32 \%)$ & $62(41,33 \%)$ & $1(0,67 \%)$ & $111(74 \%)$ \\
\hline Suplemento & $p=0,6431$ & Sim & $17(11,33 \%)$ & $21(14 \%)$ & $1(0,67 \%)$ & $39(26 \%)$ \\
\hline & & Não & $49(32,67 \%)$ & $60(40 \%)$ & $1(0,67 \%)$ & $110(73,33 \%)$ \\
\hline Hipogicemlante & $p=0,5941$ & Sim & $16(10,67 \%)$ & $23(15,33 \%)$ & $1(0,67 \%)$ & $40(26,67 \%)$ \\
\hline & & Não & $47(31,33 \%)$ & $45(30 \%)$ & $1(0,67 \%)$ & $93(62 \%)$ \\
\hline HIpolıpımıante & $p=0,0401$ & Sim & $18(12 \%)$ & $38(25,33 \%)$ & $1(0,67 \%)$ & $57(38 \%)$ \\
\hline
\end{tabular}




\section{DISCUSSÃO}

O presente estudo foi realizado no Distrito Oeste de Ribeirão Preto/SP na sub-região 09, onde estão localizados os Núcleos de Saúde da Família (NSF's) ligados à Faculdade de Medicina de Ribeirão Preto da Universidade de São Paulo. Os NSF's foram criados em 2001 através do convênio entre a Secretaria Municipal de Saúde de Ribeirão Preto, a USP Faculdade de Medicina de Ribeirão Preto, o Hospital das Clínicas da FMRPUSP e a FAEPA Fundação de Apoio ao Ensino, Pesquisa e Assistência do HCFMRP para a atuação na Estratégia de Saúde da Família. São unidades que prestam assistência à saúde da população, dentro do que é preconizado pelo Ministério da Saúde, mas também atuam como campo de estágio para alunos de graduação e pós-graduação da FMRP e das demais unidades de ensino da área da Saúde do Campus USP de Ribeirão Preto e para médicos residentes do HCFMRP (34).

O NSF 1 está localizado na Rua São Salvador. É uma área exclusivamente urbana, com 801 domicílios cadastrados, totalizando 2.227 pacientes cadastrados que possuem abastecimento de água, energia elétrica e esgoto. Comparado com as demais áreas dos outros NSF's é a área com a maior quantidade de apartamentos, podendo crescer em número de habitantes por metro quadrado e apresenta a maioria de domicílios próprios. Outra característica importante é o predomínio de moradores idosos, justificando a alta prevalência de doenças crônicas não transmissíveis (DCNT) na área (35).

O NSF 2 encontra-se na Rua Dr. Antônio José Moreira, área próxima do NSF 1 e, por isso, apresenta características semelhantes. Possui 586 domicílios cadastrados com 1.762 pacientes. Também apresenta grande quantidade de moradores idosos e é a unidade com o maior número de idosos acima de 85 anos, justificando também a alta prevalência de DCNT e grande número de pacientes acamados e domiciliados (35).

O NSF 3 está localizado na Travessa Nossa Senhora da Penha. Sua área faz divisa com os NSF's 1 e 2, apresentando características semelhantes a estas duas áreas, exceto pelo fato de apresentar menor quantidade de apartamentos. Possui 1.373 pacientes cadastrados em 507 domicílios. Também apresenta uma população idosa e grande quantidade de pacientes restritos ao leito e ao domicílio (35) (Tabela 18 e 19).

Já o NSF 4 localiza-se na Rua Padre Anchieta e possui grande quantidade de conjuntos de habitações populares em sua área. Contém 407 domicílios cadastrados com 1.241 pacientes. Seus moradores são majoritariamente adultos jovens e, embora não possua prevalência tão alta de DCNT quanto os NSF's 1, 2 e 3, é uma área de vulnerabilidade social (35). 
E, por fim, o NSF 5, localizado na Rua Martim Afonso de Souza, possui 578 domicílios cadastrados contendo 1.835 pacientes. De modo semelhante ao NSF 4, possui uma área de favela, localizada em áreas ocupadas irregularmente, contendo habitações precariamente construídas e algumas desprovidas de infraestrutura. A população da área é bastante jovem e se destaca pelo alto número de gestantes, tabagistas, usuários de álcool e drogas, demonstrando a alta vulnerabilidade social provavelmente relacionada às desigualdades sociais, à marginalização e à exclusão social (35).

Portanto, a diferença de média de idade entre os núcleos, a quantidade de idosos, pacientes acamados e restritos ao domicílio se devem às diferenças existentes na população que habita suas áreas de abrangência.

$\mathrm{O}$ estudo também demonstrou que os pacientes que mais solicitaram $\mathrm{AD}$ foram idosos do sexo feminino e pertencentes a famílias anciãs. Tais dados condizem com o estudo realizado por Fabrício et al (36) que entendem este achado como resultante da maior expectativa de vida das mulheres em relação aos homens (superior em 5 anos) e também ao aumento da expectativa de vida entre os idosos portadores de doenças crônicas.

Feliciano et al (37) relacionam a maior sobrevida das mulheres à diferença na exposição aos riscos e diferença de atitudes em relação às doenças. Os resultados relativos ao nível de escolaridade refletem a desigualdade social do país, principalmente no começo do século onde o acesso à escola era menor.

O presente estudo avaliou a higiene da casa, cama, corporal e bucal e não foram observadas grandes alterações. A maioria dos domicílios e pacientes avaliados apresentava boas condições de higiene e recebeu somente algumas orientações. $\mathrm{O}$ trabalho no domicílio representa um importante recurso que permite à equipe conhecer e compreender a realidade de cada indivíduo e sua família, proporcionando um olhar direcionado e individualizado. É de suma importância que as situações de moradia, higiene e saneamento sejam avaliadas durante as visitas domiciliares, pois segundo a Organização Pan Americana de Saúde, tais fatos são decisivos para estabelecer medidas de promoção da qualidade de vida dos indivíduos e suas famílias (32).

$\mathrm{O}$ estudo demonstrou que a maioria dos pacientes que receberam $\mathrm{AD}$ não está restrita ao leito, mas possui dificuldade ou incapacidade funcional atribuídas ao próprio processo de envelhecimento, o que justifica a necessidade da AD. Este achado é confirmado por estudos brasileiros semelhantes $(38,39,40)$. 
Sobre a presença de sondas, estomias e úlceras, os dados do presente estudo são compatíveis com o realizado por Gaspar et al (39) que mostra o aumento do nível de complexidades nesses casos. A AD para estes pacientes permite a continuidade da assistência que foi iniciada em nível hospitalar, proporcionando benefícios, como a diminuição das internações e dos custos hospitalares e a tranquilidade de estar em casa $(38,39,40)$.

Com o aumento da idade e da prevalência das DCNT, há diminuição da capacidade funcional do indivíduo, levando à diminuição da mobilidade e ao aumento do aparecimento de úlceras. Há também a dificuldade de cicatrização causada pelo próprio envelhecimento, por algumas comorbidades como o diabetes e a situação nutricional do paciente. $\mathrm{O}$ tratamento das úlceras segue o protocolo preconizado pela Secretaria de Saúde do Município de Ribeirão Preto, mas medidas de intervenção educativas voltadas à prevenção destas lesões devem ser realizadas durante as VD's para evitar complicações e recorrências.

Nos domicílios visitados notou-se que ainda existem várias barreiras arquitetônicas que dificultam o trânsito do paciente. Segundo a Associação Brasileira de Normas Técnicas $(\mathrm{ABNT})$, barreira arquitetônica seria qualquer elemento natural, instalado ou edificado que impeça a aproximação, transferência ou circulação no espaço mobiliário ou equipamento urbano (41), que dificultam a acessibilidade dos pacientes. Orientações sobre possíveis adaptações a serem realizadas no domicílio têm como objetivo auxiliar o paciente e seus familiares a identificar as dificuldades, sugerir modificações e facilitar a reabilitação. Algumas modificações de baixo custo como presença de corrimão e aumento da iluminação facilitam o acesso e previnem quedas e fraturas, além de contribuírem para maior independência do idoso.

O processo de envelhecimento é dinâmico, irreversível e progressivo, caracterizandose por uma série de alterações físicas, fisiológicas, psicológicas, econômicas e sociais que podem afetar diversos órgãos e sistemas. Por isso os aspectos relacionados à nutrição e à hidratação dos idosos precisam ser avaliados com certo rigor, já que neste grupo existem, além das DCNT, uma infinidade de fatores socioeconômicos que possibilitam o erro nutricional e desbalanço hídrico. No presente estudo, a maioria dos pacientes se alimentava por via oral e uma pequena parcela fazia uso de algum tipo de suplemento. O envelhecimento está sabidamente associado à redução da ingesta alimentar, entre outros fatores, decorrente da perda do apetite, podendo levar ao mau estado nutricional e prejuízo da capacidade cognitiva. Com relação aos minerais e vitaminas, a ingesta é menor do que a recomendação diária sugerida e por essa razão, deve ser devidamente valorizada, dada a sua importância nas funções do 
organismo (42). Entretanto, a qualidade da ingesta nutricional não foi avaliada no presente estudo por não fazer parte dos objetivos do estudo.

Os rins também sofrem com o passar dos anos com modificações que podem levar a alterações na função renal e na concentração da urina. A diminuição da sensibilidade do centro da sede associado à presença de comorbidades e uso de alguns tipos de medicação tornam os idosos mais propensos à desidratação (42). Portanto, recomenda-se uma ingesta hídrica diária entre 1,5 a 2 litros para todos os pacientes, em especial os idosos. A menor ingesta hídrica foi observada entre os pacientes dos NSF 4 e 5 e esse assunto foi tema de orientação específica (sobre a importância da ingesta hídrica adequada) durante as VD's.

Outro aspecto avaliado que se destacou foi o uso de fraldas e coletores, provavelmente devido à alteração do sistema urinário, envelhecimento, cirurgias prévias ou sequelas de outras doenças.

Verificou-se alta prevalência de uso de prótese dentária devido à deterioração da saúde bucal, ocasionando efeitos cumulativos no estilo de vida. Este é um dado de grande importância, já que os problemas associados à saúde bucal podem levar à ingesta alimentar diminuída, perda de peso involuntária, aumento do risco de hospitalização, além de diminuir a qualidade de vida. A prótese dentária tem sido uma alternativa para a falta de dentes, porém existe grande dificuldade de adaptação e rejeição por parte de alguns pacientes.

Com relação à visão e audição, a maioria dos pacientes as classificou apenas como boas. Com o passar dos anos, é esperado que ocorra certa deterioração da visão, com declínio da acuidade visual, alteração do campo visual periférico, diminuição da sensibilidade ao contraste, da discriminação de cores e, consequentemente, alteração da qualidade de vida. Os ouvidos também vão perdendo a sua capacidade funcional com o tempo, que podem ter sofrido agravamento por exposição ao longo da vida, determinando deficiências graves, declínio da qualidade de vida e grande impacto nas relações sociais (43).

Muitos pacientes avaliados possuíam alguma atividade de lazer que lhes ocupavam parte do dia e isso é de grande importância, já que grande parte dos pacientes em AD está privada de alguma função motora ou cognitiva e necessitam de tarefas estimuladoras para manutenção de sua capacidade funcional, elevação da autoestima e relaxamento. O convívio social também é essencial para evitar o isolamento e a depressão.

Outro dado de destaque no presente estudo foi a presença de animal de estimação no domicílio, pois é considerado fator de melhora da interação social e do humor. 
Os exames complementares têm por finalidade auxiliar as informações obtidas na consulta médica, melhorando a precisão diagnóstica e a escolha do tratamento mais adequado. É necessário que a solicitação de um exame seja direcionada e que se conheça o seu valor e suas limitações e os mesmos devem ser solicitados somente quando necessários, pois os recursos financeiros em saúde são limitados. Quanto aos dados do presente estudo, nota-se que os exames mais checados foram lipidograma, glicemia e função renal, resultados compatíveis com os encontrados por Capilheira et al (44) que atribuíram estes dados à alta prevalência de DCNT como Hipertensão Arterial e Diabetes. Segundo a $7^{\text {a }}$ Diretriz Brasileira de Hipertensão Arterial (45), esses exames fazem parte da rotina anual desses pacientes. No caso dos pacientes diabéticos, a Diretriz da Sociedade Brasileira de Diabetes (46) recomenda avaliação da glicemia pelo menos duas vezes por ano para todos os diabéticos e quatro vezes por ano (a cada 3 meses) para aqueles que se submeteram à alteração no esquema terapêutico ou não estejam alcançando os objetivos recomendados com o tratamento vigente.

Os diagnósticos mais prevalentes foram os neurológicos, como Acidentes vascular cerebral e demência, resultado também condizente com o estudo de Fabrício et al (36). Como já mencionado anteriormente, com o envelhecimento da população, há o aumento da prevalência de DCNT e maior procura por serviços de saúde e, consequentemente, maiores custos diretos e indiretos para o sistema de saúde $(46,47,48)$. Essas patologias são graves pois podem levar à incapacidades crônicas e à perda da independência e autonomia (48). São responsáveis por gerar maior debilidade e estão diretamente relacionadas à prevalência das DCNT na terceira idade. Essa situação faz com que muitos pacientes e familiares precisem reorganizar suas vidas para assumir os cuidados no domicílio.

As especialidades médicas mais citadas foram a cardiologia, neurologia e geriatria, demonstrando a necessidade de atendimento em especialidades relacionadas às doenças mais prevalentes em idosos. Consequentemente, os medicamentos mais utilizados pelo grupo de pacientes estudado foram os relacionados a essas doenças. Com o envelhecimento da população da área de abrangência há um aumento da demanda nos serviços de Atenção Primária à Saúde que, a depender da complexidade do caso, cria a necessidade de referência para as especialidades. Entretanto, mesmo em seguimento nos níveis secundário e terciário, os cuidados em saúde do paciente devem ser coordenados na Atenção Primária, o que gera a necessidade da restruturação, sendo que a capacitação da equipe primária pode contribuir para o tratamento e seguimento desses pacientes. 
Com relação às modalidades de $\mathrm{AD}$, houve predomínio de visitas em $\mathrm{AD} 1$, já que é a modalidade que, segundo o Ministério da Saúde, se enquadra na capacidade de atendimento da Atenção Primária e que se destina a pacientes com problemas de saúde controlados ou compensados e com deficiência ou impossibilidade física de locomoção até a unidade de saúde, necessitando de cuidados com menor frequência e menor necessidade de recursos de saúde. As equipes de ESF e Núcleo de Apoio à Saúde da Família (NASF) acompanham esses pacientes através de VD’s regulares em domicílio, no mínimo 1 vez por mês. Porém, o presente estudo identificou atendimentos em $\mathrm{AD} 2$, que são destinados a usuários que possuem problemas de saúde e dificuldade ou impossibilidade física de locomoção até a unidade de saúde, mas que necessitam de maior frequência de cuidado, recursos de saúde e acompanhamento contínuos. Tanto AD2 quanto AD3 são de responsabilidade da Equipe Multiprofissional de Atenção Domiciliar (EMAD) e da Equipe Multiprofissional de Apoio (EMAP), ambas designadas para esta finalidade, mesmo assim, nota-se que a Atenção Primária realiza atendimentos em pacientes de alta complexidade para acompanhamento dos problemas de saúde, coordenação de cuidados e apoio às necessidades do paciente e de seus familiares.

Ao avaliar os tipos de solicitação de $\mathrm{AD}$, foram encontrados mais casos novos do que consultas de seguimento, provavelmente devido ao cadastramento de novos moradores após a nova territorialização e também pela alta prevalência de DCNT que demandam mais acompanhamento.

Outra característica observada foi que a maioria das VD's agendadas foi de pacientes em acompanhamento, mostrando que dificilmente o médico consegue realizar VD eventual devido à grande demanda apresentada na Unidade. Observou-se também que outros tipos de $\mathrm{AD}$, como Busca Ativa, não foram realizados provavelmente pelas mesmas razões e que a maioria dos pacientes atendidos mantiveram o acompanhamento domiciliar, isto é, apresentavam quadros não reversíveis. A Atenção Domiciliar é um tema cada vez mais atual e vem se desenvolvendo ao longo do tempo, principalmente pela mudança do perfil da população brasileira. Novas políticas públicas voltadas para a $\mathrm{AD}$ têm sido criadas, mas é necessário que haja maior interesse político, capacitação das equipes e maior integração dos diferentes níveis de atenção para que os usuários possam se beneficiar de uma $\mathrm{AD}$ de qualidade.

Com a utilização das fichas padronizadas neste estudo, identificou-se que as fichas $1 \mathrm{e}$ 2 foram bem aplicadas e ajudaram a organizar e sistematizar as solicitações que chegavam à Unidade e a realização propriamente dita da VD. Porém, a ficha 2 é extensa e pareceu ser mais útil para realização de casos novos, ou seja, quando ainda não se conhece o paciente. Para as 
próximas VD's, ou seja, as de seguimento, poderia se criar uma nova ficha direcionada para os retornos.

Informações sobre quedas e saúde mental não constavam da ficha 2 e isso poderia tornála um instrumento mais completo. Outro ponto que poderia enriquecer o questionário seria a inclusão de escalas específicas de dependência para tornar menos intuitiva e mais sistematizada a indicação dos pacientes para alguma modalidade de $\mathrm{AD}$. Outro aspecto que não se englobou na pesquisa foi a avaliação de satisfação do usuário e de sua família.

As principais dificuldades para realização das VD's encontradas foram: domicílios de difícil acesso, ausência de cuidador mesmo nas VD's agendadas, ausência de um membro da equipe de referência para acompanhar as VD's, diferentes métodos de gestão das Unidades e os diferentes níveis de complexidade e apoio da rede de saúde.

Diante disso, o presente estudo sugere que as solicitações de AD sejam acolhidas por qualquer membro da equipe de saúde através da Ficha 1. Posteriormente, que o caso seja discutido em equipe e a melhor conduta seja selecionada para cada caso.

Para aqueles pacientes que forem selecionados para $\mathrm{AD}$ médica pela primeira vez, a melhor opção seria a utilização da Ficha 2 que possibilita coleta de maior quantidade de informações úteis na análise do caso. Após a primeira VD, seria interessante adicionar ao caso uma escala específica de dependência para avaliar a necessidade do paciente se manter em AD e, consequentemente, programar a continuidade do cuidado. Esta avaliação deveria ser feita sempre que possível nos retornos, principalmente para pacientes com quadros agudos reversíveis para otimizar esse tipo de assistência. Com o envelhecimento da população esperase um aumento da demanda por $\mathrm{AD}$ que exigiria da equipe uma estratégia de avaliação mais refinada para identificar aqueles que realmente necessitem do serviço. Além disso, outra sugestão é manter uma lista sempre atualizada dos pacientes em $\mathrm{AD}$, com suas principais doenças, cuidadores e próximas atividades programadas para facilitar o planejamento da AD e o processo de trabalho da equipe.

A análise da $\mathrm{AD}$ realizada, bem como o perfil dos pacientes atendidos em $\mathrm{AD}$, pode contribuir para aprimorar o atendimento domiciliar. 


\section{CONCLUSÕES}

Ao final deste estudo, observou-se que os indivíduos que mais receberam AD foram os idosos do sexo feminino, casados, aposentados, que estudaram por 4 anos, que possuíam cuidador e que pertenciam a famílias anciãs. Como doença mais frequente encontrou-se o Acidente Vascular Cerebral (CID 10 G 45) e a Demência (CID 10 F 02).

Com relação à $\mathrm{AD}$, conclui-se que a modalidade mais realizada foi a $\mathrm{AD} 1$, compatível com a modalidade que, segundo o Ministério da Saúde, se enquadra na capacidade de atendimento da Atenção Primária, apesar de também apresentar atendimentos em AD2 e AD3. A maioria dos atendimentos foi de casos novos, agendados e que já estavam em acompanhamento domiciliar. A maioria dos pacientes se manteve em $\mathrm{AD}$, pois possuíam quadros crônicos degenerativos.

As fichas foram bem aplicadas e ajudaram a organizar e sistematizar tanto as solicitações que chegavam à Unidade quanto a realização das VD's propriamente dita.

As principais dificuldades encontradas para realização das VD's encontradas foram: domicílios de difícil acesso, ausência de cuidador mesmo nas VD’s agendadas, ausência de um membro da equipe de referência para acompanhar as VD's, diferentes métodos de gestão das Unidades e os diferentes níveis de complexidade e apoio da rede de saúde.

Portanto, para o aprimoramento dos atendimentos domiciliares dos moradores da área de abrangência dos NSF, este estudo sugere que sejam utilizadas as Fichas 1 e 2 nos atendimentos, direcionando e sistematizando a $\mathrm{AD}$. Outra sugestão é manter uma lista sempre atualizada dos pacientes em $\mathrm{AD}$, com suas principais doenças, cuidadores e o planejamento terapêutico para cada caso.

Os resultados do presente estudo permitiram delinear o perfil de vida e saúde dos pacientes e identificar a necessidade de fortalecimento de ações de prevenção e promoção de saúde, reduzindo-se complicações e internações desnecessárias. Para que isto seja possível, políticas públicas específicas voltadas principalmente para a população mais idosa devem ser consideradas prioridades.

Conclui-se que $\mathrm{AD}$ na ESF é uma prática centrada no indivíduo e sua família, possibilitando uma maior compreensão de sua realidade. Também é responsável pela integração 
dos diferentes níveis da atenção à saúde e, por isso, tais profissionais devem ser alvo de treinamento e capacitação para se adequarem às necessidades da população em ambiente domiciliar.

A realização de estudos similares seria de grande importância para ampliar as pesquisas neste âmbito, além de reforçar a análise dos resultados deste estudo e incentivar novas políticas públicas voltadas para este público. 


\section{REFERÊNCIAS}

1. Azevedo CM, Cotta RMM, Schott M, Maia TM, Marques ES. Avaliação das condições de habitação e saneamento: a importância da visita domiciliar no contexto do Programa de Saúde da Família. Ciência \& Saúde Coletiva 2007, 12(3): 743-753.

2. Portal do Departamento de Atenção Básica, Estratégia de Saúde da Família. Disponível em:<http://dab.saude.gov.br>. Acesso em: 30 de julho de 2012.

3. Oliveira EM, Spiri WC. Programa Saúde da Família: a experiência de equipe multiprofissional. Revista de Saúde Pública 2006; 40(4): 727-33.

4. Morosini MVGC (Org). Modelos de atenção e a saúde da família. Rio de Janeiro: EPSJV/Fiocruz, 2007.

5. Dutra L, Santos AF, Werlang S. Assistência pós-alta hospitalar para pacientes com cuidados especiais. Boletim da Saúde Porto Alegre 2004; v.18 n.2.

6. Nascimento FG et al. Aplicabilidade de uma escala de risco para organização do processo de trabalho com famílias atendidas na Unidade Saúde da Família em Vitória (ES). Saúde Coletiva, Rio de Janeiro, v. 15, n. 5, Ago. 2010. Disponível em: <http://www.scielosp.org/scielo.php?script=sci_arttext\&pid=S141381232010000500021\&lng $=$ en\&nrm=iso>. Acesso em: 29 de julho de 2012 .

7. Coelho FLG, Savassi LCM. Aplicação da Escala de Risco Familiar como instrumento de priorização das visitas domiciliares. Revista Brasileira de Medicina de Família e Comunidade, Brasil, v. 1, n. 2, p. 19-26, 2004.

8. Kerber NPC. A atenção domiciliária e direito à saúde: análise de uma experiência na rede pública de saúde no Brasil, 2007, 335 f. Tese (Doutorado em Enfermagem) - Programa de PósGraduação em Enfermagem, Universidade Federal de Santa Catarina, Florianópolis.

9. Savassi LCM, Dias MF, Dias MB, Sá MMG, Sá, MJ. Relatoria do GESF: Módulo Visita Domiciliar. Grupo de Estudos em Saúde da Família. AMMFC: Belo Horizonte, 2006 (Relatório, 20p). Disponível em: <http://www.smmfc.org.br/gesf/relatoriavd.pdf>. Acesso em: 28 de julho de 2012.

10. Klock AD, Heck RM, Casarim ST. Cuidado Domiciliar: A Experiência da Residência Multiprofissional em Saúde da Família/UFPEL-MS/BID. Texto Contexto Enferm 2005, 14(2):237-45.

11. Organização Mundial da Saúde - OMS. Constituição da Organização Mundial da Saúde. Nova Iorque: OMS/WHO; 2003. 
12. Martins SK, Lacerda MR. O Atendimento Domiciliar à Saúde e as Políticas em Saúde. Revista RENE, Fortaleza, v. 9, n. 2, p. 148-156, abr./jun.2008.

13. Brasil. Ministério da Saúde. Secretaria de Atenção à Saúde. Departamento de Atenção Básica. Caderno de atenção domiciliar. Brasília: Ministério da Saúde, 2012. 2 v: il.

14. Amaral NN et al. Assistência Domiciliar à Saúde (Home Health Care): sua História e sua Relevância para o Sistema de Saúde Atual. Rev. Neurociências 2001; 9(3): 111-117.

15. Brasil. Ministério da Saúde. Atenção Domiciliar no SUS: resultados do laboratório de inovação em atenção domiciliar. Brasília: Ministério da Saúde, 2014.

16. Brasil. Ministério da Saúde. Portaria nº 2.416, de 23 de março de 1998. Estabelece requisitos para credenciamento de Hospitais e critérios para realização de internação domiciliar no sus. Disponível em: 〈http://www.saude.ba.gov.br/dae/Port2416.pdf>. Acesso em: 20 de agosto de 2014.

17. Brasil. Ministério da Saúde. Agência Nacional de Vigilância Sanitária. Resolução da Diretoria Colegiada n.11, de 26 de janeiro de 2006. Dispões sobre o Regulamento técnico de funcionamento de serviços que prestam atenção domiciliar. Brasília-DF, 2006. Disponível em: $<$ http://www20.anvisa.gov.br/segurancadopaciente/index.php/legislacao/item/resolucao-dadiretoria-colegiada-rdc-n-11-de-26-de-janeiro-de-2006>. Acesso em: 18 de agosto de 2012. 18. Brasil. Instituto para o Desenvolvimento da Saúde. Universidade de São Paulo. Ministério da Saúde. Programa Saúde da Família. Manual de Enfermagem Instituto para Desenvolvimento da Saúde. Universidade de São Paulo. Brasília-DF, 2001.

19. Brasil. Ministério da Saúde. Portaria no 825, de 25 de abril de 2016. Redefine a Atenção Domiciliar no âmbito do Sistema Único de Saúde (SUS) e atualiza as equipes habilitadas. Disponível em: http://www.cosemsrn.org.br/wp-content/uploads/2016/04/portaria825.pdf. Acesso em: 29 de junho de 2016.

20. Brasil. Ministério da Saúde. Portaria n ${ }^{\circ}$ 963, de 27 de maio de 2013. Redefine a Atenção Domiciliar no âmbito do Sistema Único de Saúde (SUS). Disponível em: <http://atencaobasica.saude.rs.gov.br/upload/arquivos/201510/0111472320141104105056port aria-n-963-de-27-de-maio-de-2013-legislacao-federal.pdf>. Acesso em 17 de março de 2014. 21. Brasil. Ministério da Saúde. Portaria No 2.529 de 19 de outubro de 2006. Institui a Internação Domiciliar no âmbito do SUS. Disponível em: http://dtr2001.saude.gov.br/sas/PORTARIAS/Port2006/GM/GM-2529.htm>. Acesso em: 10 de agosto de 2012. 
22. Brasil. Ministério da Saúde. Portaria No 2.029 de 24 de agosto de 2011. Institui a atenção domiciliar no âmbito do sistema único de saúde (SUS). Disponível em: <http://bvsms.saude.gov.br/bvs/saudelegis/gm/2011/prt2029_24_08_2011.html>. Acesso em: 10 de agosto de 2012.

23. Brasil. Ministério da Saúde. Portaria no 2.527, de 27 de outubro de 2011. Redefine a Atenção Domiciliar no âmbito do Sistema Único de Saúde (SUS). Disponível em: <http://www.saude.ba.gov.br/dae/Port2527.pdf>. Acesso em 30 de agosto de 2012.

24. Goshima ARS, Mello LM. Perfil dos Pacientes em Assistência Domiciliar no Núcleo de Saúde da Família 3 de Ribeirão Preto/SP no período de 2001 a 2012. In: Congresso Paulista de Medicina de Família e Comunidade, 4, 2012, Águas de Lindóia. Anais Eletrônicos. Águas de Lindóia: Associação Paulista de Medicina de Família, 2012.

25. Brasil. Ministério da Saúde. Portaria no 4.279, de 30 de dezembro de 2010. Estabelece diretrizes para a organização da Rede de Atenção à Saúde no âmbito do Sistema Único de Saúde (SUS).

Disponível

em:

<http://conselho.saude.gov.br/ultimas_noticias/2011/img/07_jan_portaria4279_301210.pdf>. Acesso em: 15 de setembro de 2012.

26. Brasil. Ministério da Saúde. Grupo Hospitalar Conceição. Manual de assistência domiciliar na atenção primária à saúde. Porto Alegre: Serviço de Saúde Comunitária do Grupo Hospitalar Conceição, 2003. Disponível em: <http://bvsms.saude.gov.br/bvs/publicacoes/Manual_Cuidadores_Profissionais.pdf >. Acesso em: 10 de junho de 2012.

27. Gerson LW, Collins JF. A randomized controlled trial of home care: clinical outcome for five surgical procedures. Canadian journal of surgery 1976; 19(6): 513-26.

28. Aksu H. The effect of postnatal breastfeeding education/support offered at home 3 days after delivery on breastfeeding duration and knowledge: a randomized trial. The journal of maternal-fetal \& neonatal medicine: the official journal of the European Association of Perinatal Medicine, the Federation of Asia and Oceania Perinatal Societies, the International Society of Perinatal Obstetricians 2011; 24(2):354-61.

29. Portal do Instituto Nacional do Câncer. Ministério da Saúde. Rede Câncer. Visita Domiciliar Reduz Custos e garante Bem Estar de Mais Paciente. Disponível em: <http://www2.inca.gov.br/wps/wcm/connect/fd72c7004eb6937e89a29bf11fae00ee/16_assiste ncia.pdf?MOD=AJPERES>. Acesso em 18 de julho de 2012. 
30. Morales-Asencio JM et al. Effectiveness of a nurse-led case management home care model in Primary Health Care. A quasi-experimental, controlled, multi- centre study. BMC health services research 2008; v. 8 , p. 193. Disponível em: $<$ http://bmchealthservres.biomedcentral.com/articles/10.1186/1472-6963-8-193>. Acesso em: 20 de janeiro de 2015.

31. Caccia-Bava MCGG. Os estágios do ciclo de vida familiar. Material elaborado para a disciplina Atenção à saúde na Comunidade II. Disponível em: $<$ http://www.fmrp.usp.br/rms/index.php?pg=base\&coduser=12\&codpag=349>. Acesso em 20 de janeiro de 2015.

32. Organização Pan-Americana de Saúde. Desempenho em Equipes de Saúde - Manual. Rio de Janeiro: Ministério da Saúde; 2001.

33. Fisher RA. Statistical Methods for Research Workers. 5. ed. Edinburgh: Oliver and Boyd, 1934.

34.Centro de Atenção Primária da FMRPUSP. Regulamento dos Núcleos de Saúde da Família. Disponível em: $<$ http://cap.fmrp.usp.br/index.php?option=com_content\&task=view\&id=20\&Itemid=48>. Acesso em: 10 de outubro de 2016.

35. Secretaria de Saúde de Ribeirão Preto. Tabulação do Esus. Disponível em:< http://www.saude.ribeiraopreto.sp.gov.br/ssaude/sus/i16esus.php>. Acesso em: 10 de dezembro de 2016.

36. Fabrício SCC et al. Assistência domiciliar: a experiência de um hospital do interior paulista. Rev Latino-Am Enfermagem 2004; v. 12, n. 5, p.721-6.

37. Feliciano AB et al. O perfil do idoso de baixa renda no Município de São Carlos, São Paulo, Brasil: um estudo epidemiológico. Cad. Saúde Pública, Rio de Janeiro, 20(6):1575-1585, novdez, 2004.

38. Lima-Costa MF et al. Desigualdade social e saúde entre idosos brasileiros: um estudo baseado na Pesquisa Nacional por Amostra de Domicílios. Cad Saude Publica. 2003;19(3):74557.

39. Gaspar JC, Oliveira MAC, Duayer MFF. Perfil dos pacientes com perdas funcionais e dependência atendidos pelo PSF no município de São Paulo. Rev Esc Enferm USP 2007; 41(4):619-28. Disponível em: <www.ee.usp.br/reeusp/> . Acesso em: 20 de setembro de 2016. 40. Rosa TE et al. Fatores determinantes da capacidade funcional entre idosos. Revista Saúde Pública 2003; 37(1):40-8. 
41. Associação Brasileira de Normas Técnicas. NBR 9050: Acessibilidade e edificações, mobiliário, espaços e equipamentos urbanos. Rio de Janeiro, 2004. Disponível em: <www.abnt.org.br>. Acesso em: 11 de novembro de 2007.

42. Marques FSC, Veríssimo MT. Estado nutricional e ingestão alimentar numa população de idosos institucionalizados. 2008. 156 f. Tese (Mestrado em Nutrição Clínica) - Faculdade de Medicina, Universidade de Coimbra, Portugal.

44. Lima JP. A influência das alterações sensoriais na qualidade de vida do idoso. Revista Científica Eletrônica de Psicologia, Garça 2007. Ano 5, n. 8. Disponível em: $<$ http://faef.revista.inf.br/imagens_arquivos/arquivos_destaque/SgxfdPCyrRBz4HS_2013510-16-11-50.pdf>. Acesso em: 15 de outubro de 2016.

44. Capilheira FM, Santos SI. Utilização de exames complementares. Rev Saúde Pública 2006; 40(2):289-97.

45. Malachias MVB et al. $7^{a}$ Diretriz Brasileira de Hipertensão Arterial. Arq Bras Cardiol 2016; 107(3Supl.3):1-83.

46. Milech A et al. Diretrizes da Sociedade Brasileira de Diabetes (2015-2016). São Paulo: A.C. Farmacêutica, 2016.

47. Paz AA, Santos BRL, Eidt OR. Vulnerabilidade e envelhecimento no contexto da saúde. Acta paul. enferm. v.19 n.3 São Paulo Jul/Set. 2006. Disponível em: <http://dx.doi.org/10.1590/S0103-21002006000300014>. Acesso em 15 de outubro de 2016. 48. Perlini NMOG, Faro ACM. Cuidar de pessoa incapacitada por acidente vascular cerebral no domicílio: o fazer do cuidador familiar. Rev. esc. enferm. USP v.39 n.2 São Paulo jun. 2005. Disponível em: <http://dx.doi.org/10.1590/S0080-62342005000200005>. Acesso em: 16 de outubro de 2016. 


\section{APÊNDICES}

\section{APÊNDICE A - Termo de Consentimento Livre e Esclarecido}

Você está sendo convidado (a) para participar da pesquisa "Atenção Domiciliar e Perfil dos Pacientes Assistidos em Núcleos de Saúde da Família Ligados à Faculdade de Medicina de Ribeirão Preto da Universidade de São Paulo", que tem como objetivo geral avaliar o perfil dos pacientes em Assistência Domiciliar realizada pelas equipes dos Núcleos de Saúde da Família ligados à Faculdade de Medicina de Ribeirão Preto da Universidade de São Paulo e sistematizar o atendimento aos usuários da Atenção Primária a Saúde, com vistas à planejar e organizar o trabalho do profissional que realizará a Atenção Domiciliar . Este trabalho poderá ajudar os profissionais e o governo a planejarem ações para melhorias no atendimento domiciliar. Você foi escolhido-(a) por estar cadastrado-(a) e em acompanhamento clínico em um dos Núcleos de Saúde da Família Ligados à Faculdade de Medicina de Ribeirão Preto da Universidade de São Paulo. A coleta de dados será composta por dois questionários. O primeiro vai avaliar as características das solicitações das visitas domiciliares e o segundo vai avaliar o perfil clínico e epidemiológico dos participantes. Sua participação não é obrigatória. A qualquer momento você pode desistir de participar da pesquisa e retirar seu consentimento e sua recusa não trará nenhum dano a você com a pesquisadora ou com o serviço que realiza o tratamento.

As informações obtidas através desta pesquisa serão confidenciais e asseguramos o sigilo sobre a sua participação e seu nome jamais será identificado, principalmente se os resultados forem apresentados em eventos e/ou publicados em artigos científicos.

Uma via deste termo ficará com você e qualquer dúvida sobre o projeto poderá ser esclarecida pelo endereço abaixo.

Pesquisadoras Responsáveis:

Amanda Rafaela Silveira Goshima Kronka

Profa. Dra Luane Marques de Mello

Endereço: Departamento de Medicina Social - Faculdade de Medicina Ribeirão Preto-USP Avenida dos Bandeirantes 3900, Monte Alegre - Ribeirão Preto/SP - Brasil

CEP 14049-900 Tel: (16)3602-2549 e/ou (16)3602-3070 
$\mathrm{Eu}$, declaro que compreendi os objetivos e procedimentos da pesquisa. Dessa forma, concordo em participar.

Assinatura do Participante

Ribeirão Preto, de de 2015 .

Assinatura do Entrevistador

Ribeirão Preto, de de 2015. 
APÊNDICE B - Ficha 1: Solicitação de VD - Acolhimento

SOLICITAÇÃO DE VD - ACOLHIMENTO (FICHA 1)

UNIDADE:

DATA:

$N^{\circ}$ GUIA:

NOME DO

PACIENTE:

IDADE: HYGIA:

NOME DO RESPONSÁVEL (CUIDADOR):

ENDEREÇO:

TELEFONE: NÚMERO DA FAMÍLIA/MICROÁREA:

TIPO DE SOLICITAÇÃO: ( ) CASO NOVO ( ) SEGUIMENTO MOTIVO DA SOLICITAÇÃO:

( ) VD AGENDADA DEVIDO:

( ) VD EVENTUAL DEVIDO:

( ) OUTROS:

\section{CONDUTA:}

( ) VD AGENDADA - DATA/HORA:

( ) VD EVENTUAL

( ) ORIENTADO À VIR NA UNIDADE

(EVENTUAL)

( ) ORIENTADO À CHAMAR O SAMU

( ) ORIENTADO À LEVAR AO PRONTO SOCORRO TIPO DE ATENÇÃO DOMICILIAR:

( ) RESOLVIDO SEM VD
( ) ATENDIMENTO DOMICILIAR
( ) INTERNAÇÃO DOMICILIAR
( ) ACOMPANHAMENTO DOMICILIAR
( ) BUSCA ATIVA (FALTOSOS) 
( ) OUTRA:

CONCLUSÃO:

( ) ATENDIMENTO DOMICILIAR ENCERRADO

( ) INTERNAÇÃO DOMICILIAR

( ) ACOMPANHAMENTO NA UNIDADE

( ) ACOMPANHAMENTO DOMICILIAR:

( ) ÓBITO DATA:

MOTIVO:

DATA DA PRÓXIMA VISITA:

DATA DA INCLUSÃO:

PROFISSIONAL RESPONSÁVEL: 
APÊNCICE C - Ficha 2: Atenção Domiciliar

ATENÇÃO DOMICILIAR (Ficha 2)

DATA:

NOME:

HYGIA:

IDADE:

GÊNERO: ( ) FEM ( )MASC

ESCOLARIDADE:

CUIDADOR: ( ) Sim ( ) Não

MOTIVO DA VD: ( ) SEGUIMENTO ( )SOLICITAÇÃO

QUEIXA E DURAÇÃO:

HISTÓRIA DA MOLÉSTIA ATUAL:

MEDICAMENTOS:

EXAMES (data e resultados dos últimos exames): 
ANTECEDENTES PESSOAIS:

\section{HIGIENE:}

CASA ( ) excelente ( ) muito boa ( ) boa ( ) regular ( ) péssima

CAMA ( ) excelente ( ) muito boa ( ) boa ( ) regular ( ) péssima

CORPORAL ( ) excelente ( ) muito boa ( ) boa ( ) regular ( ) péssima

BUCAL ( ) excelente ( ) muito boa ( ) boa ( ) regular ( ) péssima

MOBILIZAÇÃO: ( ) LEITO ( ) FORA DO LEITO ( ) ATIVA ( ） PASSIVA

EQUIPAMENTOS AUXILIARES: ( ) BENGALA ( ) MULETA ( ) CADEIRA DE RODAS ( )ANDADOR ( ) OUTROS:

SONDAS: ( ) SIM ( ) NÃO

TIPO:

TROCA:

FUNCIONAMENTO:

ÚLCERAS: ( ) SIM ( ) NÃO

NUMERO:

LOCAL:

TAMANHO:

DESCRIÇÃO:

TIPO:

TRATAMENTO:

ALIMENTAÇÃO:

ACEITAÇÃO VO: ( ) Sim （） Não

INGESTÃO DE LÍQUIDOS (quantidade):

SUPLEMENTOS: ( ) Sim ( ) Não

PESO:

ALTURA:

PRÓTESE: ( ) Sim ( ) Não

ELIMINAÇÃO: 
FEZES:

URINA:

USO DE FRALDAS: ( ) Sim （ ) Não

USO DE COLETOR: ( ) Sim ( ) Não

VACINAÇÃO: ( ) Atualizada （ ) Não atualizada

SONO:

\section{PERCEPÇÃO SENSORIAL:}

AUDIÇÃO: ( ) excelente ( ) muito boa ( ) boa ( ) regular ( ) péssima

VISÃO: ( ) excelente ( ) muito boa ( ) boa ( ) regular ( ) péssima

RELAÇÃO FAMILIAR:

\section{ATIVIDADES DE LAZER: ( ) SIM （ ) NÃO}

QUAIS:

FREQUENCIA:

DURAÇÃO:

ANIMAIS DOMÉSTICOS: ( ) SIM ( ) NÃO

QUAIS:

QUANTIDADE:

VACINAÇÃO:

LOCAL ADEQUADO:

ADAPTAÇÕES NA CASA: ( ) SIM ( ) NÃO

CORRIMÃ̃:

TAPETES:

DEGRAUS:

PISOS:

ILUMINAÇÃO: 
INTERRUPTOR DE FÁCIL ACESSO:

ESPAÇO PARA FLUXO NO QUARTO:

VENTILAÇÃO:

SEGUIMENTOS REALIZADOS EM OUTROS SERVIÇOS:

EXAME FÍSICO:

HIPÓTESES DIAGNÓSTICAS:

CLASSIFICAÇÃO DE RISCO:

CONDUTAS:

PROFISSIONAL RESPONSÁVEL: 


\section{ANEXOS}

\section{ANEXO A - Parecer Consubstanciado do Comitê de Ética em Pesquisa (CEP)}

Plataforma Brasil - Ministério da Saúde

Centro de Saúde Escola da Faculdade de Medicina de Ribeirão Preto - CSE/FMRP/USP

\section{PROJETO DE PESQUISA}

Título: Perfil dos Pacientes em Assistência Domiciliar no Núcleo de Saúde da Família 3 de Ribeirão Preto - SP no Período 2001 a 2012

Área Temática:

Pesquisador: Amanda Rafaela Silveira Goshima Versão: 1

Instituição: Centro de Saúde Escola da Faculdade CAAE: 04506512.0.0000.5414

de Medicina de Ribeirão Preto - USP

\section{PARECER CONSUBSTANCIADO DO CEP}

\section{Número do Parecer: 54670 \\ Data da Relatoria: 10/07/2012}

\section{Apresentação do Projeto:}

O Ministério da Saúde define Saúde da Família como uma estratégia de reorientação do modo assistencial, operacionalização mediante implantação de equipes multiprofissionais em unidades básicas de saúde. Esta equipe possui algumas competências, entre elas, a Assistência integral que define como objetos das suas ações a pessoa, o meio ambiente e os comportamentos interpessoais e a Assistência domiciliar(AD)como instrumento de monitorização da situação de saúde das famílias, fortalecendo as relações familiares respeitando vínculos afetivos. A AD é considerada, pela Organização mundial de Saúde (OMS) um processo complexo, que pode favorecer o acompanhamento clínico da pessoa, proporcionar prognósticos favoráveis, evitar a hospitalização e, por consequência, o estresse, as dificuldades decorrentes da internação hospitalar, além de humanizar o atendimento. Este estudo deve identificar o perfil clínicoepidemiológico dos indivíduos AD do Núcleo da Saúde da Família 3, localizado no Distrito Sanitário Oeste do município de Ribeirão Preto no período de 2002 a 2012.Os pesquisadores partem da hipótese que não há diferença do ponto de vista clínico, epidemiológico, nem com relação aos tipos de atendimentos realizados na $\mathrm{AD}$ e queixa que motivam a solicitação da assistência no atendimento.

\section{Objetivo da Pesquisa:}

Trata-se de um estudo que tem como objetivo primário avaliar o perfil clínico-epidemiológico dos indivíduos atendidos em assistência domiciliar pela equipe de profissionais do NSF 3 no período de 2002 a 2012 e nortear estratégias de aprimoramento do atendimento.

\section{Avaliação dos Riscos e Benefícios:}

Benefícios: O estudo deve favorecer o aprimoramento e sistematização das estratégias de AD a partir do conhecimento do perfil dos pacientes em Assistência Domiciliar e entendimentos 
das principais dificuldades que impedem um atendimento efetivo e eficaz. No estudo está prevista a utilização de informações secundárias, registradas em prontuários, não envolvendo desconforto ou riscos para os participantes.

\section{Comentários e Considerações sobre a Pesquisa:}

Trata-se de um estudo do tipo transversal com a finalidade de avaliar as características clínicaepidemiológicas, ciclo de vida, principais doenças apresentadas e identificar aspectos relacionados a AD solicitada pelos moradores da área de abrangência do NSF3. Serão utilizados os prontuários dos moradores cadastrados que concentram informações secundárias sobre os atendimentos realizados no período de 2002-2012. Os prontuários serão selecionados segundo técnica de amostragem aleatória estratificada. Serão considerados estratos as cindo micro áreas que compõem a área do núcleo. Serão selecionados aleatoriamente segundo o programa de aleatorização do Excel versão 2010,30 prontuários de cada micro área, compreendendo um total de 150 prontuários. Os prontuários serão analisados quanto aos critérios de elegibilidade e, então separados para a coleta das variáveis de interesse. Serão consideradas variáveis de interesse a faixa etária, o gênero, estado civil, nível de escolaridade, profissão, doença principal(CID10) e associadas, etapa do ciclo de vida em que se encontra o indivíduo, indicação da $\mathrm{AD}$ e modalidade de Atenção domiciliar realizada. Os dados serão coletados e dispostos em planilhas para análise estatística.

\section{Considerações sobre os Termos de apresentação obrigatória:}

O desenvolvimento da pesquisa contemplará o cumprimento da Resolução 196/97 e capítulo IV da Resolução 251/97, da Comissão Nacional de Ética em Pesquisa (CONEP). A folha de rosto para pesquisa envolvendo seres humanos foi devidamente preenchida e assinada pelo responsável da instituição proponente. No estudo está prevista a utilização de informações secundárias, registradas em prontuários, não envolvendo riscos e, portanto, não estando prevista a obtenção do consentimento livre e esclarecido dos participantes. Apesar disso, o pesquisador assegura o direito ao sigilo e à privacidade quanto aos dados confidenciais levantados ao longo da pesquisa. $\mathrm{O}$ pesquisador se compromete com os custos referentes a esta pesquisa.

\section{Recomendações:}

Não há recomendações

\section{Conclusões ou Pendências e Lista de Inadequações:}

O projeto mostra-se pertinente, de relevância para a sociedade, e assim, considero o projeto aprovado.

\section{Situação do Parecer: \\ Aprovado}

\section{Necessita Apreciação da CONEP:}

Não

Considerações Finais a critério do CEP:

Proposta atende aos preceitos éticos.

Recomendamos sua aprovação.

RIBEIRAO PRETO, 11 de Julho de 2012

Assinado por: LAÉRCIO JOEL FRANCO 